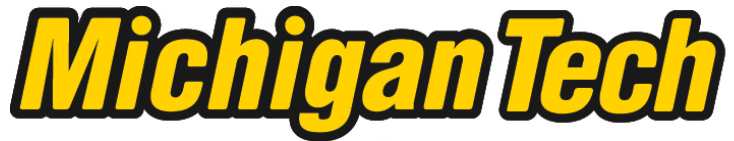 \\ Michigan Technological University Create the Future Digital Commons @ Michigan Tech
}

\section{Effect of external electric field on hydrogen adsorption over activated carbon separated by dielectric materials}

Zheng Zhang

Michigan Technological University

Follow this and additional works at: https://digitalcommons.mtu.edu/etds

Part of the Engineering Science and Materials Commons

Copyright 2012 Zheng Zhang

\section{Recommended Citation}

Zhang, Zheng, "Effect of external electric field on hydrogen adsorption over activated carbon separated by dielectric materials", Dissertation, Michigan Technological University, 2012.

https://doi.org/10.37099/mtu.dc.etds/16

Follow this and additional works at: https://digitalcommons.mtu.edu/etds

Part of the Engineering Science and Materials Commons 


\title{
EFFECT OF EXTERNAL ELECTRIC FIELD ON HYDROGEN ADSORPTION OVER ACTIVATED CARBON SEPARATED BY DIELECTRIC MATERIALS
}

\author{
By \\ Zheng Zhang
}

\begin{abstract}
A DISSERTATION
Submitted in partial fulfillment of the requirements for the degree of DOCTOR OF PHILOSOPHY

(Environmental Engineering)

MICHIGAN TECHNOLOGICAL UNIVERSITY

2012

(C) 2012 Zheng Zhang
\end{abstract}


This dissertation, "Effect of External Electric Field on Hydrogen Adsorption over Activated Carbon Separated by Dielectric Materials," is hereby approved in partial fulfillment of the requirements for the Degree of DOCTOR OF PHILOSOPHY IN ENVIRONMENTAL ENGINEERING.

Department of Materials Science and Engineering

Signatures:

Dissertation Advisor

Jiann-Yang Hwang

Department Chair

Mark R. Plichta

Date 


\section{Contents}

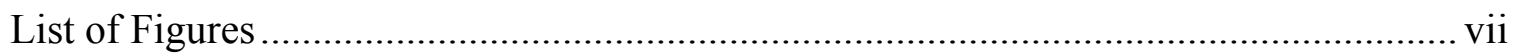

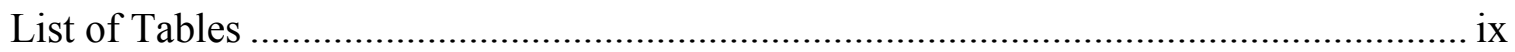

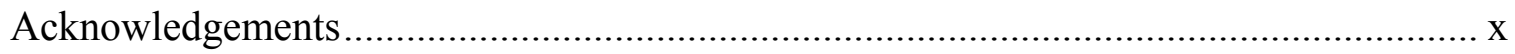

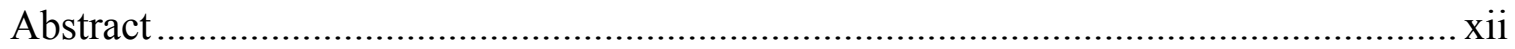

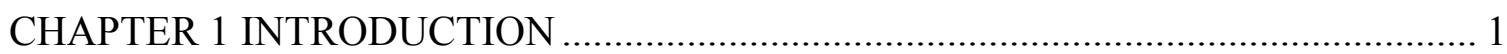

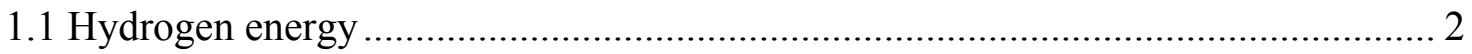

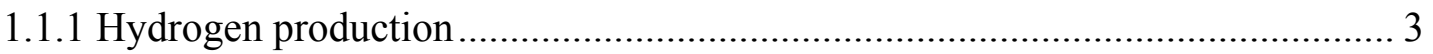

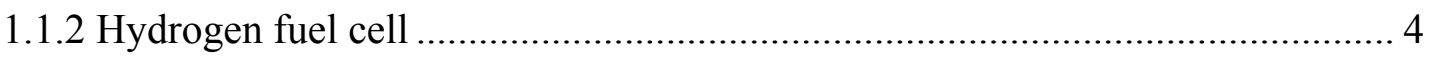

1.1.3 Hydrogen storage ..................................................................................... 7

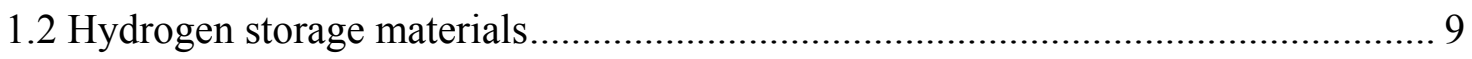

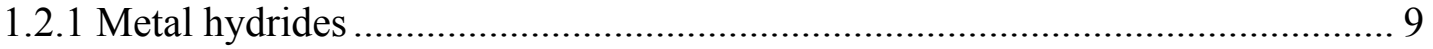

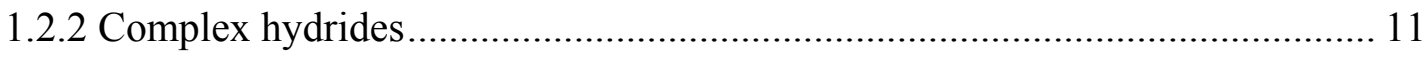

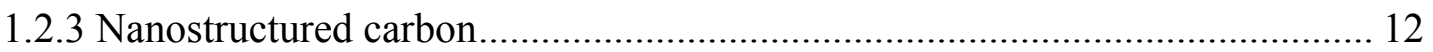

1.2.4 Metal organic frameworks (MOFs) …………………….............................. 14

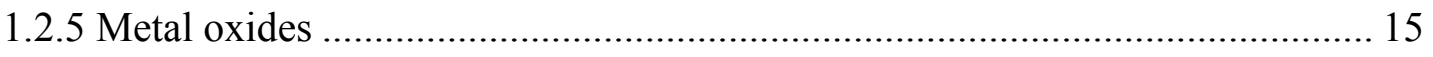

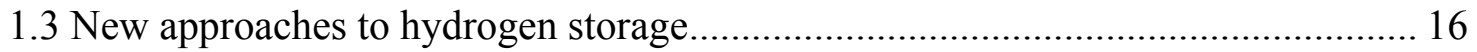

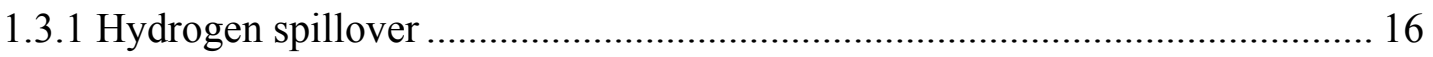

1.3.2 Combination of light metal hydrides and carbon materials for hydrogen storage Combing

1.3.3 Electric field assisted hydrogen adsorption ...................................................... 17

CHAPTER 2 BACKGROUND AND LITERATURE REVIEW .................................... 19

2.1 Hydrogen adsorption mechanism..................................................................... 19

2.2 Hydrogen cluster .......................................................................................... 22

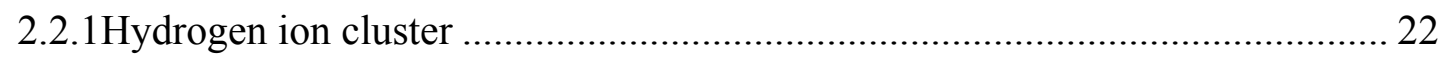

2.2.2 Metal hydrogen cluster .............................................................................. 23

2.3 Influential factors of hydrogen storage on carbon materials .................................. 23

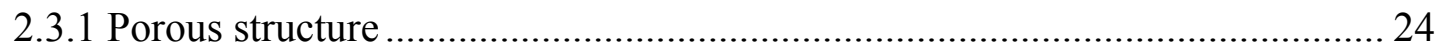

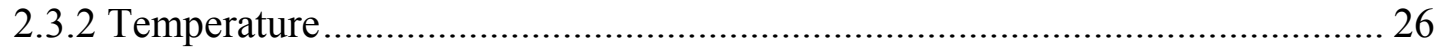




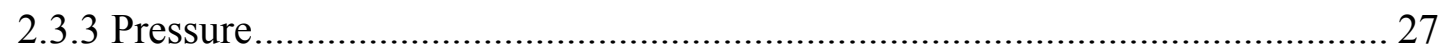

2.4 Hydrogen adsorption measurement methods ....................................................... 27

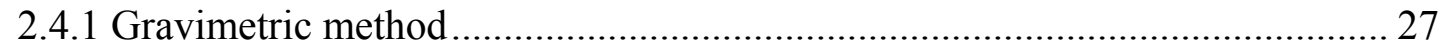

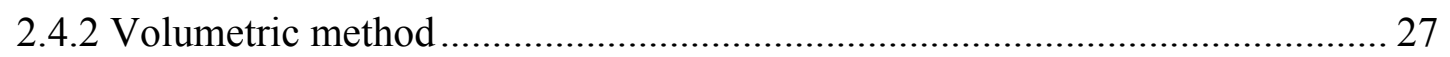

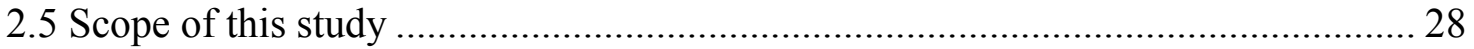

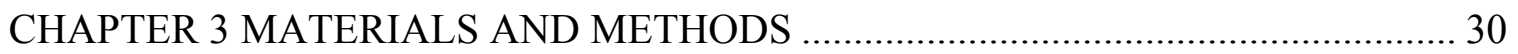

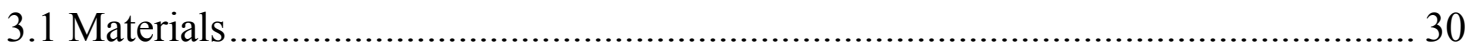

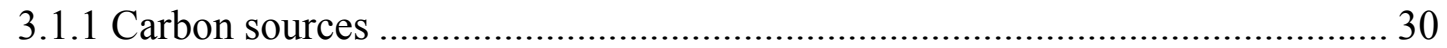

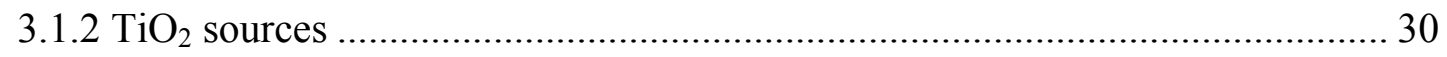

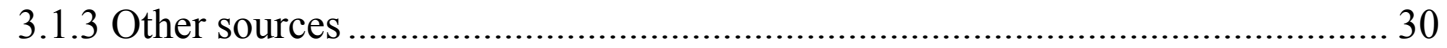

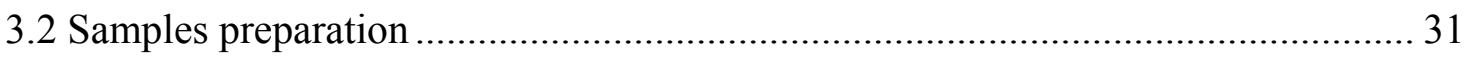

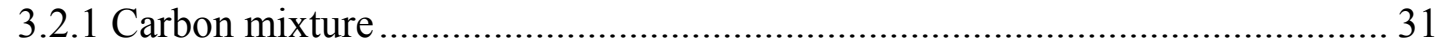

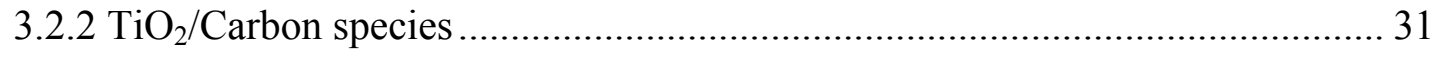

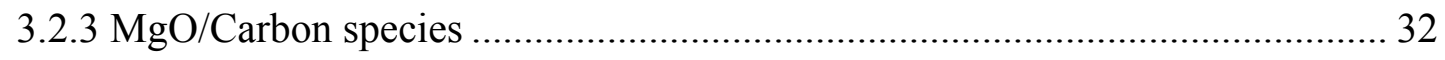

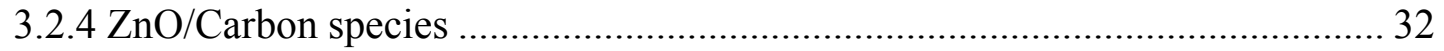

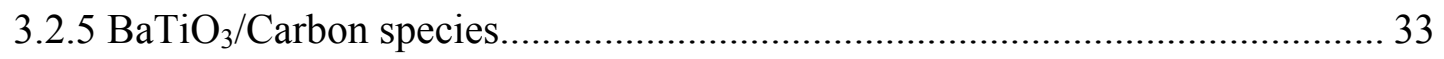

3.3 Hydrogen adsorption measurements ................................................................... 33

3.3.1 Measurements with electric field generated by piezoelectric element ............. 35

3.3.2 Measurements with electric field generated by applied electric potential........ 38

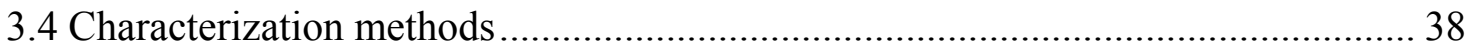

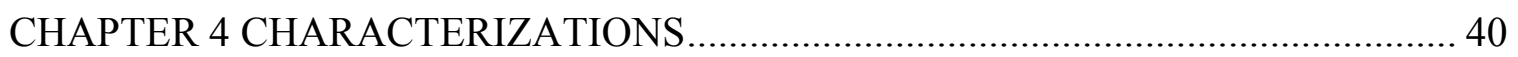

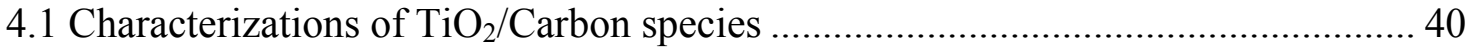

4.1.1 Mechanically mixed $\mathrm{TiO}_{2} /$ Carbon mixture ................................................... 40

4.1.2 $\mathrm{TiO}_{2} /$ Carbon synthetics prepared from Premix of $\mathrm{TiO}_{2}$ powder ...................... 40

4.1.3 $\mathrm{TiO}_{2} /$ Carbon synthetics prepared through chemical deposition ........................ 44

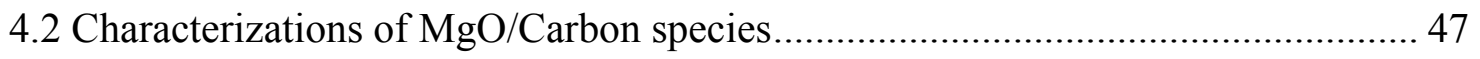

CHAPTER 5 EXAMINATION OF HYDROGEN ADSORPTION ON ACTIVATED

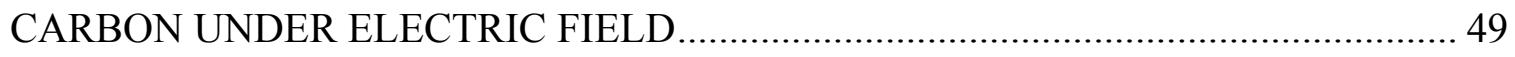

5.1 Hydrogen adsorption on pristine activated carbon.............................................. 50 


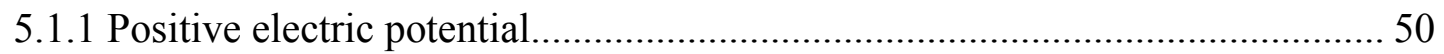

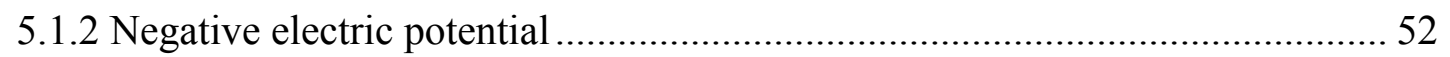

5.2 Hydrogen adsorption on Pt-doped activated carbon ............................................. 53

CHAPTER 6 EXAMINATION OF HYDROGEN ADSORPTION ON ACTIVATED CARBON SEPARATED BY TITANIUM DIOXIDE UNDER ELECTRIC FIELD ..... 55

6.1 Hydrogen adsorption on mechanically mixed $\mathrm{TiO}_{2} /$ Carbon mixture....................... 55

6.2 Hydrogen adsorption on $\mathrm{TiO}_{2} /$ Carbon synthetics prepared from $\mathrm{TiO}_{2}$ premix ...... 56

6.2.1 Hydrogen adsorption with applied electric field ............................................. 56

6.2.2 Hydrogen adsorption with the presence of piezoelectric element ..................... 62

6.3 Hydrogen adsorption on chemically deposited $\mathrm{TiO}_{2} /$ Carbon synthetics ................ 66

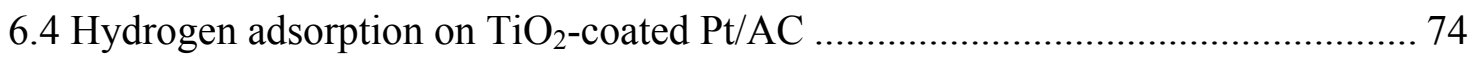

CHAPTER 7 EXAMINATION OF HYDROGEN ADSORTPION ON ACTIVATED CARBON SEPARATED BY OTHER DIELEDTRIC MATERIALS UNDER

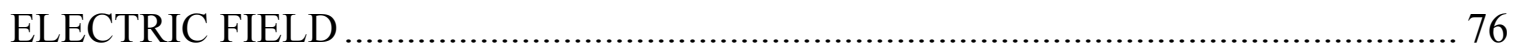

7.1 Hydrogen adsorption on $\mathrm{MgO} /$ Carbon species ........................................................ 76

7.2 Hydrogen adsorption on $\mathrm{ZnO} /$ Carbon species .................................................... 77

7.3 Hydrogen adsorption on $\mathrm{BaTiO}_{3} /$ Carbon species .................................................. 78

CHAPTER 8 COMPUTATIONAL CALCULATIONS ………………........................ 80

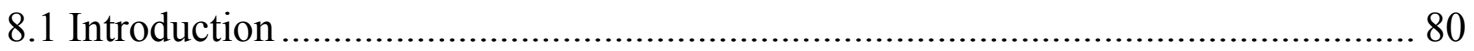

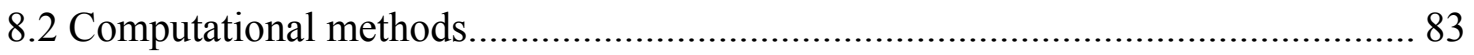

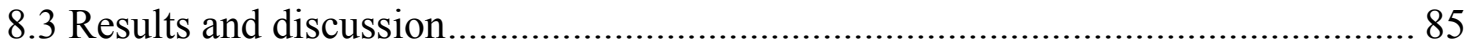

8.3.1 Hydrogen adsorption on charged $\mathrm{TiO}_{2}$ molecule …………………................ 85

8.3.2 Hydrogen adsorption on $\mathrm{TiO}_{2}$ molecule under electric field............................ 86

8.3.3 Hydrogen adsorption on coronene under electric field .................................... 87

8.3.4 Hydrogen adsorption on $\mathrm{TiO}_{2}$-doped coronene under electric field.................. 89 CHAPTER 9 SUMMARY AND CONCLUSIONS ……………………………….... 92

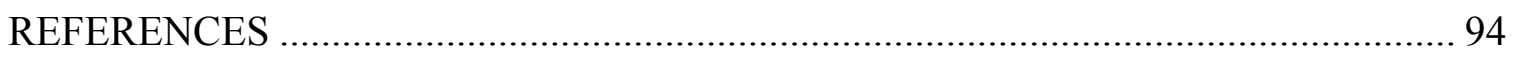

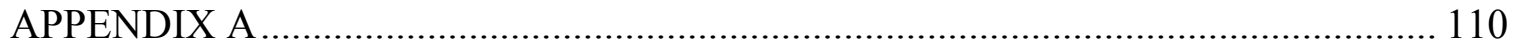

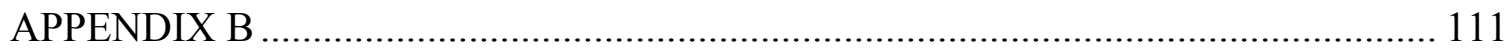

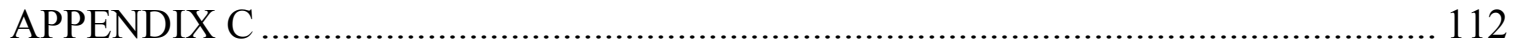




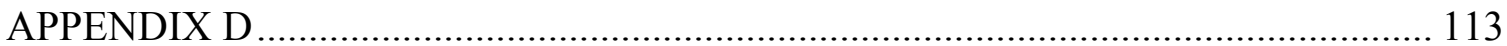

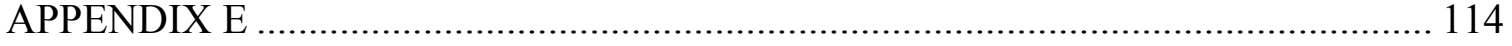

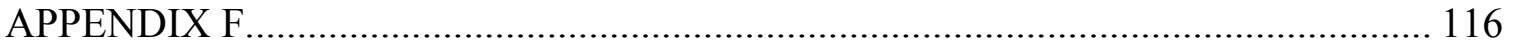

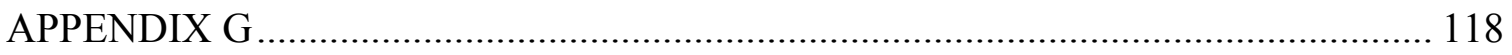

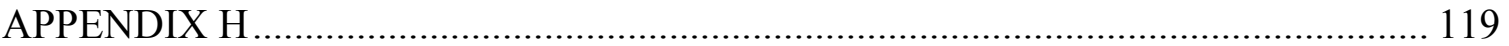




\section{List of Figures}

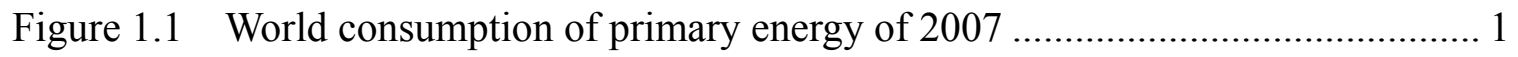

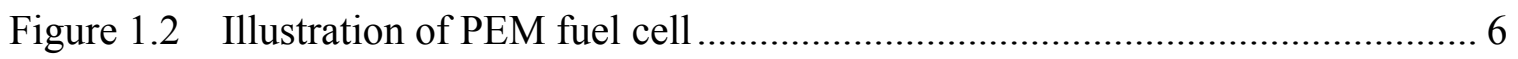

Figure 1.3 Estimates of gravimetric and volumetric capacities projected for on-board

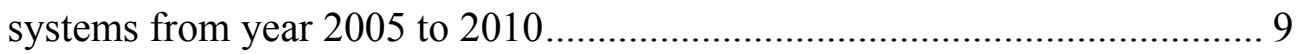

Figure 2.1 Hydrogen adsorption capacity at $77 \mathrm{~K}$ and 1 bar for different carbon samples versus total pore volume and micropore volume ....................................... 25

Figure 2.2 Isobars for hydrogen desorption from a certain activated carbon at 1 bar and isotherm data from adsorption at 1 bar .................................................... 26

Figure 2.3 Approach for charged zone enlargement ................................................. 29

Figure 3.1 Outlook of the PCT-Pro 2000 instrument................................................... 33

Figure 3.2 Master control panel of PCT-Pro 2000 ................................................... 34

Figure 3.3 Experimental setup for hydrogen adsorption measurement in the presence of

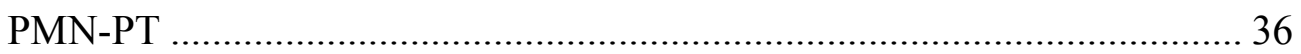

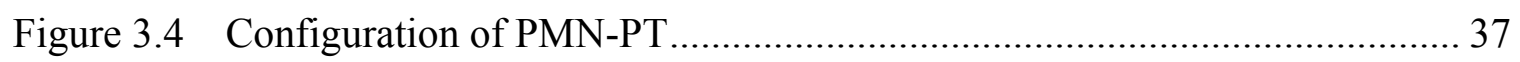

Figure 3.5 Cross-section view of modified sample holder ........................................ 37

Figure 3.6 Cross-section view of sample holder used for resistivity test ..................... 39

Figure 4.1 XRD patterns of $\mathrm{TiO}_{2} /$ Carbon synthetics $\mathrm{P} 1 \mathrm{H} 1, \mathrm{P} 2 \mathrm{H} 1, \mathrm{P} 3 \mathrm{H} 1$ and $\mathrm{P} 4 \mathrm{H} 1$.... 41

Figure 4.2 FE-SEM images of P4 and P4H1 ......................................................... 42

Figure 4.3 Relationship between BET surface area and micropore volume of $\mathrm{TiO}_{2} /$ Carbon synthetics ........................................................................ 43

Figure 4.4 XRD patterns of chemical deposited $\mathrm{TiO}_{2} /$ Carbon synthetics $\mathrm{TC} 1$ and

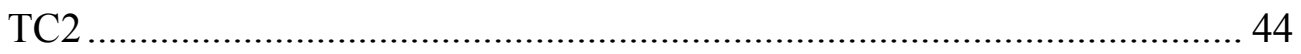

Figure 4.5 FE-SEM images of chemically deposited $\mathrm{TiO}_{2} /$ Carbon synthetics ............. 45

Figure 4.6 TGA analyses of $\mathrm{TiO}_{2} /$ Carbon synthetics TC1 and TC2 ........................... 46

Figure 4.7 XRD pattern of $\mathrm{MgO} / \mathrm{Carbon}$ synthetic $\mathrm{MC}$............................................. 48

Figure 4.8 FE-SEM images of $\mathrm{MgO} /$ Carbon synthetic MC ....................................... 48

Figure 5.1 Hydrogen adsorption on blank sample holder with and without $1000 \mathrm{~V}$

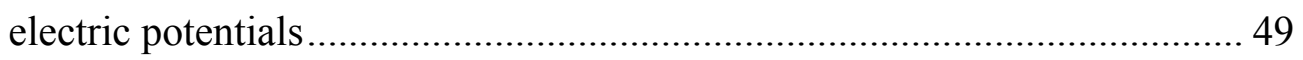

Figure 5.2 Hydrogen adsorption on NAC under various electric potentials................. 51

Figure 5.3 Hydrogen adsorption on NAC with and without $-1000 \mathrm{~V}$ electric potential 53

Figure 5.4 Hydrogen adsorption on PAC with and without $2000 \mathrm{~V}$ electric potential .. 54

Figure 6.1 Hydrogen adsorption on sample MM with and without $2000 \mathrm{~V}$ electric potential ...................................................................................... 56

Figure 6.2 Hydrogen adsorption on $\mathrm{TiO}_{2} /$ Carbon synthetics $\mathrm{P} 1 \mathrm{H} 1, \mathrm{P} 2 \mathrm{H} 1, \mathrm{P} 3 \mathrm{H} 1, \mathrm{P} 4 \mathrm{H} 1$

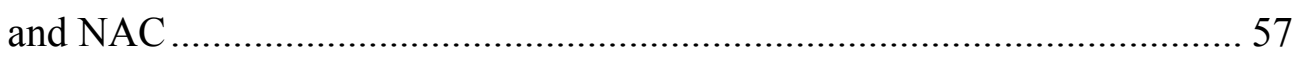

Figure 6.3 Hydrogen adsorption isotherms of PTPD and blank test ........................ 57 
Figure 6.4 Hydrogen adsorption on $\mathrm{TiO}_{2} /$ Carbon synthetics $\mathrm{P} 1 \mathrm{H} 1, \mathrm{P} 2 \mathrm{H} 1, \mathrm{P} 3 \mathrm{H} 1$ and

P4H1 with and without $1000 \mathrm{~V}$ electric potential .................................... 59

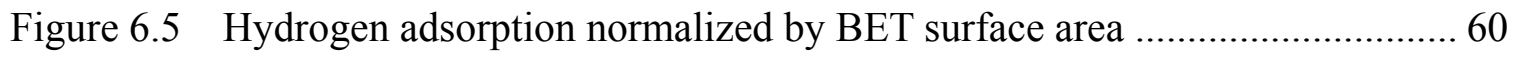

Figure 6.6 Hydrogen adsorption on P4 with the presence of a PMN-PT .................... 63

Figure 6.7 Change rate of hydrogen adsorption with the presence of a PMN-PT ......... 63

Figure 6.8 Schematic of charge distribution with the presence of PMN-PT $(+)$........... 65

Figure 6.9 Relationship between hydrogen pressure and charges generated................ 66

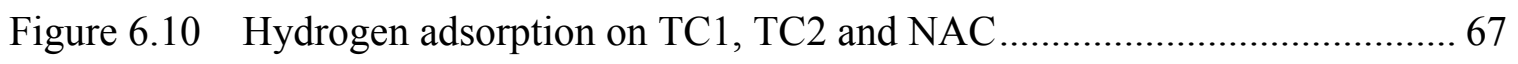

Figure 6.11 Hydrogen adsorption on TC1 and TC2 with and without $1000 \mathrm{~V}$ electric

potential ............................................................................................ 68

Figure 6.12 Hydrogen adsorption on $\mathrm{HCl} / \mathrm{NAC}$ with and without $1000 \mathrm{~V}$ electric

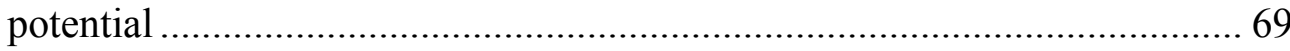

Figure 6.13 Hydrogen adsorption on $\mathrm{TiO}_{2} /$ Carbon synthetics $\mathrm{TC} 2$ under various electric potentials. 70

Figure 6.14 Electricity detected by ammeter under various electric potentials ............ 71

Figure 6.15 Adsorption change rate of TC2 at 20,50 and 80 bar under various electric

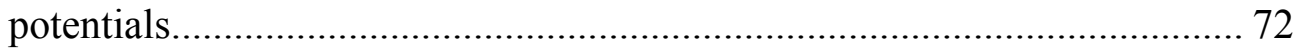

Figure 6.16 Illustration of hydrogen adsorption mechnisam under electric field......... 72

Figure 6.17 Hydrogen adsorption on $\mathrm{TiO}_{2}$-coated Pt/AC synthetic TPC under electric potential

Figure 7.1 Hydrogen adsorption on $\mathrm{MgO} / \mathrm{Carbon}$ synthesis $\mathrm{MC}$ with and without

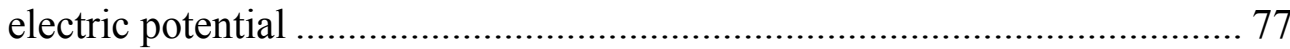

Figure 7.2 Hydrogen adsorption on $\mathrm{ZnO}$ /Carbon mixture $\mathrm{ZC}$ with and without electric potential ................................................................................. 78

Figure 7.3 Hydrogen adsorption on $\mathrm{BaTiO}_{3} / \mathrm{Carbon}$ mixture $\mathrm{BC}$ with and without

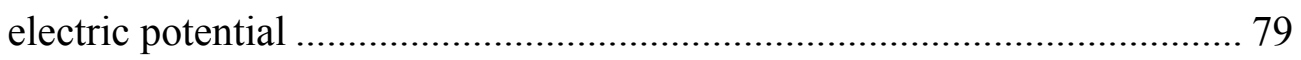

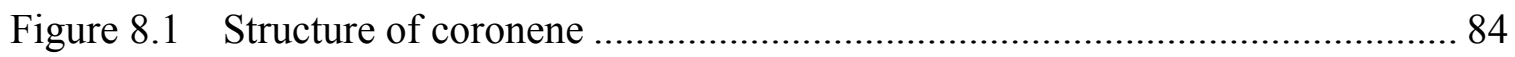

Figure 8.2 Initial state of $\mathrm{H}_{2}-\mathrm{TiO}_{2}$ system........................................................ 85

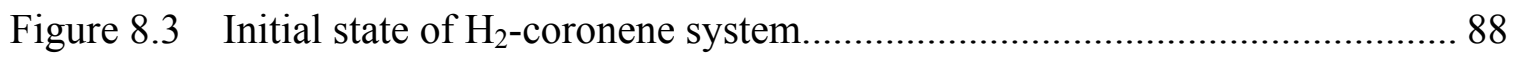

Figure 8.4 Initial state of $\mathrm{H}_{2}-\mathrm{TiO}_{2}$-coronene system........................................... 90 


\section{List of Tables}

Table 1.1 Techniques for producing hydrogen....................................................... 3

Table 1.2 Comparison of current fuel cell technologies ................................................ 5

Table 2.1 Comparison of physisorption and chemisorption ......................................... 20

Table 4.1 BET analyses of $\mathrm{TiO}_{2} /$ Carbon synthetics prepared from premix of $\mathrm{TiO}_{2}$

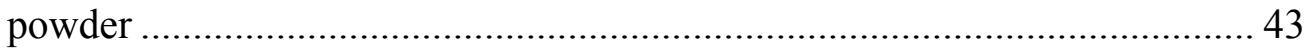

Table 4.2 Electrical resistivity of $\mathrm{TiO}_{2} /$ Carbon synthetics prepared from premix of $\mathrm{TiO}_{2}$

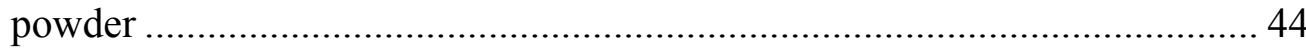

Table 4.3 BET analyses of chemically deposited $\mathrm{TiO}_{2} /$ Carbon synthetics $\mathrm{TC} 1$ and TC2

Table 4.4 Electrical resistivity of chemically deposited $\mathrm{TiO}_{2} /$ Carbon synthetics $\mathrm{TC} 1$ and

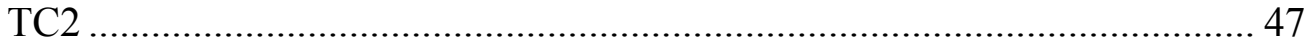

Table 8.1 Geometric parameters and binding energies of $\mathrm{H}_{2}$ and charged $\mathrm{TiO}_{2} \ldots \ldots \ldots \ldots . .86$

Table 8.2 Geometric parameters and binding energies of $\mathrm{H}_{2}$ and $\mathrm{TiO}_{2}$ under electric

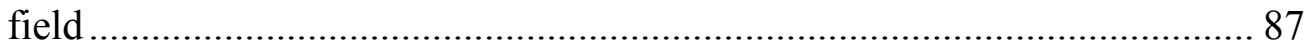

Table 8.3 Geometric parameters and binding energies of $\mathrm{H}_{2}$ and coronene under electric

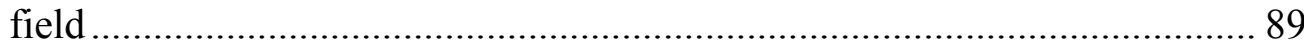

Table 8.4 Geometric parameters and binding energies of hydrogen and $\mathrm{TiO}_{2}$-doped coronene under electric field 


\section{Acknowledgements}

This dissertation would never have been finished without the guidance of my committee members, help of my friends and support from my family. It is a pleasure to convey my gratitude to them all in this acknowledgement.

In the first place, I would like to express my deepest gratitude to my advisor, Dr Jiann-Yang Hwang, for his excellent guidance, encouragement, and financial support. $\mathrm{He}$ guided me to the real research and taught me the way to think logically. His optimistic attitude to the life encouraged me to step out one difficulty and another.

I would like to thank my committee members Dr. Yun Hang Hu, Dr. David W. Hand, Dr. Paul V. Doskey and Dr. Xinli Wang for their precious advices.

I also would like to thank my current and previous group members, Shangzhao Shi, Xiang Sun, Zhiwei Peng, Chienyu Wen, Xiaodi Huang, Bowen Li, Matthew Andriese, Wayne Bell and Allison Hein for their collaborations.

I am very grateful to Ming Ning for his time and the patient guidance in computational calculations.

I would also like to thank Stephen F. Forsell, Owen P. Mills, Edward A. Latitila, Patrick D. Quimby and Ruth I. Kramer for their technical assistances in instrument operations and material preparations.

Special thanks go to my friends Shuhan Ding and Shuqian Xie, who have accompanied 
my through the most difficult periods in Houghton. Chatting and laughing with them was the happiest thing of those days. Many thanks go to my other lovely friends, Xinxin Jin, Ming Xie, Wei Wang, Yunhua Li, Zhiyao An, Hui Wang, Yao Li, Liu Chen, Ding Chu. They have made my life more colorful.

Finally, I would like to thank my mother Xinmin Zeng, my father Wu Zhang and my husband Xuan Li. They were always supporting me and encouraging me with their best wishes.

This dissertation is dedicated to Xinmin, Wu and Xuan. 


\begin{abstract}
Energy crisis and worldwide environmental problem make hydrogen a prospective energy carrier. However, storage and transportation of hydrogen in large quantities at small volume is currently not practical. Lots of materials and devices have been developed for storage hydrogen, but to today none is able to meet the DOE targets.
\end{abstract}

Activated carbon has been found to be a good hydrogen adsorbent due to its high surface area. However, the weak van der Waals force between hydrogen and the adsorbent has limited the adsorption capacity. Previous studies have found that enhanced adsorption can be obtained with applied electric field. Stronger interaction between the polarized hydrogen and the charged sorbents under high voltage is considered as the reason.

This study was initiated to investigate if the adsorption can be further enhanced when the activated carbon particles are separated with a dielectric coating. Dielectric $\mathrm{TiO}_{2}$ nanoparticles were first utilized. Hydrogen adsorption measurements on the $\mathrm{TiO}_{2}$-coated carbon materials, with or without an external electric field, were made. The results showed that the adsorption capacity enhancement increased with the increasing amount of $\mathrm{TiO}_{2}$ nanoparticles with an applied electric field. Since the hydrogen adsorption capacity on $\mathrm{TiO}_{2}$ particles is very low and there is no hydrogen adsorption enhancement on $\mathrm{TiO}_{2}$ particles alone when electric field is applied, the effect of dielectric coating is demonstrated.

Another set of experiments investigated the behavior of hydrogen adsorption over $\mathrm{TiO}_{2}$-coated activated carbon under various electric potentials. The results revealed that the hydrogen adsorption first increased and then decreased with the increase of electric 
field. The improved storage was due to a stronger interaction between charged carbon surface and polarized hydrogen molecule caused by field induced polarization of $\mathrm{TiO}_{2}$ coating. When the electric field was sufficient to cause considerable ionization of hydrogen, the decrease of hydrogen adsorption occurred. The current leak detected at $3000 \mathrm{~V}$ was a sign of ionization of hydrogen.

Experiments were also carried out to examine the hydrogen adsorption performances over activated carbon separated by other dielectric materials, $\mathrm{MgO}, \mathrm{ZnO}$ and $\mathrm{BaTiO}_{3}$, respectively. For the samples partitioned with $\mathrm{MgO}$ and $\mathrm{ZnO}$, the measurements with and without an electric field indicated negligible differences. Electric field enhanced adsorption has been observed on the activated carbon separated with $\mathrm{BaTiO}_{3}$, a material with unusually high dielectric constant.

Corresponding computational calculations using Density Functional Theory have been performed on hydrogen interaction with charged $\mathrm{TiO}_{2}$ molecule as well as $\mathrm{TiO}_{2}$ molecule, coronene and $\mathrm{TiO}_{2}$-doped coronene in the presence of an electric field. The simulated results were consistent with the observations from experiments, further confirming the proposed hypotheses. 


\section{CHAPTER 1 INTRODUCTION}

Over the next decades, decreasing world supply of fossil fuels, and increasing global warming and climate change will be two major concerns. United States' development highly relies on petroleum, as shown in Figure 1.1. Among them, 2/3 of the petroleum is consumed in transportation 1. US imports half of its petroleum and the dependence on foreign oil is expected to grow in the future. However, petroleum is a kind of non-renewable energy, which will probably run out in next 50 years if people keep the steps. Thus, an alternative energy source is highly demanded.

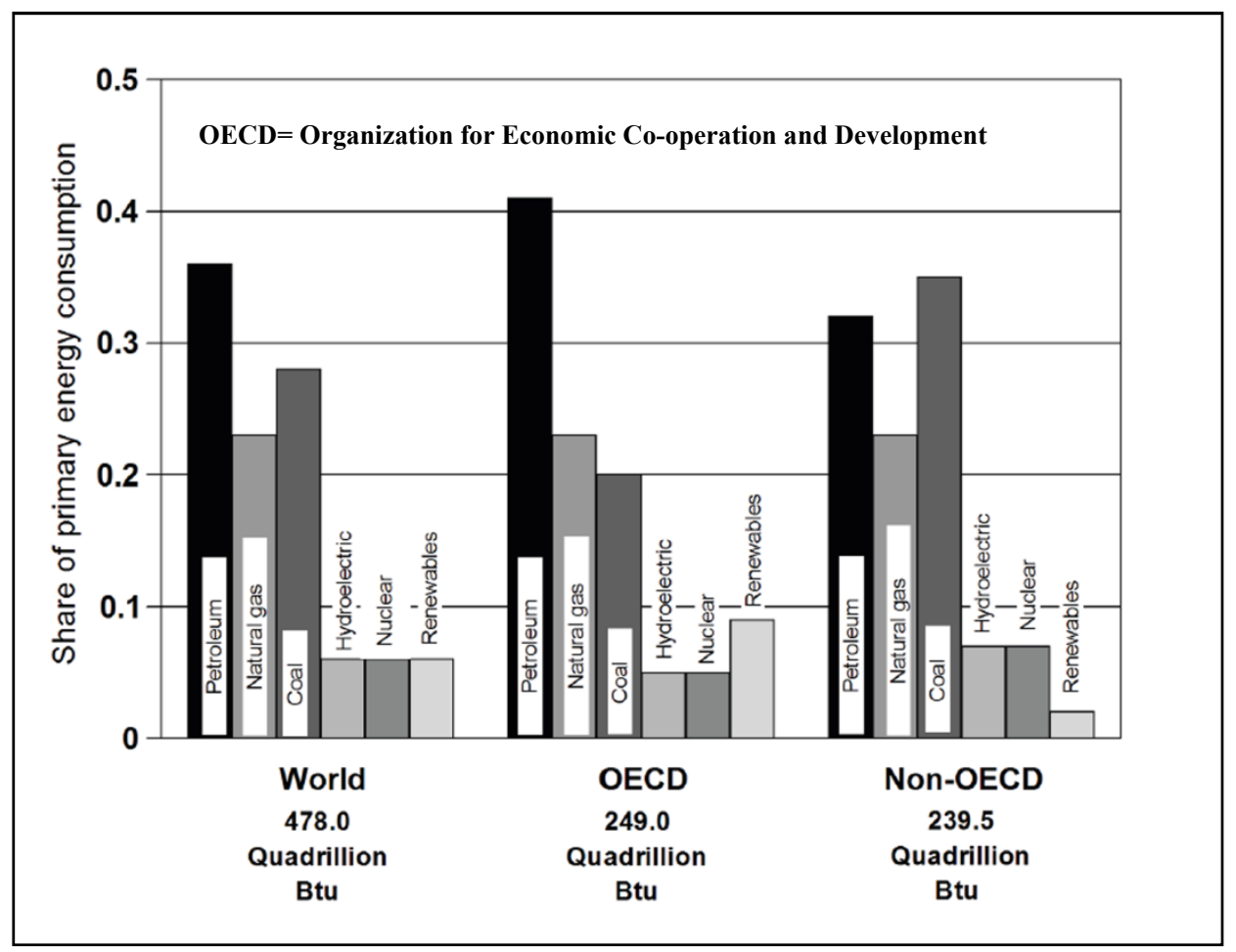

Figure 1.1 World consumption of primary energy of $2007^{1}$ (graph courtesy of DOE, see Appendix A)

These years, environmental problem and global warming have attracted more and more attention. Scientific research is focused on clean and renewable energy source. According to US Department of Energy (DOE) database, transportation is responsible for $73 \%$ of 
$\mathrm{CO}, 58 \%$ of $\mathrm{NO}_{\mathrm{x}}$ and $33 \%$ of $\mathrm{CO}_{2}$ in air pollution 1 . The pollutants come from the combustion of gasoline or diesel and need to be reduced by adopting clean energy. Hydrogen, which does not generate pollutants and greenhouse gas, is considered an ideal energy source to compensate or even take the place of fossil fuels. Application of vehicle powered by hydrogen will not only reverse today's situation, but also benefit long-term development.

Due to great advantages of hydrogen energy, President Bush launched the Hydrogen Fuel Initiative in 2003, which commits $\$ 1.2$ billion over five years to fund hydrogen fuel cell research. The fund would be used in the research of powering automobiles by hydrogen fuel cells, and also the studies of producing, storing and transporting hydrogen. The goal is to put hydrogen fuel cell vehicles in the showroom and hydrogen at fueling station by $2020^{2}$.

\subsection{Hydrogen energy}

Hydrogen is qualified as ideal energy carrier largely due to its unique characteristics. Hydrogen is very abundant in the universe, which constitutes normal matters $75 \%$ by mass and $>90 \%$ by number of atoms. Hydrogen is also the lightest element. Only a single proton is included in the protium $(\mathrm{H})$, the most common isotope of hydrogen. Hydrogen possesses the highest gravimetric energy content $(142 \mathrm{~kJ} / \mathrm{g})$ of all fuels, whereas liquid hydrogen's volumetric energy density $(8 \mathrm{MJ} / \mathrm{L})$ is only one quarter of that of gasoline ${ }^{3}$. Water is the only product when hydrogen reacts with oxygen, so no pollutant is produced. Moreover, efficiency can be significantly increased if fuel cells with hydrogen are applied. 


\subsubsection{Hydrogen production}

Although hydrogen is abundant, naturally occurring elemental hydrogen is relatively rare on Earth. In order to take use of hydrogen as energy carrier, molecular hydrogen is required to be produced. Generally, technologies for producing hydrogen can be classified into seven areas, as listed in Table 1.1. The first three ones have been commercialized and the others are still being studied in the lab.

Table 1.1

Techniques for producing hydrogen ${ }^{4}$

\begin{tabular}{ccc}
\hline Technologies & Raw materials \\
\hline Commercialized & Steam reforming & $\begin{array}{c}\text { Light hydrocarbon gases } \\
\left(\text { mainly } \mathrm{CH}_{4} \text { ) and } \mathrm{H}_{2} \mathrm{O}\right. \\
\text { Coal and } \mathrm{H}_{2} \mathrm{O}\end{array}$ \\
Water electrolysis & $\mathrm{H}_{2} \mathrm{O}$ \\
\hline R\&D & Gasification & Biomass and $\mathrm{H}_{2} \mathrm{O}$ \\
& Thermo-chemical & Sulfur-iodine \\
& Bioprocess & Biomass or $\mathrm{H}_{2} \mathrm{O}$ \\
Photolysis & $\mathrm{H}_{2} \mathrm{O}$ \\
\hline
\end{tabular}

Currently the dominant technology for direct production is steam reformation from natural gas, methanol, coal or even gasoline 5. In US, around $95 \%$ of the hydrogen is produced through this way 6. Gasification is also a process usually used to obtain hydrogen. It first converts fossil based carbonaceous materials into hydrogen, carbon monoxide and carbon dioxide and then separates the hydrogen from the resultant gas products. Another major source is collecting hydrogen as the product of water electrolysis. At present, the electric energy used to split water molecule is mainly from coal. All the three methods are largely depends on limited fossil fuel source, so it is highly demanded 
to find out sustainable techniques for hydrogen production.

The latter four techniques under development are very promising due to the utilization of renewable energy sources. The novel gasification is producing hydrogen from gasification of biomass resources such as agricultural residue, including waste grease, peanut shells or crops 7 . The thermo-chemical way only uses solar and nuclear energy in waste splitting cycle. Bioprocess system use natural photosynthetic microbes such as green algae and bacteria to produce hydrogen by splitting water. Photolysis is a process that splits water to obtain hydrogen using sunlight as the only energy source.

\subsubsection{Hydrogen fuel cell}

To make best use of hydrogen energy, fuel cell is introduced. A fuel cell is an electrochemical cell to convert fuel to electricity and chemical products. A single fuel cell is composed of an electrolyte sandwiched between two catalyst-coated electrodes, a porous anode and a porous cathode. Depending on the difference of electrolytes, fuel cells can be sorted as alkaline fuel cell (AFC), polymer electrolyte membrane or proton exchange membrane fuel cell (PEM), phosphoric acid fuel cell (PAFC), molten carbonate fuel cell (MCFC) and solid oxide fuel cell (SOFC). Operating temperature, efficiency of each type of fuel cell is given in table 1.2. Efficiency of fuel cell lies between $45 \%-60 \%$, which is much higher than that of internal combustion engines using fossil fuels $(<20 \%)$ 8,9 . 


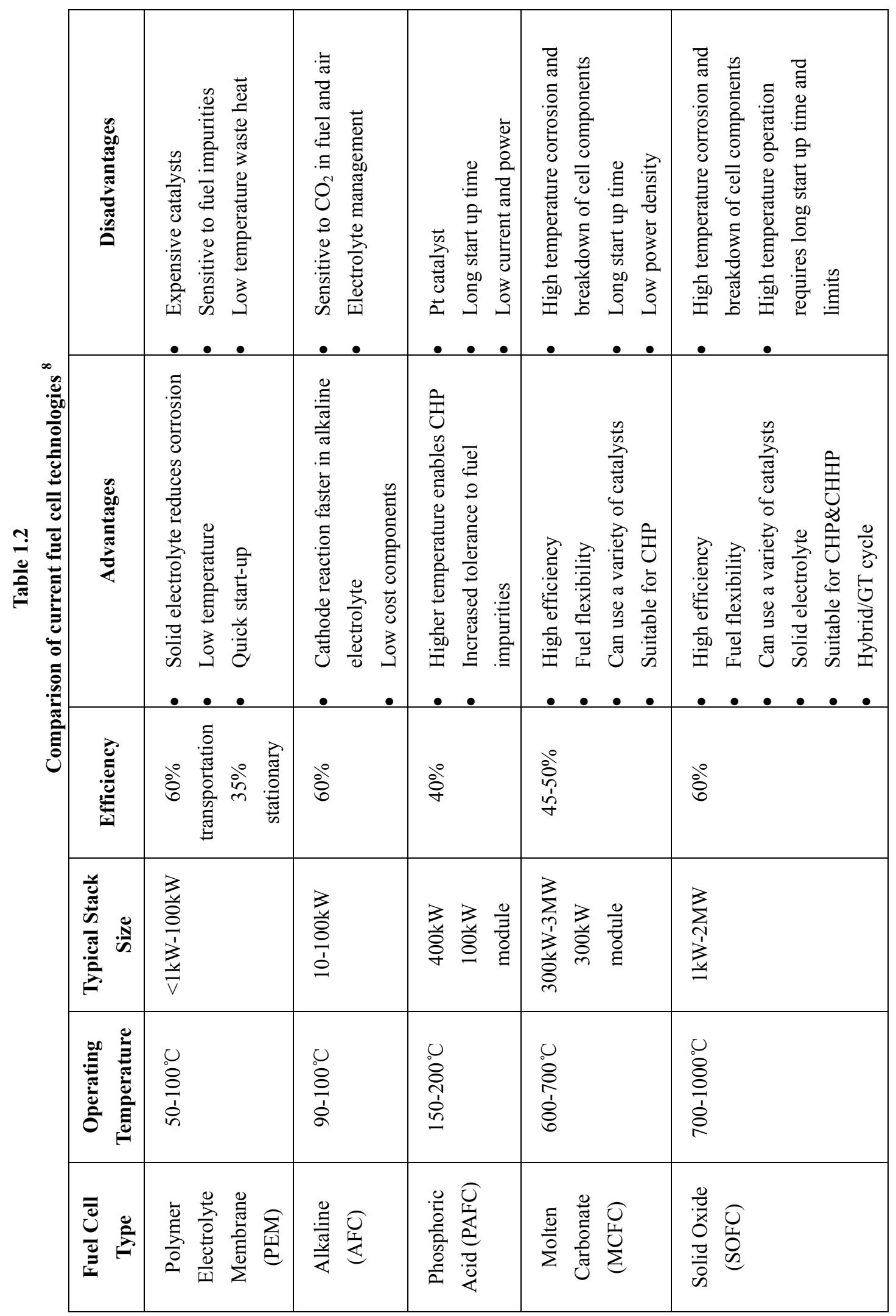




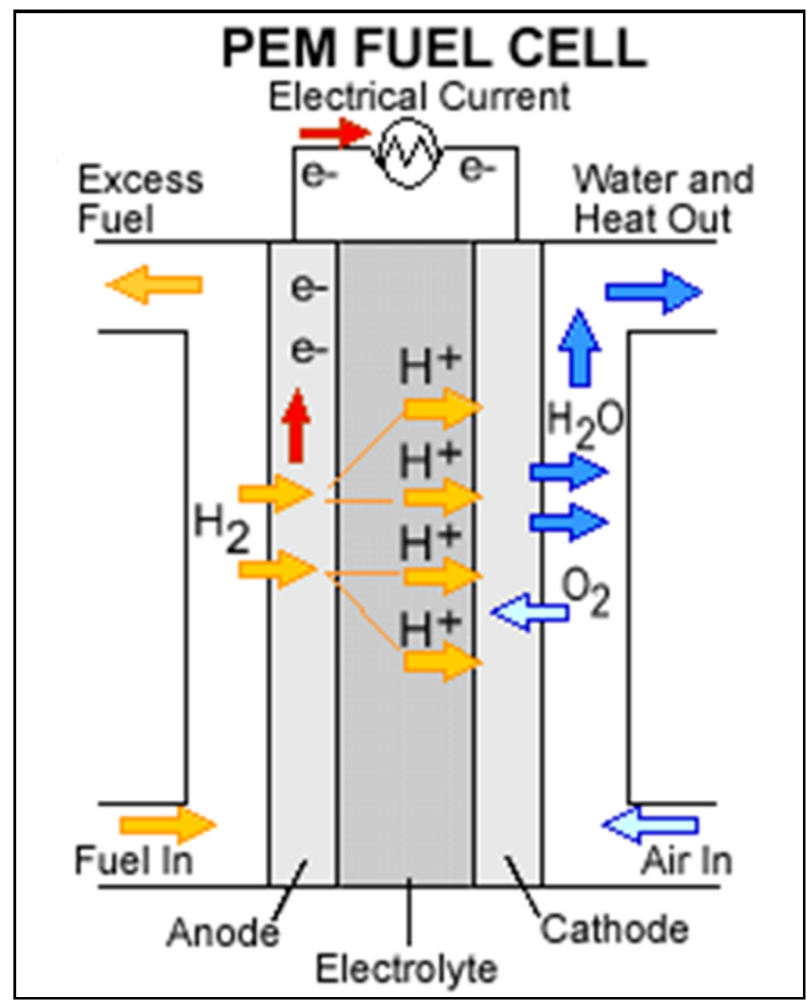

Figure 1.2 Illustration of PEM fuel cell ${ }^{9}$ (graph courtesy of DOE, see Appendix B)

PEM is widely considered as the most suitable fuel cell for light duty transportation. Configuration of PEM is shown in Figure 1.2. Hydrogen and oxygen gases are fed through each bipolar plate to anode and cathode, respectively. At the anode Hydrogen molecules are dissociated to protons and electrons and then protons move through the membrane to the other side of the cell while the electrons flow along the external circuit to the cathode. At the cathode, oxygen molecules arrest the electrons from the anode and form water with protons by exothermic reaction. Current operation cost of PEM is too high to afford, which indicates existing technologies need further improvement.

Although hydrogen owns attractive bright sides for being the new generation of energy, there is still a long way to go to put it into commercial use due to critical barriers, among which, hydrogen storage is the most crucial one. 


\subsubsection{Hydrogen storage}

The application of hydrogen energy may proceed probably via portable storage of hydrogen first. A medium with high-capacity hydrogen storage is hunted to better promote the use of hydrogen as an energy source, particularly applications in transportation. Conventional methods to store hydrogen include compression and liquefaction of hydrogen. However, these methods are unlikely able to satisfy practical application in the future due to safety and economic issues ${ }^{10-12}$. The storage approach most researchers interested in is to make hydrogen interact with a host material, like metal hydrides, complex hydrides, nanostructured carbon and metal organic frameworks (MOFs) ${ }^{10,11}$.

Table 1.3 illustrate the requirements renewed by DOE in 2011 on a storage system for fuel cell electric vehicles running on hydrogen. It is noted that the targets shown in the table (5.5 wt.\% and $40 \mathrm{~g}$ hydrogen/L by 2017) are capacities for the whole storage system, including adsorbent materials, container, and all the other related components. Previous targets by 2010 have not been really fulfilled. Research on hydrogen storage has been pursued for decades and improvement in storage system capacity obtained in recent years can be seen in Figure 1.3. The data points are obtained by averaging all the analyzed values during each year. The bars indicate the range of values acquired in each year. Although recent achievements indicate materials-based capacities exceeding 5 wt.\%, capacities will fall far below the targets if system is counted. None of the current systems meets the combination target of gravimetric, volumetric and system cost for $2017^{13}$. 
Table 1.3

DOE's hydrogen storage target ${ }^{13}$ (table courtesy of DOE, see Appendix C)

\begin{tabular}{|c|c|c|c|}
\hline Storage Parameter & Units & 2017 & Ultimate \\
\hline $\begin{array}{l}\text { System Gravimetric Capacity: } \\
\text { Usable, specific-energy from } \mathrm{H}_{2} \\
\text { (net useful energy/max system mass) }^{a}\end{array}$ & $\begin{array}{c}\mathrm{kWh} / \mathrm{kg} \\
(\mathrm{kg} \mathrm{H} / \mathrm{kg} \\
\text { system) }\end{array}$ & $\begin{array}{l}1.8 \\
(0.055)\end{array}$ & $\begin{array}{c}2.5 \\
(0.075)\end{array}$ \\
\hline $\begin{array}{l}\text { System Volumetric Capacity: } \\
\text { Usable energy density from } \mathrm{H}_{2} \\
\text { (net useful energy/max system volume) }\end{array}$ & $\begin{array}{l}\mathrm{kWh} / \mathrm{L} \\
\text { (kg H} / / \mathrm{L} \\
\text { system) }\end{array}$ & $\begin{array}{c}1.3 \\
(0.040)\end{array}$ & $\begin{array}{c}2.3 \\
(0.070)\end{array}$ \\
\hline $\begin{array}{l}\text { Storage System Cost }{ }^{\mathrm{b}} \text { : } \\
\text { Fuel cost }\end{array}$ & $\begin{array}{c}\text { \$/kWh net } \\
\left(\$ / \mathrm{kg} \mathrm{H}_{2}\right) \\
\text { \$/gge at pump }\end{array}$ & $\begin{array}{c}\text { TBD } \\
(\mathrm{TBD}) \\
2-4\end{array}$ & $\begin{array}{c}\text { TBD } \\
(\mathrm{TBD}) \\
2-4\end{array}$ \\
\hline $\begin{array}{l}\text { Durability/Operability: } \\
\text { Operating ambient temperature }\end{array}$ & ${ }^{\circ} \mathrm{C}$ & $-40 / 60$ (sun) & $-40 / 60$ (sun) \\
\hline Min/max delivery temperature & ${ }^{\circ} \mathrm{C}$ & $-40 / 85$ & $-40 / 85$ \\
\hline Operational cycle life $(1 / 4 \text { tank to full })^{e}$ & Cycles & 1500 & 1500 \\
\hline $\begin{array}{l}\text { Min delivery pressure from storage system; } \\
\mathrm{FC}=\text { fuel cell, ICE= internal combustion engine }\end{array}$ & bar (abs) & $5 \mathrm{FC} / 35 \mathrm{ICE}$ & $3 \mathrm{FC} / 35 \mathrm{ICE}$ \\
\hline Max delivery pressure from storage system ${ }^{\prime}$ & bar (abs) & $12 \mathrm{FC} / 100 \mathrm{ICE}$ & $12 \mathrm{FC} / 100 \mathrm{ICE}$ \\
\hline Onboard Efficiency & $\%$ & - & 90 \\
\hline "Well" to Powerplant Efficiency & $\%$ & - & 60 \\
\hline $\begin{array}{l}\text { Charging / Discharging Rates: } \\
\text { System fill time }(5 \mathrm{~kg})\end{array}$ & $\min$ & 3.3 & 2.5 \\
\hline Minimum full flow rate & ( $\left.\mathrm{kg} \mathrm{H}_{2} / \mathrm{min}\right)$ & (1.5) & (2.0) \\
\hline Start time to full flow $\left(20^{\circ} \mathrm{C}\right)^{g}$ & $(\mathrm{~g} / \mathrm{s}) / \mathrm{kW}$ & 0.02 & 0.02 \\
\hline Start time to full flow $\left(-20^{\circ} \mathrm{C}\right)^{g}$ & s & 5 & 5 \\
\hline $\begin{array}{l}\text { Transient response } 10 \%-90 \% \\
\text { and } 90 \%-0 \%{ }^{h}\end{array}$ & s & $\begin{array}{l}15 \\
0.75\end{array}$ & $\begin{array}{l}15 \\
0.75\end{array}$ \\
\hline Fuel Purity ( $\mathrm{H}_{2}$ from storage $)^{i}$ & $\% \mathrm{H}_{2}$ & \multicolumn{2}{|c|}{$\begin{array}{c}\text { SAE J2719 and ISO/PDTS } 14687-2 \\
\text { (99.97\% dry basis) }\end{array}$} \\
\hline $\begin{array}{l}\text { Environmental Health \& Safety: } \\
\text { Permeation \& leakage } \\
\text { Toxicity } \\
\text { Safety }\end{array}$ & $\begin{array}{c}\text { Scc/h } \\
- \\
-\end{array}$ & \multicolumn{2}{|c|}{ Meets or exceeds applicable standards } \\
\hline Loss of useable $\mathrm{H}_{2}{ }^{k}$ & $\begin{array}{l}(\mathrm{g} / \mathrm{h}) \mathrm{kg} \mathrm{H} \\
\text { stored }\end{array}$ & 0.05 & 0.05 \\
\hline
\end{tabular}

* Useful constants: $0.2778 \mathrm{kWh} / \mathrm{MJ} ; 33.3 \mathrm{kWh} / \mathrm{kg} \mathrm{H} \mathrm{H}_{2} ; 1 \mathrm{~kg} \mathrm{H} \mathrm{H}_{2} \approx 1$ gal gasoline equivalent. 


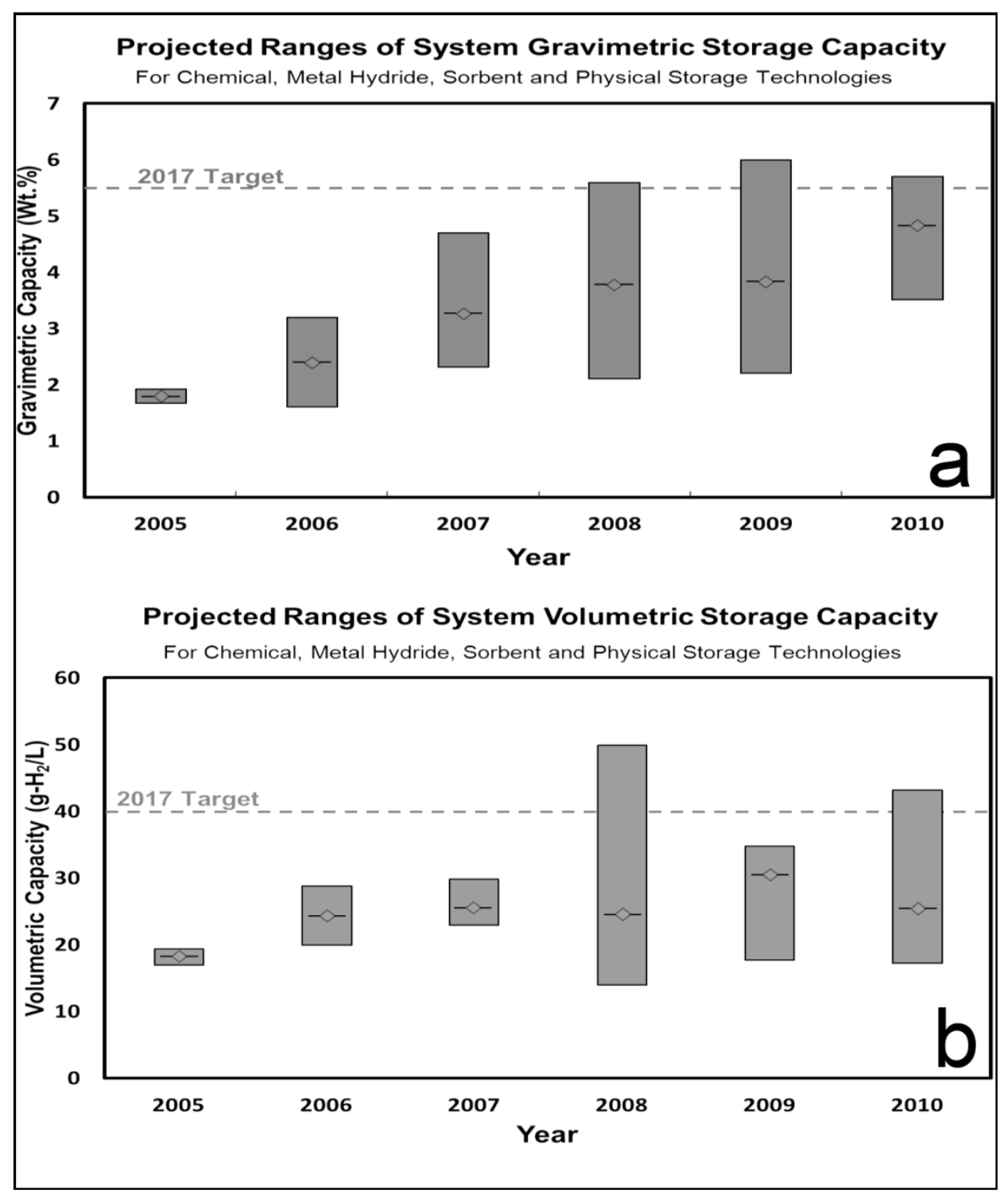

Figure 1.3 Estimates of (a) gravimetric and (b) volumetric capacities projected for on-board systems from year 2005 to $2010{ }^{13}$ (graph courtesy of DOE, see Appendix D)

\subsection{Hydrogen storage materials}

\subsubsection{Metal hydrides}

Hydrogen can react with metals and alloys at elevated temperature to form metal hydrides. Hydrides are considered to exist in ionic, covalent, and metallic forms, but the boundary between them is not that sharp ${ }^{14}$. Metal hydrides are very promising as they 
allow the storage of large amounts of hydrogen in a small volume at room temperature. $\mathrm{MgH}_{2}$ is considered as the most possible hydride for on-board hydrogen storage, since it is a costless and reversible medium with storage capacity as high as $7.7 \mathrm{wt} . \%$. However, the temperature required to release hydrogen is around $300{ }^{\circ} \mathrm{C}{ }^{15,16}$, which is much higher than the operation temperature of PEM fuel cell. The binary hydrides of the transition metals predominantly show metallic characteristics, like conductive and metallic-like appearance. In such compounds $\left(\mathrm{MH}_{\mathrm{n}}\right)$, the hydrogen usually takes up interstitial sites, resulting in large scales of non-stoichiometry. Many transition metals have stable hydrides except for the part from group $6(\mathrm{Cr})$ to group $11(\mathrm{Cu})$, resulting in the demand of very high temperature to harvest hydrogen from the hydrides ${ }^{14}$. This drawback makes the binary hydrides unable to be applied in a vehicle driven by hydrogen.

Typical alloys for hydrogen storage can be divided into three categories: $A B, \mathrm{AB}_{2}$ and $\mathrm{AB}_{5}$, in which $\mathrm{A}$ is a rare earth or alkaline earth metal tending to form stable hydrides and $\mathrm{B}$ is a transition metal forming only unstable hydrides ${ }^{17-19}$. A typical $\mathrm{AB}_{5}$ alloys $\mathrm{LaNi}_{5}$ can adsorb $\sim 1.4$ wt. $\%$ hydrogen at $0.2 \mathrm{MPa}$ room temperature ${ }^{20}$. Not to mention the low storage capacity, the high price of lanthanum largely prevents the further development of this material. For some $\mathrm{AB}_{2}$ compounds $(\mathrm{A}=\mathrm{Ti}, \mathrm{Zr}, \mathrm{Mg} ; \mathrm{B}=\mathrm{V}, \mathrm{Cr}, \mathrm{Fe}, \mathrm{Mn})$ with cheaper elements, up to $2 \mathrm{wt} \%$ hydrogen uptakes can be obtained ${ }^{15}$. However, at room temperature, the hydrogen pressures at equilibrium are relatively low and not suitable for practical uses.

As most metal hydrides are in solid phase, the volumetric target of DOE $\left(>0.040 \mathrm{~kg} \mathrm{H}_{2} / \mathrm{L}\right)$ is not a big issue for such materials. Classical metal hydrides usually contain transition metals, so the gravimetric capacity for hydrogen is limited to roughly $2 \mathrm{wt.} \%$, much lower than the DOE target $\left(>5.5 \mathrm{wt} . \% \mathrm{H}_{2}\right)$. To realize on-board automotive applications, 
most current research on metal hydrides for hydrogen storage is focused on using light weight metals, such as $\mathrm{Al}, \mathrm{Mg}$ and $\mathrm{Na}$, to develop new materials that have high gravimetric hydrogen density and also satisfy the kinetic and thermodynamic requirements for hydrogen uptake and release.

\subsubsection{Complex hydrides}

As conventional metal hydrides only have hydrogen storage capacities no greater than 2 wt.\% at room temperature, much attention has been paid to the complex hydrides which are composed primarily of light elements $(Z \leq 13)$ with the interest of high gravimetric capacities. In a complex hydride, hydrogen is covalently bonded to a central atom to form a complex anion and stabilized by a cation, typically an alkali or alkaline earth metal.

Complex hydrides have shown surprising gravimetric capacities. One of the best performing and well studied reversible complex hydrides is sodium alanate $\left(\mathrm{NaAlH}_{4}\right)$, which has a theoretical storage capacity of $6.7 \mathrm{wt} . \%$ in total that can be described in a three-step reaction ${ }^{21}$

$$
\begin{aligned}
3 \mathrm{NaAlH}_{4} & \rightarrow \mathrm{Na}_{3} \mathrm{AlH}_{6}+2 \mathrm{Al}+3 \mathrm{H}_{2} \\
\mathrm{Na}_{3} \mathrm{AlH}_{6} & \rightarrow 3 \mathrm{NaH}+\mathrm{Al}+1.5 \mathrm{H}_{2} \\
3 \mathrm{NaH} & \rightarrow 3 \mathrm{Na}+1.5 \mathrm{H}_{2}
\end{aligned}
$$

The first and second decomposition steps can release $3.7 \mathrm{wt.} \%$ and $1.9 \mathrm{wt} . \%$ hydrogen at $0.1 \mathrm{MPa}$ and reasonable temperature. The decomposition temperature required for the third step is very high for on-board applications and thus most of the time it is not regarded as a hydrogen source. Another very popular complex hydride $\mathrm{LiBH}_{4}$ is able to 
discharge 13.5 wt.\% hydrogen at temperature $>380{ }^{\circ} \mathrm{C}$ according to the following reaction $^{22}$

$$
\mathrm{LiBH}_{4} \rightarrow 2 \mathrm{LiH}+2 \mathrm{~B}+3 \mathrm{H}_{2}
$$

Hydrogen uptake by $\mathrm{Li}_{3} \mathrm{~N}$ was first discovered by Dafert and Miklauz ${ }^{23}$ a hundred years ago. Significant attention has not been paid to it until Chen and co-workers recently proposed it as a promising candidate for hydrogen storage with overall 10.4 wt.\% adsorption capacity. The hydrogen storage and generation process is composed of following two steps 23

$$
\mathrm{LiNH}_{2}+2 \mathrm{LiH} \leftrightarrow \mathrm{Li}_{2} \mathrm{NH}+\mathrm{LiH}+\mathrm{H}_{2} \leftrightarrow \mathrm{Li}_{3} \mathrm{~N}+2 \mathrm{H}_{2}
$$

At temperature of up to $200{ }^{\circ} \mathrm{C}, 6$ wt.\% hydrogen can be desorbed, while a complete desorption requires temperature as high as $420{ }^{\circ} \mathrm{C}$.

As a result of high thermodynamic stability of complex hydrides, high temperature is usually needed to release hydrogen. Current research efforts are devoted to reducing the decomposition enthalpy by introducing a second species that can stabilize the reaction product. In addition, creating nanoscale powders and incorporating the hydride into nanoporous scaffolds or frameworks have also been tested to improve the reaction kinetics $^{24}$.

\subsubsection{Nanostructured carbon}

The carbon materials with porous structure have attracted considerable attentions as potential hydrogen storage media mainly due to their low cost, low density and good 
chemical stability. ${ }^{25}$. A series of carbon materials have been intensively studied, like carbon nanofibers (CNFs), carbon nanotubes (CNTs), activated carbons (ACs), and ordered porous carbons ${ }^{26-31}$. As most porous materials, the hydrogen adsorption mechanism on nanostructured carbon is primarily based on physisorption.

As ACs have the characteristics of enormous chemical and structural complexity and heterogeneity, the hydrogen uptakes on ACs differed with a marked dependency on the materials employed $25,27,32,33$. Yang and colleagues obtained an exceptionally high hydrogen storage capacity of around 7 wt.\% at $77 \mathrm{~K}$ and 20 bar over a microporous carbon synthesized by templating using zeolite beta ${ }^{32}$. However, at room temperature and high pressure (100 bar) the highest storage value is still below 1 wt.\%, even via highly developed porous carbon specific with surface area of greater than $3700 \mathrm{~m}^{2} / \mathrm{g}^{34}$.

Dillon et al. ${ }^{35}$ reported for the first time on hydrogen storage in CNTs in 1997. Since then, single-wall carbon nanotubes (SWCNTs) and multi-wall carbon nanotubes (MWCNTs) have attracted considerable attention for hydrogen storage. The known carbon structure is considered as the major advantage of CNTs, which can correlate experimental results with theoretical predictions and better illuminate the adsorption mechanism. However, the presence of metal impurities in CNTs from production process may cause unpredictable influence on the storage behaviors, because the distribution and chemisorption effects of those metals are very various ${ }^{36}$. Some exciting results have been reported in early time, even with hydrogen storage value up to $14 \mathrm{wt.} \%$ 35,37,38. Nevertheless, these extremely high results were finally proven to be caused by errors in the experiments ${ }^{39,40}$. The hydrogen adsorption capacities of SWCNTs and MWCNTs have been demonstrated by abundant studies to be no greater than 1 wt.\% at ambient temperature and around 100 bar $^{41-45}$, but can be enhanced to between 5 to 8 wt.\% when 
conducting tests at $77 \mathrm{~K}^{42,44,46,47}$.

Countless reports have demonstrated that the hydrogen storage capacities in pure carbon materials achieved by physisorption are impossible to meet targets of DOE.

\subsubsection{Metal organic frameworks (MOFs)}

Metal organic frameworks are porous crystalline compounds constructed by metal ions or small metal cluster joint together by organic ligand linkers. Recently, MOFs has been developed to store hydrogen due to their extremely large surface area and potential applications as sorbents ${ }^{48-52}$. Typical MOFs have inorganic groups $\left[\mathrm{OZnO}_{4}\right]^{6+}$ at the corner of the structure and are connected with carboxylate organic links ${ }^{48}$. The linkers are isolated from each other but can be accessed from all sides, leading to extremely high surface areas up to $5000 \mathrm{~m}^{2} / \mathrm{g}$ of such materials. According to theoretical calculations, hydrogen preferred to be adsorbed to the sites of metal oxide clusters in MOFs, but increasing the pressure would cause the effect of organic linker more evident ${ }^{53}$. Also, the character of the organic bridges affected the interaction of hydrogen with the inorganic cluster sites ${ }^{54}$. To achieve relatively high adsorption capacity, MOFs are required to possess high surface area structure with interconnected small pores for a strong interaction with hydrogen ${ }^{52}$.

In 2003, Yaghi et al. first reported a high hydrogen adsorption of 4.5 wt. $\%$ on MOF-5 $\left(\mathrm{Zn}_{4} \mathrm{O}(\mathrm{bdc})_{3}\right)$ at $77 \mathrm{~K}$ and less than $1 \mathrm{bar}^{48}$. The results were lower in their latter work ${ }^{55,56}$. Other publications revealed MOF-177 $\left(\mathrm{Zn}_{4} \mathrm{O}(\mathrm{BTB})_{2}\right)$ had a super large BET surface area up to $4700 \mathrm{~m}^{2} / \mathrm{g}$ and the highest hydrogen storage of $7.5 \mathrm{wt} . \%$ at $77 \mathrm{~K}$ and $70 \mathrm{bar}^{57,58}$. Although some kinds of MOFs have remarkable hydrogen capacities at $77 \mathrm{~K}$, no significant hydrogen storage capacity was observed on MOFs at room temperature. The 
temperature is apparently a crucial factor to assess hydrogen storage behavior in MOFs, just like the ACs. No finding has been addressed that the increase of pressure alone is likely to improve hydrogen adsorption at room temperature to a comparable level at $77 \mathrm{~K}$ 46. Extensive work will be directed toward the synthesis of effective MOFs with larger heat of hydrogen adsorption.

\subsubsection{Metal oxides}

Metal oxides attract attention for hydrogen adsorption due to their wide application in catalysis ${ }^{59-61}$, gas storage ${ }^{62-64}$, and sensors ${ }^{65}$. Most metal oxides possess unsaturated metal centers, which accounts for strong interaction with hydrogen ${ }^{66,67}$. Synthesizing highly porous metal oxides for hydrogen storage remains a tough task.

Titanium oxide $\left(\mathrm{TiO}_{2}\right)$ is the most studied metal oxide for hydrogen storage ${ }^{62,68-71}$. Lim et al. ${ }^{70}$ reported hydrogen storage capacities up to $\sim 2 \mathrm{wt} . \%$ at room temperature and 6 MPa over synthesized $\mathrm{TiO}_{2}$ nanotube. Around 75\% stored hydrogen was releasable under ambient pressure and others could be desorbed at $120{ }^{\circ} \mathrm{C}$. Experimental results from Bavykin et al. ${ }^{71}$ showed that around $1.5 \mathrm{~mol} \mathrm{H}_{2}$ could be adsorbed to $1 \mathrm{~mol} \mathrm{TiO}_{2}$ at $77 \mathrm{k}$ and 2 bar, corresponding to $3.75 \mathrm{wt} \%$ storage capacity. Complete desorption needed to heat the sample in a vacuum to $200{ }^{\circ} \mathrm{C}$. For a commercial pure $\mathrm{ZnO}$ (nanopowder, $30 \mathrm{~nm}$ in diameter), hydrogen uptake at room temperature and 860 psi was 1.05 wt. $\%, 65.2 \%$ of which could be released ${ }^{72}$. The incomplete desorption indicated that both physisorption and chemisorption are responsible for the hydrogen uptake on metal oxides ${ }^{72,73}$. Hydrogen uptakes on porous $\mathrm{NiO}\left(382.56 \mathrm{~m}^{2} / \mathrm{g}\right)$ and $\mathrm{MgO}\left(363.59 \mathrm{~m}^{2} / \mathrm{g}\right)$ at room temperature were 0.08 wt.\% at 135 bar and 0.2 wt.\% at 90 bar, respectively ${ }^{64}$. Although the reported hydrogen storage capacities of the metal oxides are not that impressive, efforts may be devoted to combine the oxides with other materials for better results. 


\subsection{New approaches to hydrogen storage}

\subsubsection{Hydrogen spillover}

The introduction of spillover techniques to hydrogen adsorption process encourages scientists who are working on hydrogen storage. Hydrogen spillover may be broadly defined as the transportation of dissociated hydrogen adsorbed or formed on a first surface onto another surface. The first surface is typically a metal and the second surface is usually the support on which the metal is doped ${ }^{34}$. It was theoretically predicted that isolated transition metal atoms ( $\mathrm{Sc}, \mathrm{Ti}, \mathrm{V}, \mathrm{Pt}$, Pd, etc) stabilized on $\mathrm{sp}^{2}$-hybridized carbons (nanotubes, fullerenes, graphenes etc) induce multiple bonding of molecular $\mathrm{H}_{2}$ with adsorption energies intermediate between physisorption and chemisorption ${ }^{74}$. By applying the spillover approach, considerable enhancement can be obtained at $298 \mathrm{~K}$ on a lot of sorbents, which includes both SWCNTs and MWCNTs ${ }^{75-78}$, CNFs ${ }^{76}$, ACs ${ }^{78,79}$, MOFs ${ }^{80,81}$, and so on.

Lueking and Yang ${ }^{75}$ studied hydrogen storage on MWCNTs with various degrees of catalyst $(\mathrm{Ni}, \mathrm{Mg})$ removal and observed that removal of the catalyst decreased the uptake from 0.6 wt.\% to below detection limits. Yang and $\mathrm{Li}^{79}$ doped Pt nanoparticles on a superactivated carbon (AX-21). The hydrogen storage capacity of carbon sample without doping was just 0.6 wt. $\%$ at $298 \mathrm{~K}$ and 100 bar, while that of doped carbon achieved 1.2 wt.\% under the same condition. Furthermore, MOF-177 got an enhancement factor of $\sim 2.5$ at $298 \mathrm{~K}$ and 100 bar by doping with Pt, from 0.62 wt.\% to 1.5 wt. $\%{ }^{81}$. A large number of computational results have also demonstrated the dissociative chemisorption of hydrogen on different solid state materials ${ }^{82}$. 


\subsubsection{Combination of light metal hydrides and carbon materials for hydrogen storage}

In recent years, carbon materials have been reported to lead to improvement in kinetics and thermodynamics of hydrogen adsorption for different metal hydride systems. Carbon materials have been chosen as additive or support because of their light weight, relative inertness, porostiy and abundance. Carbon is also able to bond with itself (and other atoms) with different hybridizations, giving rise to allotropes of completely different properties. In addition, the ability of carbon to efficiently conduct heat and the fast hydrogen diffusion along the carbon phase can improve the hydrogen adsorption properties ${ }^{83}$.

A lot of research has been devoted to ball-milling of $\mathrm{MgH}_{2}$ or $\mathrm{NaAlH}_{4}$ with different carbon materials ${ }^{84-86}$, among which CNTs and CNFs show the best performance. Imamura et al. ${ }^{87}$ reported enhanced hydrogen adsorption properties for supported $\mathrm{Mg}$ nanoparticles that were synthesized by solution impregnation of activated carbon with magnesium dissolved in ammonia. Liang and Kung ${ }^{88}$ calculated a decrease in enthalpy of formation by $50 \%$ for the confinement of $\mathrm{MgH}_{2}$ clusters in $(10,10)$ CNTs of $1.2 \mathrm{~nm}$ in diameter. Another example for the kinetics improvement of hydrogen discharge is $\mathrm{NaAlH}_{4}$ particles of 2-10 nm deposited on CNFs. Activation energy of the first decomposition step decreased from $116 \mathrm{~kJ} / \mathrm{mol}$ to $58 \mathrm{~kJ} / \mathrm{mol}^{89}$.

\subsubsection{Electric field assisted hydrogen adsorption}

Over decades, hydrogen storage development is focused on searching novel materials and improving fabrication techniques. Recently a novel method has been proposed by Hwang's group ${ }^{90-93}$ to increase hydrogen storage capacity by applying an external electric field. Polarization of hydrogen molecule may occur under electric field and thus 
leads to a stronger interaction between hydrogen and adsorbents ${ }^{93}$. The approach is expected to make materials synthesis less complicated while improving the thermodynamics and reversibility of hydrogen storage.

It was observed by Li et al. ${ }^{90}$ that electric field could lead to enhanced hydrogen adsorption over activated carbon and the adsorption increased with the increase in applied voltage. At 83 bar, the adsorption capacity increased from $0.45 \mathrm{wt} . \%$ at $0 \mathrm{~V}$ to $0.46,0.49$, 0.53 and 0.55 wt. $\%$ at 500, 1000, 2000 and $3000 \mathrm{~V}$, respectively. Sun et al. ${ }^{64}$ introduced an external electric field to metal oxide sorbents and found that it could increase hydrogen uptake by $37.5 \%$ for $\mathrm{NiO}$ and $25 \%$ for $\mathrm{MgO}$ in range of 0 to 60 bar. A computational work conducted by Liu and co-workers ${ }^{94}$ also reported that hydrogen storage over graphenes can be enhanced by introducing an electric field. Additionally, calculations by Zhou et al. ${ }^{95}$ showed an applied electric field can substantially improve the hydrogen capacity of polarizable boron nitride (BN) substrates. These findings may stimulate further research in this direction. 


\section{CHAPTER 2 BACKGROUND AND LITERATURE REVIEW}

\subsection{Hydrogen adsorption mechanism}

No matter how developed the materials or methods for hydrogen storage are, adsorption properties are ultimately determined by the nature and strength of the fundamental binding between hydrogen and the storage material. A weak binding would lead to very low hydrogen storage capacity at ambient temperature, while a strong interaction might result in irreversible adsorption or need extreme conditions to discharge hydrogen. Therefore, it is essential to understand the hydrogen adsorption mechanism for better developing adsorbents that possess desired interactions with hydrogen.

The process of trapping or binding hydrogen to surface of adsorbent is known as adsorption. There are two types of adsorption: physisorption and chemisorptions. All the hydrogen adsorption processes can be attributed to either or both of them. The major properties of physisorption and chemisorption are given in Table 2.1. Physisorption theoretically can take place between any gas molecule and any solid surface if the temperature is low enough, and multilayer adsorbate molecules can be attached during this exothermic process. Interactions based on physisorption are usually very weak and will decrease with increasing temperature. Chemisorption takes place only at specific sites and only a monolayer of adsorbates can be attached to adsorbent surface. Chemisorption can be either exothermic or endothermic, so its behaviors in different cases highly depend on surrounding temperature.

It was estimated that ideal hydrogen binding affinity should be in the range of 20-40 $\mathrm{kJ} / \mathrm{mol}^{96}$. Binding energy lower than $20 \mathrm{~kJ} / \mathrm{mol}$ correspond to complexes that can hardly exist at ambient condition, while binding energy higher than $40 \mathrm{~kJ} / \mathrm{mol}$ would cause 
trouble in hydrogen desorption. As shown in the Table 2.1, adsorption heat of physisorption is only $\sim 10 \mathrm{~kJ} / \mathrm{mol}$, while that of chemisorptions is much higher than desired binding energy. Thus, reversible hydrogen storage cannot depend on either physisorption or chemisorption alone.

Table 2.1

Comparison of physisorption and chemisorption ${ }^{4}$

\begin{tabular}{|c|c|c|}
\hline & Physisorption & Chemisorption \\
\hline Cause & Van der Waals forces & Chemical bonding \\
\hline Adsorbents & All solids & Some solids \\
\hline Adsorbates & All gases & Some chemical reactive gases \\
\hline Temperature & Low temperature & Higher temperatures \\
\hline Heat of adsorption & Low $(\sim 10 \mathrm{~kJ} / \mathrm{mol})$ & High $(80-200 \mathrm{~kJ} / \mathrm{mol})$ \\
\hline Rate & Very fast & Temperature-dependent \\
\hline Surface coverage & Multilayer & Monolayer \\
\hline Reversibility & High reversible & Temperature-dependent \\
\hline Application & $\begin{array}{l}\text { Determination of surface } \\
\text { area and pore size }\end{array}$ & $\begin{array}{l}\text { Determination of active site of } \\
\text { catalysts }\end{array}$ \\
\hline
\end{tabular}

Hydrogen can either interact with the adsorbent as a molecular or dissociate to bond with the material. The former interaction can be achieved via either physisorption or chemisorption, which is the way nanostructrued carbon and MOFs interact with hydrogen. The latter is chemisorption involving breakdown and formation of chemical bonds. Hydrogen storage using metal hydrides and complex hydrides is classified to this category. Some light metal hydrides like $\mathrm{MgH}_{2}$ possesses very attractive storage capacity, but strong hydride bond of around $75 \mathrm{~kJ} / \mathrm{mol}$ requires temperature up to $300{ }^{\circ} \mathrm{C}$ to completely release hydrogen. In most cases, such processes are irreversible or partially 
irreversible $^{11}$.

Adsorption of molecular hydrogen over sorbent materials depends on three types of interactions: van der Waals force, electrostatic interactions and orbital interaction ${ }^{96}$. Van der Waal attraction is the weakest and always exists between electron clouds that do not overlap. The interaction between hydrogen and neutral carbon is considered primarily van der Waals force, which is typically in the order of a few $\mathrm{kJ} / \mathrm{mol}$. Theoretical investigations suggest that hydrogen adsorption materials rely only on this interaction is impossible to fulfill DOE target at ambient temperature.

When hydrogen gets close to the charged sites, an interaction known as electrostatic interaction which is stronger than van der Waals can be formed. In the presence of other charges, hydrogen would be moderately polarized, which induces a dipole moment in the molecule by distorting the bonding $\sigma$ orbital. Overlap of the electron clouds may occur and makes the binding stronger. The strength of the binding mainly depends on the nature of the charged site ${ }^{97}$. Adsorption energy is expected to be enhanced by introducing alkali metal ions to matrix materials such as carbon through doping treatment. Interaction of hydrogen and alkali-doped graphene was simulated to be around $10 \mathrm{~kJ} / \mathrm{mol}^{98,99}$.

Orbital interaction is a strong existing binding between hydrogen molecule and transition metal (TM). TM- $\mathrm{H}_{2}$ bond is stabilized by the "forward donation of the $\mathrm{H}-\mathrm{H}$ electron density into low-lying vacant metal d-orbital and back-donation from the metal to the anti-bonding $\sigma^{*} \mathrm{H}_{2}$ orbital". Transition metal-hydrogen complexes can capture and release $\mathrm{H}_{2}$ reversibly and the range of the $\mathrm{TM}-\mathrm{H}_{2}$ binding energy varies between 20 and $160 \mathrm{~kJ} / \mathrm{mol}^{97}$. Although the very high atomic weights of the transition metals are not beneficial for obtaining high gravimetric density, the idea of strong $\sigma$-bonded $\mathrm{H}_{2}$ 
complexes is still possible to be exploited for further development of novel hydrogen storage materials.

\subsection{Hydrogen cluster}

\subsubsection{Hydrogen ion cluster}

Unlike van der Waals bonded neutral cluster, hydrogen ion cluster is at transition from a chemical bound molecular to a van der Waals bound cluster ${ }^{100}$. Since Thomson first discovered $\mathrm{H}_{3}{ }^{+}$in $1912^{101}$, a lot of experimental and theoretical work has been thrown into the investigation of $\mathrm{H}_{\mathrm{n}}{ }^{+}(\mathrm{n}=3,5,7,9,11,13)$ clusters. $\mathrm{H}_{3}{ }^{+}$has been proven to be a very stable ion with a structure of equilateral triangular ${ }^{102}$. The reaction of $\mathrm{H}_{3}^{+} \rightarrow \mathrm{H}_{2}+$ $\mathrm{H}^{+}$is endothermic and its required energy was calculated as $106 \mathrm{kcal} / \mathrm{mol}{ }^{103}$. The geometrical structures of $\mathrm{H}_{\mathrm{n}}{ }^{+}$clusters have been simulated to be composed of $\mathrm{H} \mathrm{H}_{3}{ }^{+}$in the core, which is surrounded by weakly bound $\mathrm{H}_{2}$ molecules ${ }^{101}$. As the cluster size $\mathrm{n}$ increases, the distance between the core triangle and external molecules increases, and the dissociation energies decreases. In addition, the interaction between the electron-hole delocalization and ion-molecules polarization also becomes significantly reduced, resulting in lower bonding energies. Hiraoka and Kebarle ${ }^{104}$ plot Van't Hoff curves for equilibrium $\mathrm{H}_{\mathrm{n}}^{+}+\mathrm{H}_{2}=\mathrm{H}_{\mathrm{n}+2}{ }^{+}$and showed the dissociation enthalpies were 9.6, 4.1, 3.8, and $2.4 \mathrm{kcal} / \mathrm{mole}$ for $\mathrm{n}=3,5,7,9$, respectively.

Negative hydrogen ion clusters $\mathrm{H}_{n}^{-}(\mathrm{n}=3,5,7,9,11,13)$ have also been reported ${ }^{105,106}$. The existence of negative ion clusters is critical, as their stabilization energy is very small ( $<1 \mathrm{kcal}$ ). Hirao and Yamabe ${ }^{106}$ examined the structure and stability of $\mathrm{H}_{\mathrm{n}}{ }^{+}$and $\mathrm{H}_{\mathrm{n}}^{-}$, revealing that $\mathrm{H}_{\mathrm{n}}^{+}$is a "charge-transfer complex", while the stability of $\mathrm{H}_{n}{ }^{-}$comes primarily from the "ion-induced-dipole attractions". 


\subsubsection{Metal hydrogen cluster}

Besides hydrogen ion cluster, hydrogen is capable of forming clusters with metals. The experimental work by Kubas et al. ${ }^{107}$ first showed that $\mathrm{H}_{2}$ could be attached as an uninserted species to an oxidized transition metal center. Since then, lots of experiments and simulations have been conducted on metal hydrogen clusters. The results showed that monovalent alkali metal cations $\left(\mathrm{Na}^{+}\right.$and $\left.\mathrm{K}^{+}\right)$have much lower gas phase $\mathrm{H}_{2}$ binding energies than the transition metal cations. $\mathrm{H}_{2}$ molecules and the first row transition metals typically form clusters with the general formula of $\left[\mathrm{M}\left(\mathrm{H}_{2}\right)_{\mathrm{n}}^{+}\right](\mathrm{M}=\mathrm{Sc}, \mathrm{Ti}, \mathrm{V}, \mathrm{Cr}, \mathrm{Mn}, \mathrm{Fe}$, $\mathrm{Co}, \mathrm{Ni}, \mathrm{Cu}, \mathrm{Zn} ; \mathrm{n}=1-6)^{108}$. Unexpectedly, the gas phase measurements revealed that the bond dissociation energy (BDE) typically increases from $n=1$ to $n=2$ for the transition metal ions. For example, a experiment was conducted to generate $\left[\mathrm{Ti}\left(\mathrm{H}_{2}\right)_{\mathrm{n}}{ }^{+}\right]$clusters using $\mathrm{TiCl}_{4}$ as ion source and the BDEs were 7.5, 9.7, 9.3, 8.5, 8.2, $8.7 \mathrm{kcal} / \mathrm{mol}$ for $\mathrm{n}=1-6$, respectively ${ }^{109}$. This initial increase has been attributed to the mixing between the $3 \mathrm{~d} \sigma$ orbital and the empty $4 \mathrm{~s}$ orbital, which is already present in the $\left[\mathrm{M}\left(\mathrm{H}_{2}\right)^{+}\right]$cluster. The linear geometry of the $\left[\mathrm{M}\left(\mathrm{H}_{2}\right)_{2}{ }^{+}\right]$cluster allows both $\mathrm{H}_{2}$ ligands to share the cost of the hybridization, resulting in a larger BDE to the second $\mathrm{H}_{2}$ molecule ${ }^{110}$. Further increase of $\mathrm{n}$ for all transition metal ions just leads to a mild decrease in BDE.

The binding of $\mathrm{H}_{2}$ to transition metal dimer cations $\left(\left[\mathrm{M}_{2}\left(\mathrm{H}_{2}\right)_{\mathrm{n}}{ }^{+}\right]\right)$has been rarely examined. Manard and co-workers ${ }^{67}$ used equilibrium methods to measure binding energies and entropies for the attachment of up to six $\mathrm{H}_{2}$ ligands to ground-state $\mathrm{Cu}_{2}{ }^{+}$. BDEs of the six $\mathrm{H}_{2}$ ligands added are 12.4, 10.1, 4.9, 3.8, 2.1 and probable $1.7 \mathrm{kcal} / \mathrm{mol}$ for dissociated $\mathrm{H}_{2}$ number of 1, 2, 3, 4, 5 and 6, respectively.

\subsection{Influential factors of hydrogen storage on carbon materials}

Although pristine carbon adsorbents primarily capture hydrogen molecules by weak 
attractions, their fast adsorption and desorption kinetics is still attractive for fast charging and discharging of hydrogen. Several factors are responsible for hydrogen adsorption characteristics on carbon materials such as the accessible surface area, the pore sized and the applied temperature and pressure.

\subsubsection{Porous structure}

Porous structure of carbon materials is the key factor in determining hydrogen storage capacity. As a portion of the pores in the carbon is small enough to capture the $\mathrm{H}_{2}$ molecule, the narrowest porosity in the carbon sample play a decisive role in hydrogen adsorption characteristics. Micropores with pore size smaller than $0.6 \mathrm{~nm}$ have been reported to be the effective sites for hydrogen adsorption in porous materials ${ }^{25}$. Mesopores contribute to the total pore volume but relatively very little to adsorption

capacity. Thomas ${ }^{46}$ collected hydrogen adsorption data obtained at $77 \mathrm{~K}$ and 1 bar on a bunch of nanostructured carbon materials with wide ranges of total pore volume and micropore volume, as shown in Figure 2.1. The correlation between hydrogen uptake and total pore volume showed greater scatter in the data. Some of the carbon materials only adsorbed a small amount of hydrogen, even though they possessed very high total pore volume. However, an approximately linear relation was found between hydrogen captured and micropore volume, which indicated larger micropore volume could lead to more captured hydrogen molecules. 

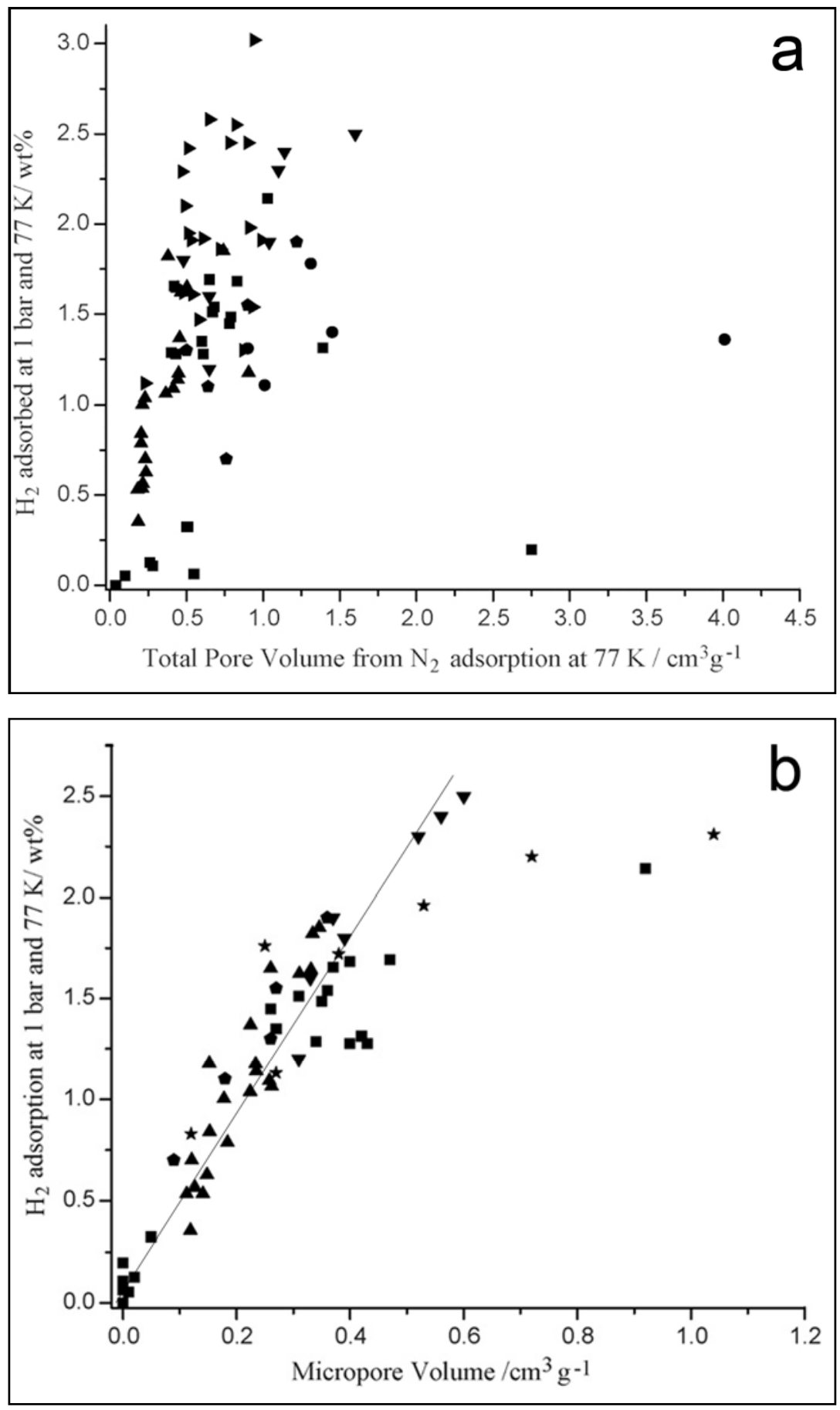

Figure 2.1 Hydrogen adsorption capacity at $77 \mathrm{~K}$ and 1 bar for different carbon samples versus (a) total pore volume and (b) micropore volume ${ }^{46}$ (reprinted with permission from Elsevier, see Appendix E) 


\subsubsection{Temperature}

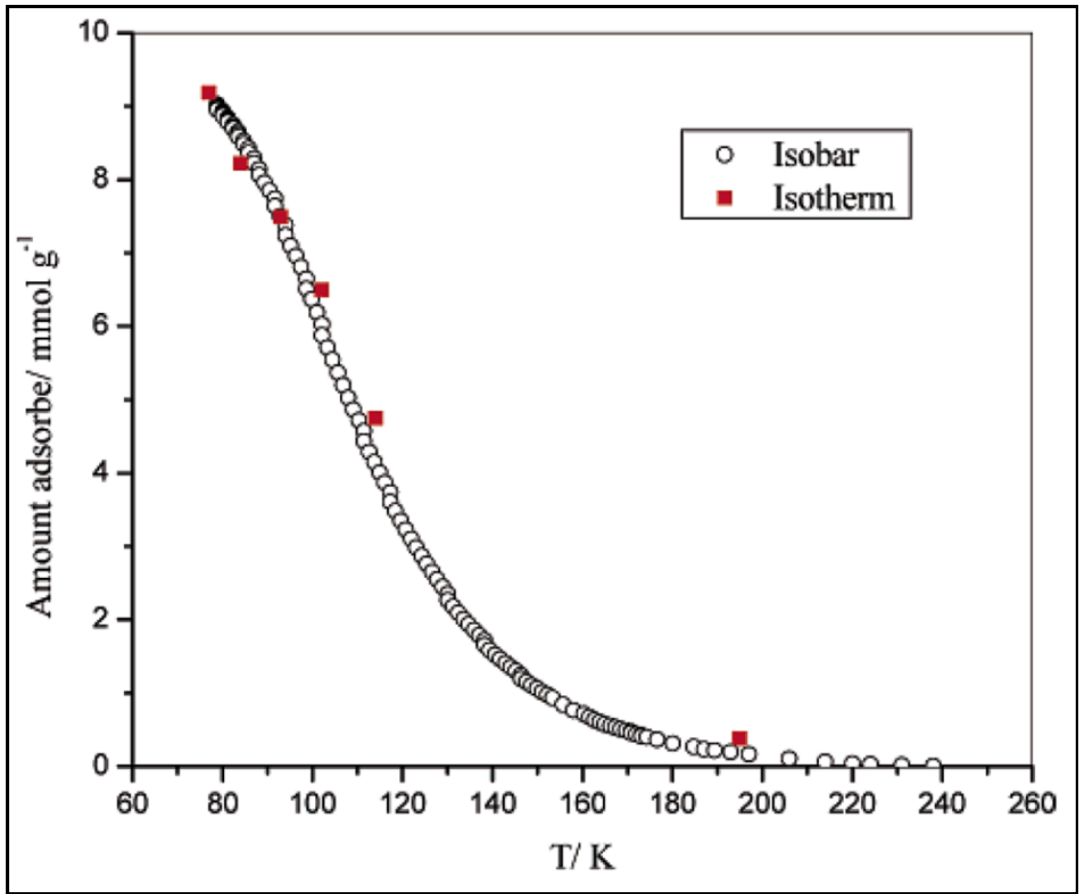

Figure 2.2 Isobars for hydrogen desorption from a certain activated carbon at 1 bar (heating rate 0.3 $\mathrm{K} / \mathrm{min}$ ) and isotherm data from adsorption at 1 bar ${ }^{111}$ (reprinted with permission from American Chemical Society, see Appendix F)

Remarkable temperature dependence of hydrogen adsorption over carbon materials has been demonstrated by a large number of experimental results. Usually storage capacities up to 8 wt. $\% \mathrm{H}_{2}$ could be obtained at $77 \mathrm{~K}$ while reliable results only showed $<1 \mathrm{wt} . \%$ adsorbed $\mathrm{H}_{2}$ at ambient temperature ${ }^{41-47}$. Temperature dependence of hydrogen adsorption has been experimentally studied by Zhao et al. ${ }^{111}$. They tested hydrogen desorption isobars at pressure of 1 bar on a certain activated carbon and compared the results with the adsorption isotherm data in the same temperature range, as shown in Figure 2.2. The image shows very low amount adsorption when the temperature was higher than $200 \mathrm{~K}$. To store significant hydrogen at ambient temperature, applying high pressure is the method generally used. However, it is unlikely to realize an extent 
comparable at $77 \mathrm{~K}$ by increasing pressure alone.

\subsubsection{Pressure}

A high pressure ensures a higher hydrogen adsorption capability, but the measurements at high pressure and ambient temperature usually lead to greater errors. This is because corrections for buoyancy and dead volumes in gravimetric system and volumetric system will become much larger at high pressure. Moreover, more available impurities from hydrogen under high pressure and they are adsorbed to adsorbent materials and thus lead to greater influence on measured results ${ }^{46}$.

\subsection{Hydrogen adsorption measurement methods}

It is a tough task to accurately measure the hydrogen adsorption over porous material. Many errors have been created due to invalid measurements ${ }^{35,38}$. Two conventional methods used for determining hydrogen capacities during adsorption and desorption are gravimetric and volumetric method.

\subsubsection{Gravimetric method}

Gravimetric method provides a direct measurement of adsorption. The major problem of this method is that any impurity, either from hydrogen used or within the vacuum system, can end with a considerable error. The reason is that the weight of an impurity molecule like $\mathrm{H}_{2} \mathrm{O}$ is equal to that of nine $\mathrm{H}_{2}$ molecules. 0.6 wt.\% of $\mathrm{H}_{2} \mathrm{O}$ adsorbed is referred to 5.4 wt.\% of $\mathrm{H}_{2}$ capacity. As a result, an ultra-clean high vacuum system and ultra-pure hydrogen are needed for valid measurements ${ }^{52}$.

\subsubsection{Volumetric method}

Volumetric method indirectly determines hydrogen uptake through the pressure change in 
a closed chamber filled with hydrogen. Compared to gravimetric method, hydrogen adsorption data obtained through this way lead to a much lower error. Currently most measurements of hydrogen adsorption were taken out by using this method. One big concern of this method is that extremely small leaks in the instrument may lead to inaccurate data at high pressure ${ }^{46}$.

\subsection{Scope of this study}

The toughness of conventional approaches is the weak interactions between hydrogen and adsorbent materials. The effect of an external electric field on hydrogen adsorption over carbon materials has been experimentally and theoretically demonstrated ${ }^{90-95}$. The applied electric field is able to introduce charges to the adsorbent. Meanwhile, hydrogen may be polarized or dissociated under the field and form interaction stronger than van der Waals with charged adsorbents. However, carbon is electrically conductive and the induced charges would distribute onto the layer of sample surface, resulting in a limited region named charged zone where strong interactions take place.

This study was initiated to investigate if the adsorption can be further increased by enlarging the size of the charged zone. One approach for the charged zone enlargement is illustrated conceptually in Figure 2.3, which is using a dielectric phase to separate the carbon particles to hold the charges generated by electric field at the interface of carbon and dielectric material. $\mathrm{TiO}_{2}$ is primarily examined as candidate of dielectric phase mainly due to its good dielectric properties. Besides, the inclusion of transition metal Ti provides possibility of forming metal hydrogen clusters during hydrogen adsorption process under electric field. Furthermore, other dielectric materials like magnesium oxide $(\mathrm{MgO})$, zinc oxide $(\mathrm{ZnO})$ and barium titanate $\left(\mathrm{BaTiO}_{3}\right)$ were introduced to the activated carbon respectively and hydrogen adsorption behaviors of the synthetics under electric 
field were tested.

Another primary goal of this study is to examine the influence of parameters of the applied electric field on the hydrogen adsorption performance over prepared samples. Electric fields with different strengths and different directions were applied during the adsorption process. Computational calculations were also carried out corresponding to the experiments for understanding the underlying principles and verify our observations.

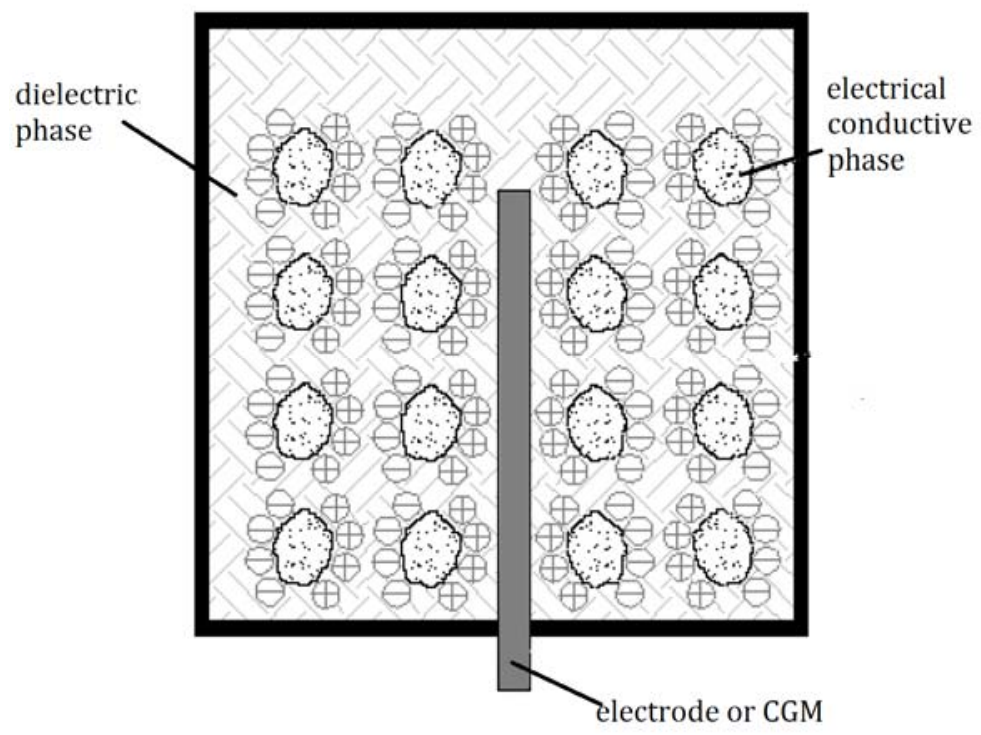

Figure 2.3 Approach for charged zone enlargement (CGM = charge generating material) 


\section{CHAPTER 3 MATERIALS AND METHODS}

\subsection{Materials}

\subsubsection{Carbon sources}

The pristine activated carbon used in this study was a commercial product of Norit (denoted as NAC), with a Brunauer-Emmett-Teller (BET) surface area of $1836.2 \mathrm{~m}^{2} / \mathrm{g}$ and an average particle size of $20 \mu \mathrm{m}$. Another carbon source, Pt-doped activated carbon (contains 5 wt.\% platinum, denoted as Pt/AC) was purchased from Aldrich.

\subsection{2 $\mathrm{TiO}_{2}$ sources}

$\mathrm{TiO}_{2}$ powder in anatase phase with an average particle diameter of $30 \mathrm{~nm}$ (NanoTek Ltd., USA) was used as a starting material. Another $\mathrm{TiO}_{2}$ source was a commercial premix of $\mathrm{TiO}_{2}$ powder (200 nm average diameter) dispersed in an aqueous polyacrylic solution with propylene glycol, ester-alcohol, and ethylene glycol as stabilizer (Colorplace, Walmart). This premix is denoted as PTP (Premix $\mathrm{TiO}_{2}$ powder). PTP contains around $10 \%$ $\mathrm{TiO}_{2}, 33 \%$ organics and $57 \%$ water. $\mathrm{TiCl}_{4}(\geqslant 99.0 \%)$ purchased from Aldrich was also used to prepare $\mathrm{TiO}_{2}$ nanoparticles through hydrolysis.

\subsubsection{Other sources}

The $\mathrm{MgO}$ powder (> 98\%) used in this study was from Aldrich. $\mathrm{ZnO}$ nanopowder with particle size $<10 \mathrm{~nm}$ was purchased from $\mathrm{Aldrich} . \mathrm{BaTiO}_{3}$ powder $(>99 \%)$ with particle size $<3 \mu \mathrm{m}$ was from Aldrich. Aluminum oxide $\left(\mathrm{Al}_{2} \mathrm{O}_{3}\right)$ aerosol was from ZYP Coatings, Inc. 


\subsection{Samples preparation}

\subsubsection{Carbon mixture}

A mixture of carbon (denoted as PAC) was prepared by mixing NAC and $\mathrm{Pt} / \mathrm{AC}$ in a ball mill at a ratio of $4: 1$.

\subsection{2 $\mathrm{TiO}_{2} /$ Carbon species}

Three techniques were used to prepare various $\mathrm{TiO}_{2} /$ Carbon synthetics.

\subsubsection{Mechanical mixing}

The $\mathrm{TiO}_{2} /$ Carbon mixture (denoted as $\mathrm{TCM}$ ) was prepared by ball milling $\mathrm{TiO}_{2}$ nanopowder and NAC at a ratio of 1:1 by weight for $30 \mathrm{~min}$.

\subsubsection{Preparation with premix}

A standard solution was first prepared by adding $5.0 \mathrm{~g}$ PTP into $500 \mathrm{ml}$ pure ethanol and magnetically stirring for $20 \mathrm{~min}$. Then $10 \mathrm{ml}, 50 \mathrm{ml}, 100 \mathrm{ml}$ and $150 \mathrm{ml}$ standard solutions, which contained $0.01 \mathrm{~g}, 0.05 \mathrm{~g}, 0.1 \mathrm{~g}$ and $0.15 \mathrm{~g} \mathrm{TiO}_{2}$ respectively, were taken out to mix with $1.0 \mathrm{~g}$ NAC. Ultrasonication was used to ensure the distribution of $\mathrm{TiO}_{2}$ particles on NAC. Next, the obtained cloudy liquids were heated, accompanied by stirring, to promote volatilization until thick slurries formed. The obtained slurries were dried at $105{ }^{\circ} \mathrm{C}$ overnight to remove the solvents (water and ethanol) and other volatiles. The dried samples were denoted as P1, P2, P3 and P4. The residual organics were removed by heating $\mathrm{P} 1, \mathrm{P} 2, \mathrm{P} 3$ and $\mathrm{P} 4$ at $300{ }^{\circ} \mathrm{C}$ for $2 \mathrm{~h}$ (referred to as $\mathrm{P} 1 \mathrm{H} 1, \mathrm{P} 2 \mathrm{H} 1, \mathrm{P} 3 \mathrm{H} 1$, and P4H1) in a high temperature tube furnace (59300, Thermolyne) in air. For contrast, dehydrated PTP (denoted as PTPD) was prepared by dried PTP at $105{ }^{\circ} \mathrm{C}$ overnight. 
A species named TPC was prepared following the same procedure as P4 except using $\mathrm{Pt} / \mathrm{AC}$ to replace NAC.

\subsubsection{Chemical deposition}

The synthesis procedure is similar to the method developed by Lin et al. ${ }^{112}$. In brief, $0.5 \mathrm{~g}$ NAC was first separately added into $100 \mathrm{ml}$ solution containing $5 \mathrm{M} \mathrm{HCl}, 0.25 \mathrm{M} \mathrm{TiCl}_{4}$ and $100 \mathrm{ml}$ solution containing $5 \mathrm{M} \mathrm{HCl}, 0.5 \mathrm{M} \mathrm{TiCl}_{4}$. Then the mixtures were kept in an oven at $100{ }^{\circ} \mathrm{C}$ for $4 \mathrm{~h}$ for hydrolysis. The final products (referred to as $\mathrm{TC} 1$ for the product from $0.25 \mathrm{M} \mathrm{TiCl}_{4}$ and $\mathrm{TC} 2$ for the $0.5 \mathrm{M}$ one) were obtained by filtering and drying the slurry at $120{ }^{\circ} \mathrm{C}$ for $0.5 \mathrm{~h}$. For contrast, sample $\mathrm{HCl} / \mathrm{NAC}$ was prepared as follows: $0.5 \mathrm{~g} \mathrm{NAC}$ and $100 \mathrm{ml} 5 \mathrm{M} \mathrm{HCl}$ solution were mixed and magnetically stirred at room temperature for $24 \mathrm{~h}$. The obtained slurry was then filtered and dried in an oven at $105{ }^{\circ} \mathrm{C}$ overnight to obtain the final product.

\subsubsection{MgO/Carbon species}

The method of preparing $\mathrm{MgO} /$ Carbon species (denoted as $\mathrm{MC}$ ) followed a previous technique conducted by Yacob et al. ${ }^{113}$ to prepare $\mathrm{MgO}$ nanoparticles. Around $6.0 \mathrm{~g}$ of $\mathrm{MgO}$ powder was dispersed in $150 \mathrm{ml}$ distilled water and stirred at about $100{ }^{\circ} \mathrm{C}$ for $24 \mathrm{~h}$ to obtain magnesium hydroxide, $\mathrm{Mg}(\mathrm{OH})_{2}$. $3.0 \mathrm{~g}$ NAC was added to the hydroxide

solution and stirred for another $4 \mathrm{~h}$ under the same conditions. The $\operatorname{Mg}(\mathrm{OH})_{2} / \mathrm{NAC}$ precipitate was then yielded by filtration and dried in oven at $105{ }^{\circ} \mathrm{C}$ overnight to remove excess water. The obtained solid was grinded using mortar and pestel and afterward activated by heating in an oven in air at $400{ }^{\circ} \mathrm{C}$ for $1 \mathrm{~h}$ to obtain the final product.

\subsubsection{ZnO/Carbon species}

A $\mathrm{ZnO} /$ Carbon mixture (denoted as $\mathrm{ZC}$ ) was prepared by ball milling $\mathrm{ZnO}$ nanopowder 
and $\mathrm{NAC}$ at a ratio of $1: 1$ by weight for $30 \mathrm{~min}$.

\subsection{5 $\mathrm{BaTiO}_{3} / \mathrm{Carbon}_{\text {species }}$}

$\mathrm{A} \mathrm{BaTiO}_{3} /$ Carbon mixture (denoted as $\mathrm{BC}$ ) was prepared by ball milling $\mathrm{BaTiO}_{3}$ powder and $\mathrm{NAC}$ at a ratio of $1: 1$ by weight for $30 \mathrm{~min}$.

\subsection{Hydrogen adsorption measurements}

Hydrogen adsorption measurements were carried out with an automatic Sieverts' instrument (PCT-Pro 2000, Hy-Energy LLC) at pressure range of 0-80 bar. Figure 3.1 and Figure 3.2 show the outlook and master control panel of the instrument.

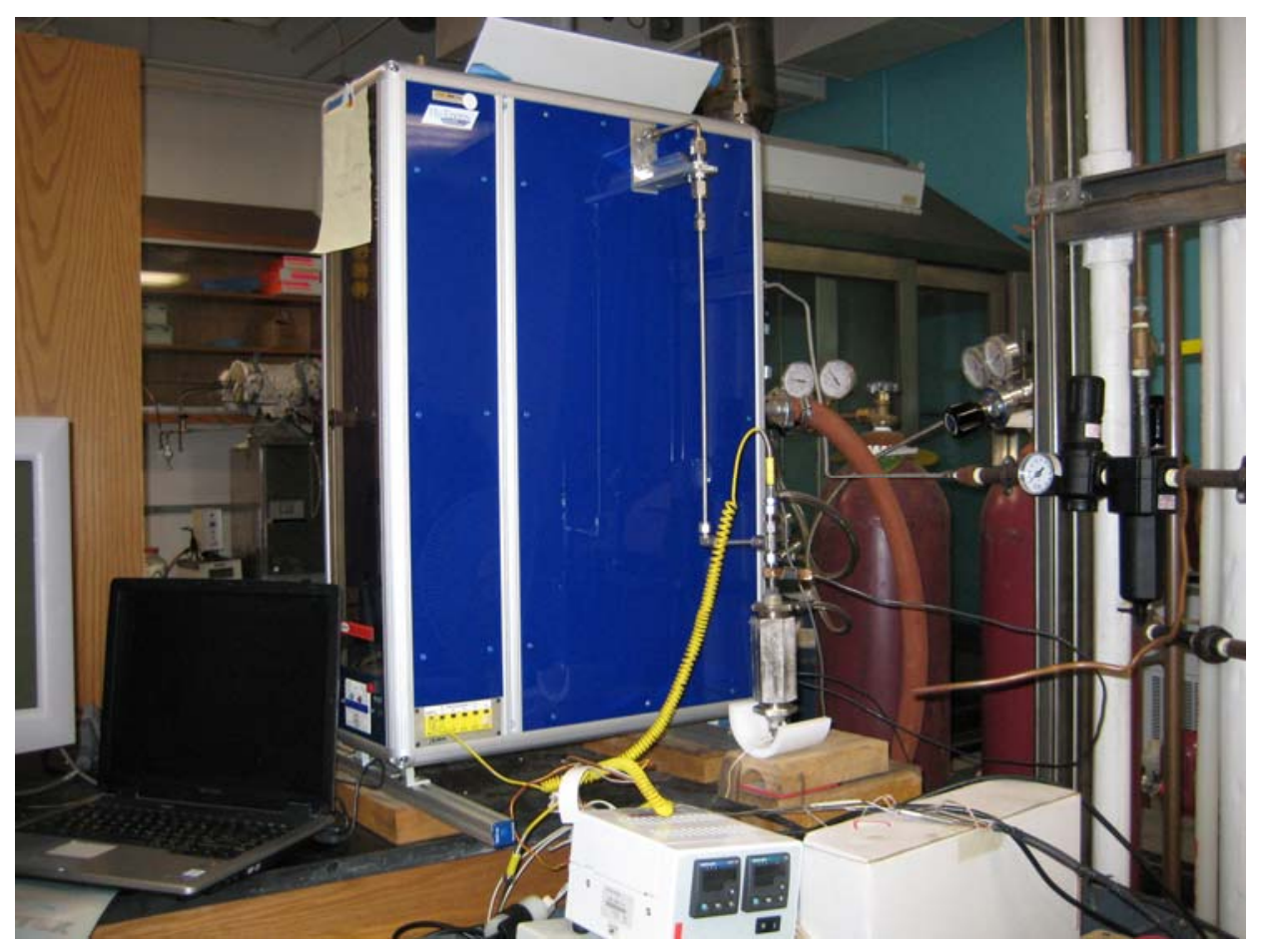

Figure 3.1 Outlook of the PCT-Pro 2000 instrument 


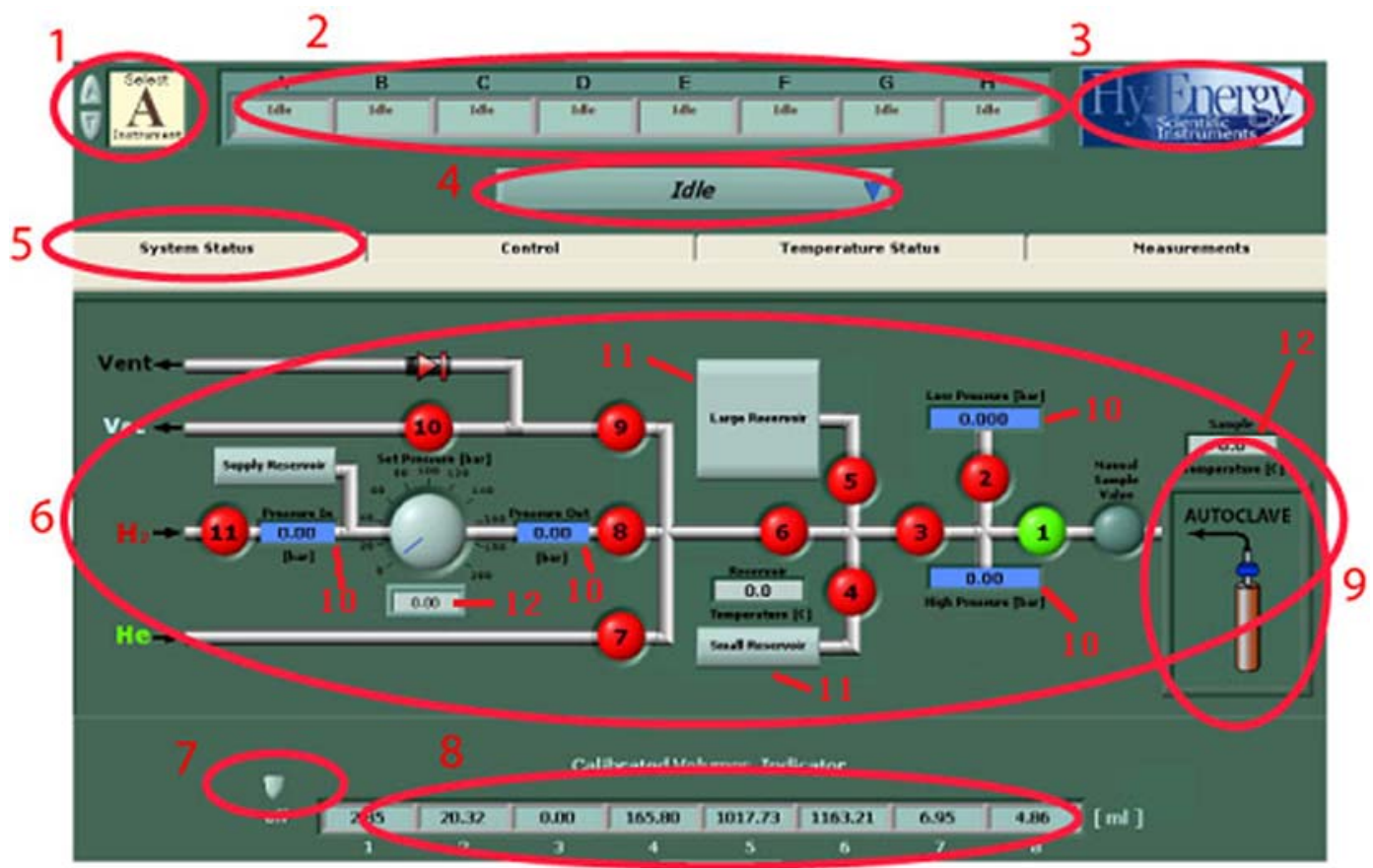

Figure 3.2 Master control panel of PCT-Pro $2000{ }^{114}$

(Indicators: 1-allows selection of any one of a number of instruments; 2-shows the status of up to 8 different instruments labeled $\mathrm{A}$ to $\mathrm{H}$; 3-corporation logo; 4-allows the user to select a process to be performed; 5-control tab used to select; 6-operational status; 7-allows the user to see which physical volumes in the instrument correspond to the calibrated volumes used for making measurements; 8-instrument's volume calibrations; 9-sample holder; 10-barometers; 11-reservoirs; 12-thermometers. reprinted with permission from American Chemical Society, see Appendix F)

Prior to the test, the samples were dried in an oven at $105{ }^{\circ} \mathrm{C}$ for $12 \mathrm{~h}$ and then moved into the sample holder and evacuated at $100{ }^{\circ} \mathrm{C}$ for $2 \mathrm{~h}$ to ensure the removal of any contaminations on the sample surface. Around $300 \mathrm{mg}$ sample was used in each run. Ultrapure (99.99999\%) hydrogen and helium gases were used for all calibrations and measurements. All the adsorption measurements were conducted under room temperature $\left(22 \pm 0.8{ }^{\circ} \mathrm{C}\right)$. A blank test was also performed to exclude possible adsorption of hydrogen on the inner wall of the sample holder.

Two methods were used to provide an electric field to the testing sample. One was 
putting a charge generating material inside the adsorbent and the other was applying an external electric potential to the sample holder. The specific illustrations are given as follows.

\subsubsection{Measurements with electric field generated by piezoelectric element}

Piezoelectric elements are energy transformation devices that are capable of transforming mechanical energy into electricity and vice versa. They are often found in wide applications of sound production and detection, high voltages generation, electronic frequency generation, etc. Piezoelectric elements are typically based on lead oxide compounds. At present, PMN-PT ((1-x) $\left.\mathrm{Pb}\left(\mathrm{Mg}_{1 / 3} \mathrm{Nb}_{2 / 3}\right) \mathrm{O}_{3}-\mathrm{xPbTiO}_{3}\right)$ based piezoelectric materials are very popular due to the large dielectric constant, outstanding piezoelectric properties and high electrostriction ${ }^{115}$.

In this study, a piezoelectric element was designed to be surrounded by the adsorbent. Under hydrogen pressure, charges will be generated and accumulated at the surface of the element in response to the applied mechanical stress. The electrical charge generated at the surface of PMN-PT under static hydrogen pressure can be calculated by ${ }^{116}$

$$
Q=d_{33} P S
$$

where $Q$ stands for the electrical charge, $d_{33}$ is the piezoelectric charge constant, $P$ represents the hydrogen pressure, and $S$ is the surface area upon which hydrogen pressure is exerted.

The experimental setup is depicted in Figure 3.3. Adsorbent and a PMN-PT slab were placed inside a glass container, which was capped by a paper filter and put inside the 
stainless sample holder to stop the charges produced from spreading out. The PMT-PT was purchased from Morgan Electroceramics with a dimension of $5 \times 5 \times 1 \mathrm{~mm}$ and a weight of $\sim 0.2 \mathrm{~g}$, as shown in Figure 3.4. One side of the slab was covered by an $\mathrm{Al}_{2} \mathrm{O}_{3}$ thin film (prepared from $\mathrm{Al}_{2} \mathrm{O}_{3}$ aerosol) to ensure the generation of only negative or positive charges. The $d_{33}$ value of the material is in the range of $1200-2000 \mathrm{pC} / \mathrm{N}^{92}$.

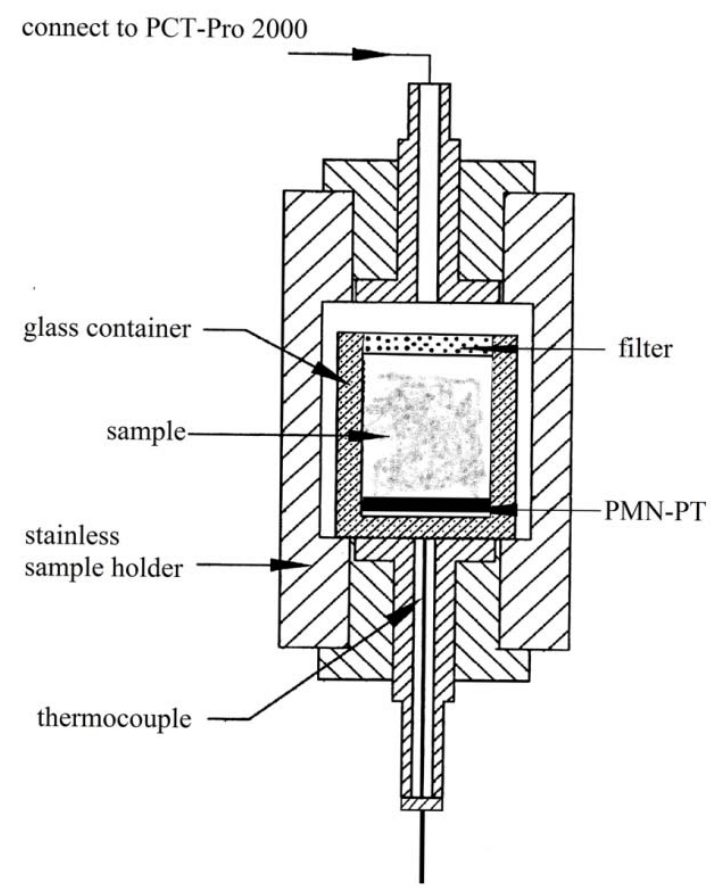

Figure 3.3 Experimental setup for hydrogen adsorption measurement in the presence of PMN-PT 

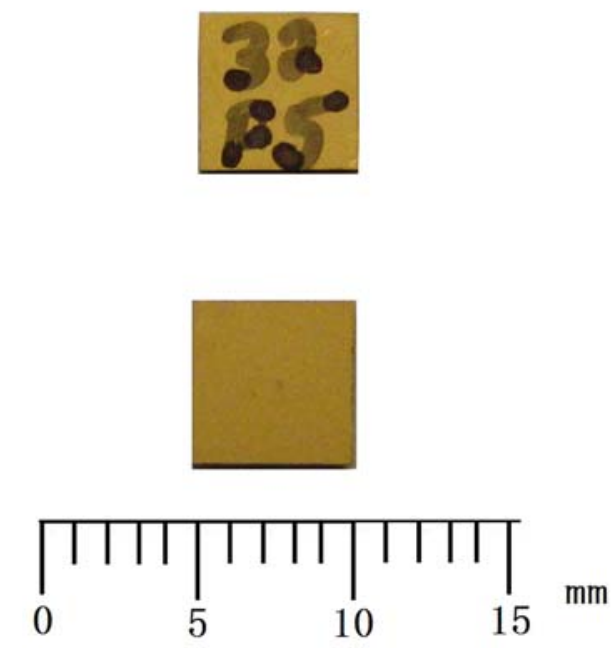

Figure 3.4 Configuration of PMN-PT

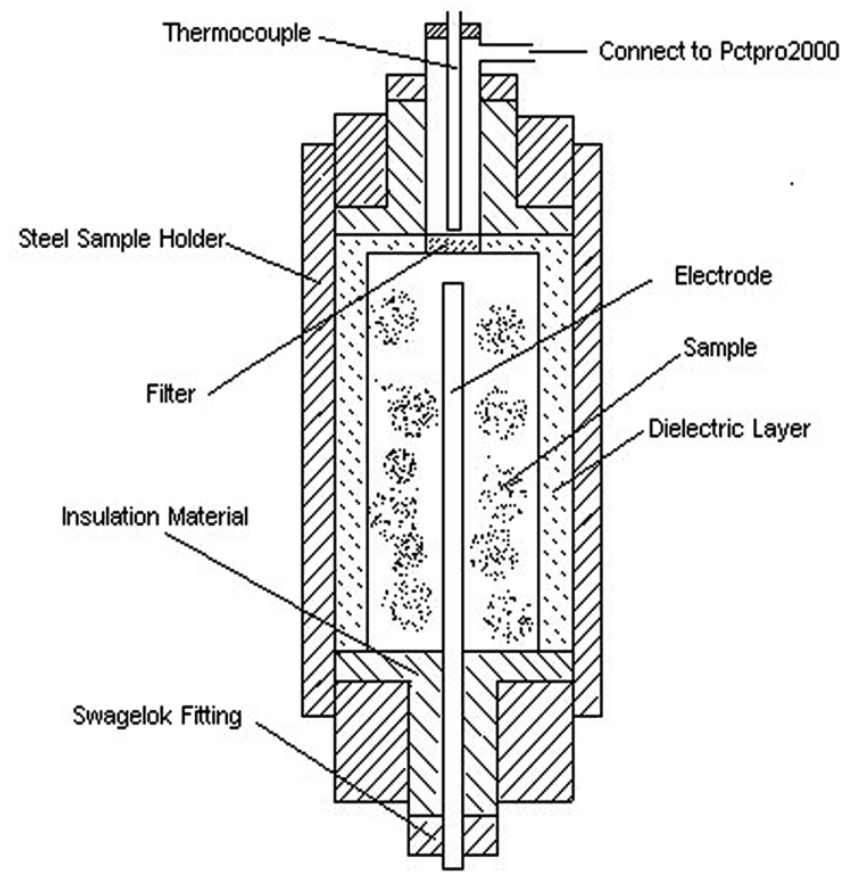

Figure 3.5 Cross-section view of modified sample holder ${ }^{90}$ (reprinted with permission from American Carbon Committee, see Appendix H) 


\subsubsection{Measurements with electric field generated by applied electric potential}

Electric potentials of opposite directions were introduced by two different sets of equipment. A high voltage DC power supply device from Del High Voltage Corporation (model RLPS 100-100 P), which was capable of providing voltage from 200 to 20,000 V, was used to provide positive electric potential. A high voltage switch and an electro-circuit were connected between the power supply and the sample holder. An incorporated ammeter is sensitive to current greater than $0.001 \mathrm{~mA}$. Negative potential was provided by a laboratory DC power supply (72-2085, Tenma) associated with a high voltage DC/DC converter (P10-250, American Power Design). The devices are able to provide voltage from -833 to $-2500 \mathrm{~V}$.

The electrode in the center of the cylindrical sample holder was connect to the power supply, while the upper end of the sample holder was electrically grounded. The sample holder has been modified for introducing an electric potential to the testing material, as shown in Figure 3.5. The Inner wall was coated with $2 \mathrm{~mm}$ dielectric layer to hold charges. The filter was used for preventing carbon particles from entering the PCT-Pro 2000 instrument. The thermocouple was used for measuring the temperature.

\subsection{Characterization methods}

X-ray diffraction (XRD) was carried out using a Scintag XDS2000 powder diffractometer at a scan rate of $0.08 \%$ with $\mathrm{Cu}$ radiation at $45 \mathrm{kV}, 35 \mathrm{~mA}$.

A Hitachi S-4700 field emission-scanning electron microscope (FE-SEM) was used to examine the microstructure of the samples.

The surface area and pore volume synthesized samples was measured with a 
Micromeritics ASAP2000 instrument using nitrogen adsorption at liquid nitrogen temperature $(77 \mathrm{~K})$. Total surface area was calculated by BET equation ${ }^{117}$. Micropore volume was obtained from t-plot analysis using the Jura-Harkins equation ${ }^{118}$.

Thermogravimetric analysis (TGA) was performed under $50 \mathrm{ml} / \mathrm{min}$ oxygen flow at a heating rate of $10{ }^{\circ} \mathrm{C} / \mathrm{min}$ from $30{ }^{\circ} \mathrm{C}$ to $1200{ }^{\circ} \mathrm{C}$ by using TGA/DSC 1 (Mettler Toledo).

The electrical resistivity was tested by a digital multimeter (Agilent 34405 A) with around $500 \mathrm{mg}$ of sample powder loosely placed inside a specially designed sample holder, as shown in Figure 3.6.

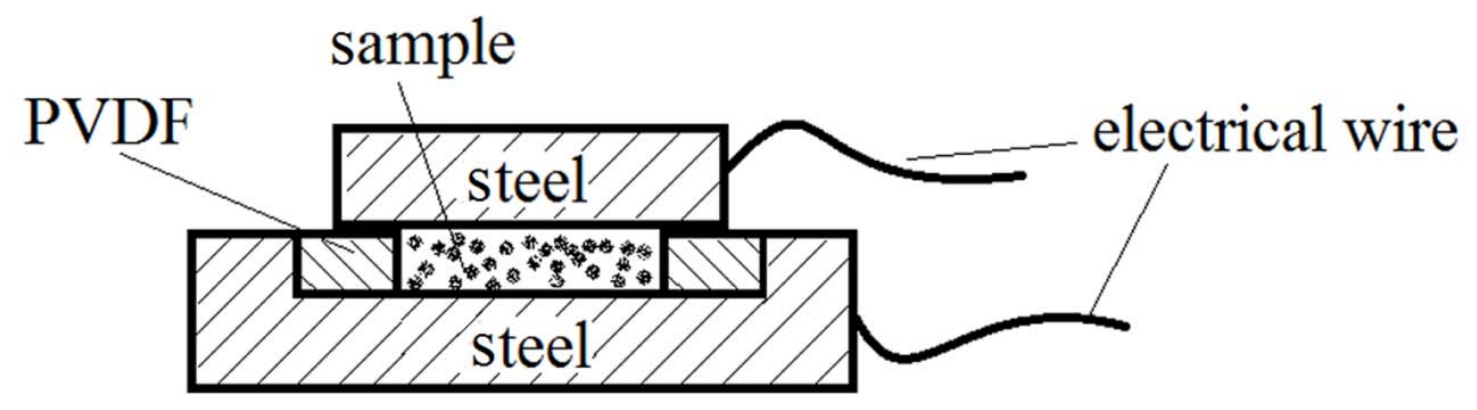

Figure 3.6 Cross-section view of sample holder used for resistivity test 


\section{CHAPTER 4 CHARACTERIZATIONS}

\subsection{Characterizations of $\mathrm{TiO}_{2} /$ Carbon species}

\subsubsection{Mechanically mixed $\mathrm{TiO}_{2} /$ Carbon mixture}

The BET surface area and micropore volume of TCM sample are $613.19 \mathrm{~m}^{2} / \mathrm{g}$ and 0.12

$\mathrm{cm}^{3} / \mathrm{g}$. Compared to NAC, the surface area and micropore volume of the mixture were largely decreased due to the addition of $\mathrm{TiO}_{2}$ particles. On the other hand, the electric resistivity of TCM is greater than $100 \mathrm{M} \Omega$. The introduction of dielectric $\mathrm{TiO}_{2}$ converted conductive carbon into a dielectric material.

\subsection{2 $\mathrm{TiO}_{2} /$ Carbon synthetics prepared from premix of $\mathrm{TiO}_{2}$ powder}

The studies are focused on synthesized samples P1H1, P2H1, P3H1 and P4H1. P1, P2, P3 and P4 have been previously studied by Wen ${ }^{119}$ and some results are also provided here for comparison.

The X-ray diffraction patterns of synthetics $\mathrm{P} 1 \mathrm{H} 1, \mathrm{P} 2 \mathrm{H} 1, \mathrm{P} 3 \mathrm{H} 1$ and $\mathrm{P} 4 \mathrm{H} 1$ are given in Figure 4.1. The XRD analyses clearly show the existence of rutile phase. According to composition of the $\mathrm{TiO}_{2}$ premix, the $\mathrm{TiO}_{2}$ contents in $\mathrm{P} 1 \mathrm{H} 1, \mathrm{P} 2 \mathrm{H} 1, \mathrm{P} 3 \mathrm{H} 1$ and $\mathrm{P} 4 \mathrm{H} 1$ were calculated as 1.0, 4.8, 9.1 and 13.0 wt.\%, respectively. It is obvious that the peaks of $\mathrm{TiO}_{2}$ become sharper as the $\mathrm{TiO}_{2}$ content increases. 


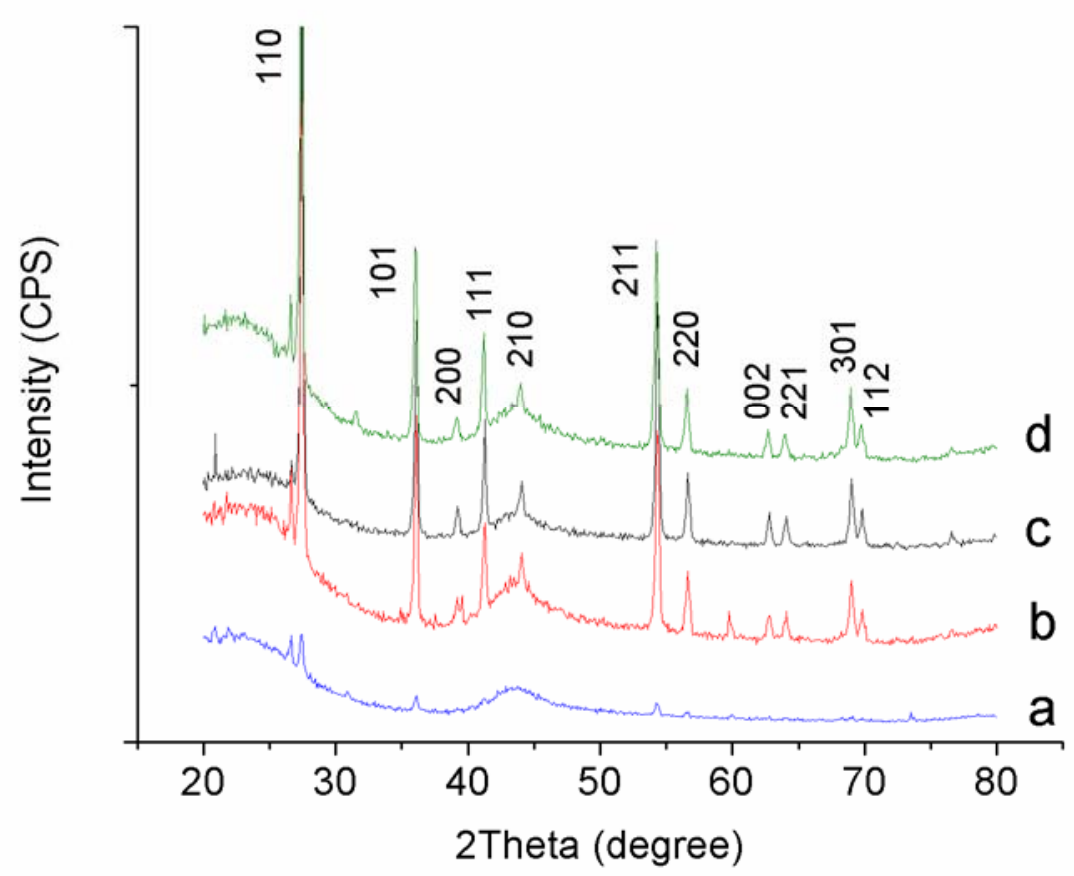

Figure 4.1 XRD patterns of $\mathrm{TiO}_{2} /$ Carbon synthetics P1H1, P2H1, P3H1 and P4H1

Figure 4-2 shows FE-SEM images of the P4 and P4H1 species. It can be clearly seen that the $\mathrm{TiO}_{2}$ particles coated on the carbon surface are in tetragonal prism or tetragonal pyramid form with uniform size around $200 \mathrm{~nm}$. Residual organics are obviously observed in P4, as circled in Figure 4.2b. After heating, the organics are thoroughly removed, as shown in Figure 4.2d. 


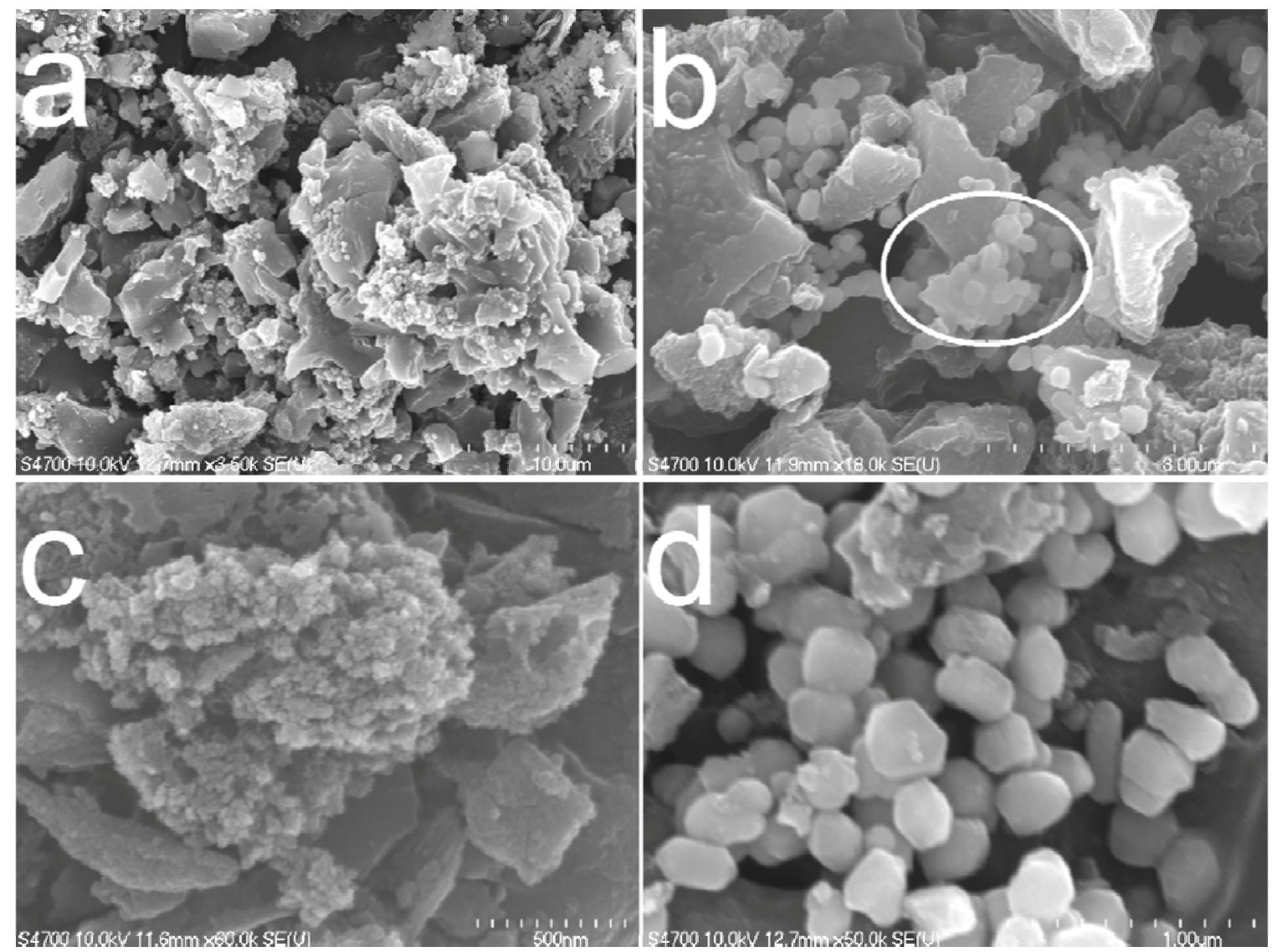

Figure 4.2 FE-SEM images of P4 (a and b) and P4H1 (c and d)

BET surface areas and micropore volumes of the prepared synthetics are listed in Table 4.1. As shown in the table, for the two sets of samples, BET surface area and micropore volume decrease with the increasing $\mathrm{TiO}_{2}$ content. BET analysis of PTPD showed surface area of only $1.9 \mathrm{~m}^{2} / \mathrm{g}$. The small surface area could explain the increase in surface area after the removal of the organics for P2, P3 and P4. Surface area of P1 was reduced due to small amount of organic residues and pore collapse caused by heating. Figure 4.3 shows the relationship between BET surface area and micropore volume of the eight samples, which indicates micropore almost linearly increases with the increasing of surface area. 
Table 4.1

BET analyses of $\mathrm{TiO}_{2} /$ Carbon synthetics prepared from premix of $\mathrm{TiO}_{2}$ powder

\begin{tabular}{lllll}
\hline Sample ID & P1 & P2 & P3 & P4 \\
\hline BET surface area $\left(\mathrm{m}^{2} / \mathbf{g}\right)$ & 1787.2 & 1167.0 & 896.2 & 719.8 \\
Micropore V $\left(\mathrm{cm}^{3} / \mathbf{g}\right)$ & 0.21 & 0.13 & 0.09 & 0.05 \\
\hline Sample ID & P1H1 & P2H1 & P3H1 & P4H1 \\
\hline BET surface are $\left(\mathbf{m}^{2} / \mathbf{g}\right)$ & 1615.5 & 1361.0 & 1086.2 & 846.1 \\
Micropore V $\left(\mathrm{cm}^{3} / \mathbf{g}\right)$ & 0.19 & 0.14 & 0.11 & 0.07 \\
\hline
\end{tabular}

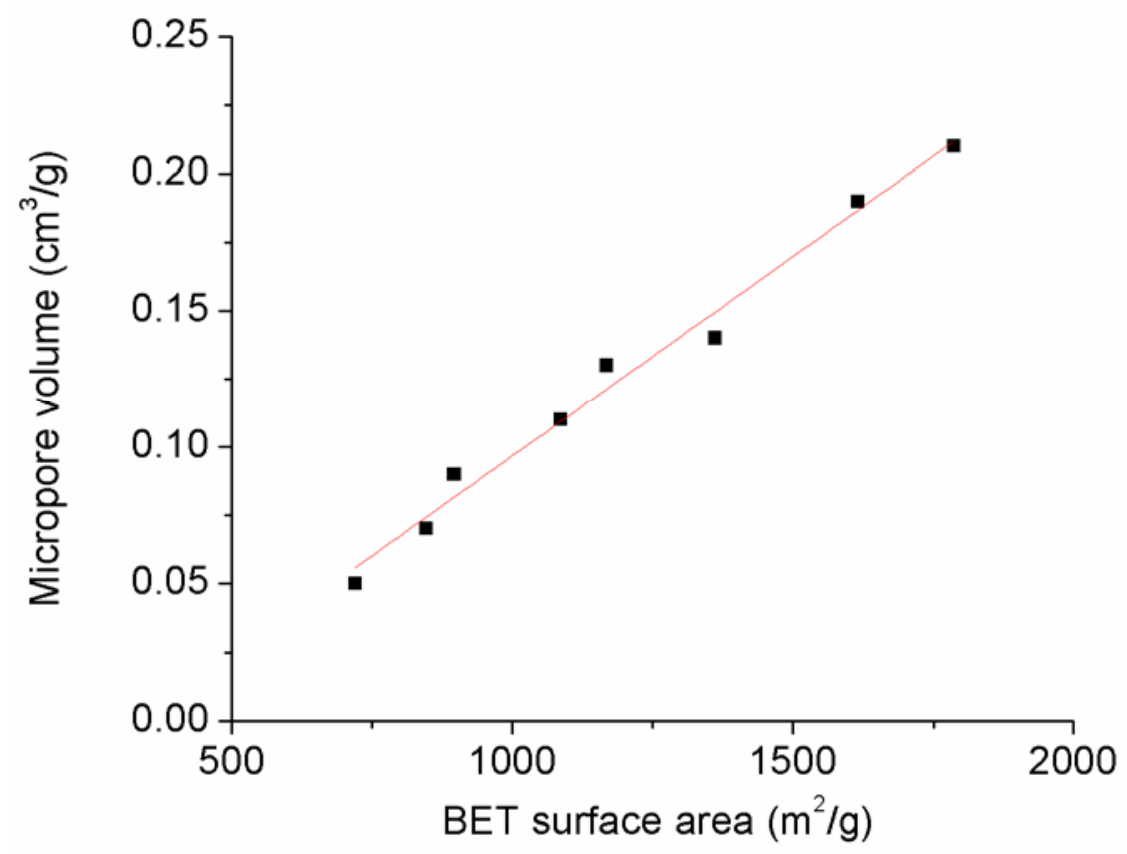

Figure 4.3 Relationship between BET surface area and micropore volume of $\mathrm{TiO}_{2} /$ Carbon synthetics

Electric resistivity data of the prepared synthetics is given in Table 4.2. It is indicated that resistivity increases with the rising $\mathrm{TiO}_{2}$ content for both series. It is known that the addition of insulating material into a conductive matrix would raise the resistivity of the matrix. However, the addition of dielectric materials would largely decrease the surface 
area of the composite and adversely affect a relative high storage capacity. What we expect is a conductor-insulator transition point which can not only offer the ideal charged zone but also enough available sites for hydrogen adsorption. It is also noted that heating treatment reduced resistivity of the synthetics due to the absence of the organics.

Table 4.2

Electrical resistivity of $\mathrm{TiO}_{2} /$ Carbon synthetics prepared from premix of $\mathrm{TiO}_{2}$ powder

\begin{tabular}{|c|c|c|c|c|}
\hline Sample ID & P1 & $\mathbf{P 2}$ & P3 & $\mathbf{P 4}$ \\
\hline Resistivity (M $\Omega$ ) & 0.035 & 2 & 20 & $>50$ \\
\hline Sample ID & P1H1 & P2H1 & P3H1 & P4H1 \\
\hline Resistivity (M $\Omega$ ) & 0.01 & 0.9 & 2.0 & 20.0 \\
\hline
\end{tabular}

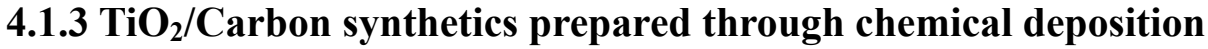

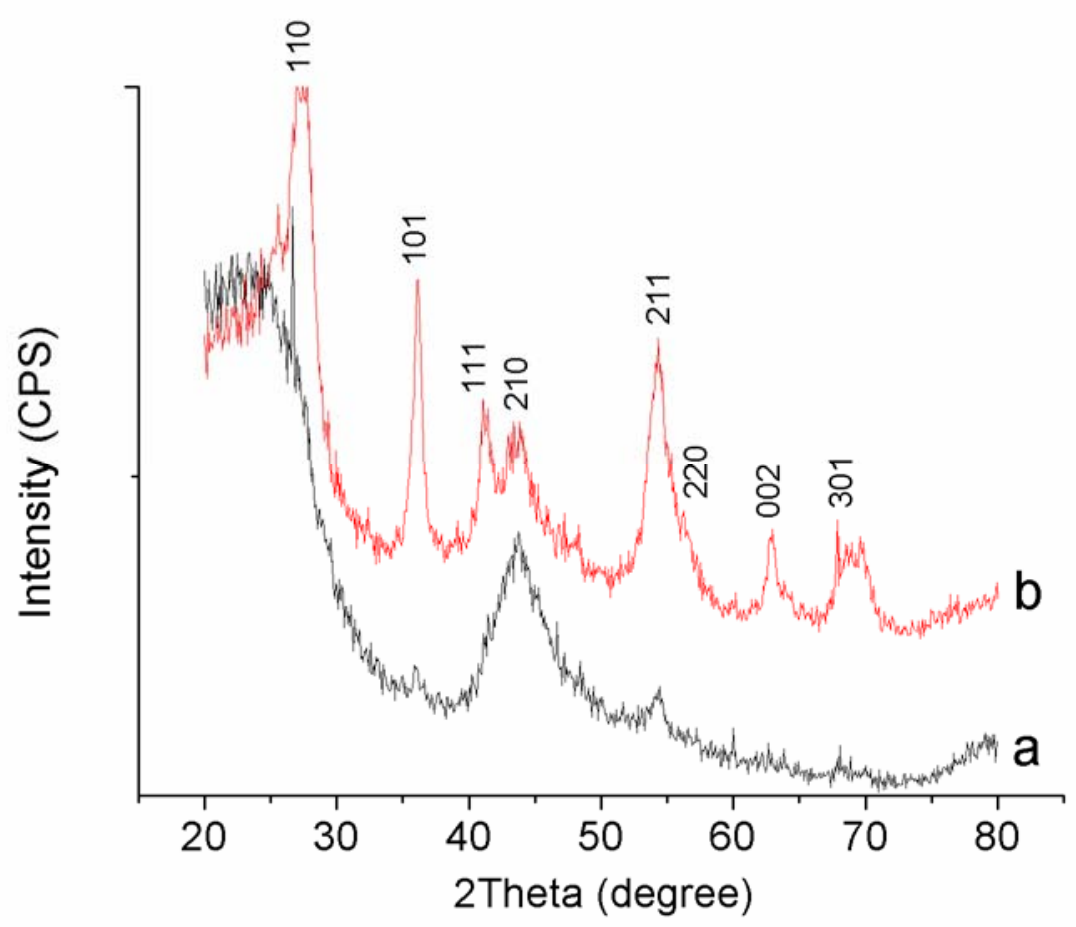

Figure 4.4 XRD patterns of chemical deposited $\mathrm{TiO}_{2} /$ Carbon synthetics $\mathrm{TC1}$ (a) and TC2 (b) 

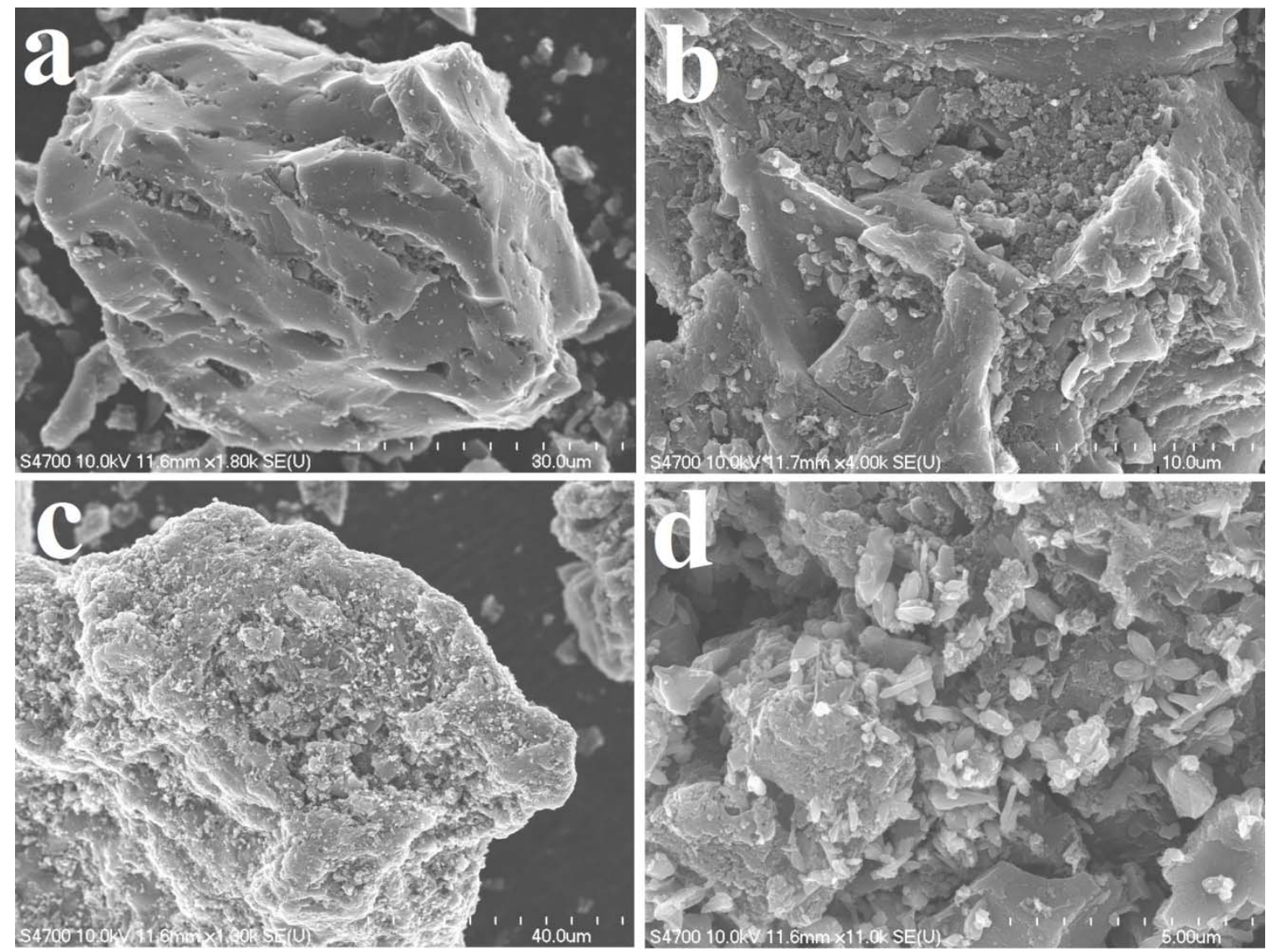

Figure 4.5 FE-SEM images of chemically deposited $\mathrm{TiO}_{2} /$ Carbon synthetics TC1 (a and b) and TC2 (c and d)

X-ray diffraction spectra of prepared TC1 and TC2 are shown in Figure 4.4. It is seen that the XRD analyses show Rutile peaks. The peaks of TC2 are much sharper than TC1. The broadening of the peaks indicates crystal size of the synthesized $\mathrm{TiO}_{2}$ particles is very small ${ }^{64}$.

FE-SEM images of $\mathrm{TC} 1$ and $\mathrm{TC} 2$ are shown in Figure 4.5. For both species, $\mathrm{TiO}_{2}$ particles have been uniformly deposited on the carbon surface. It is also noticed that for TC2 particles on the carbon are much denser than TC1, indicating a higher $\mathrm{TiO}_{2}$ content.

TGA analysis results of $\mathrm{TC} 1$ and $\mathrm{TC} 2$ are given in Figure 4.6. Two weight-loss steps 
were observed for each test. The first occurred in the range of 30-300 ${ }^{\circ} \mathrm{C}$, corresponding to around $2.5 \%$ weight loss for both samples, which is related to the elimination of water and residual $\mathrm{HCl}$. The second started at $400{ }^{\circ} \mathrm{C}$, which is due to the combustion of activated carbon. The final residue was considered to be $\mathrm{TiO}_{2}$, which takes up 5.8 and 18.8 wt. $\%$ of TC 1 and TC2, respectively.

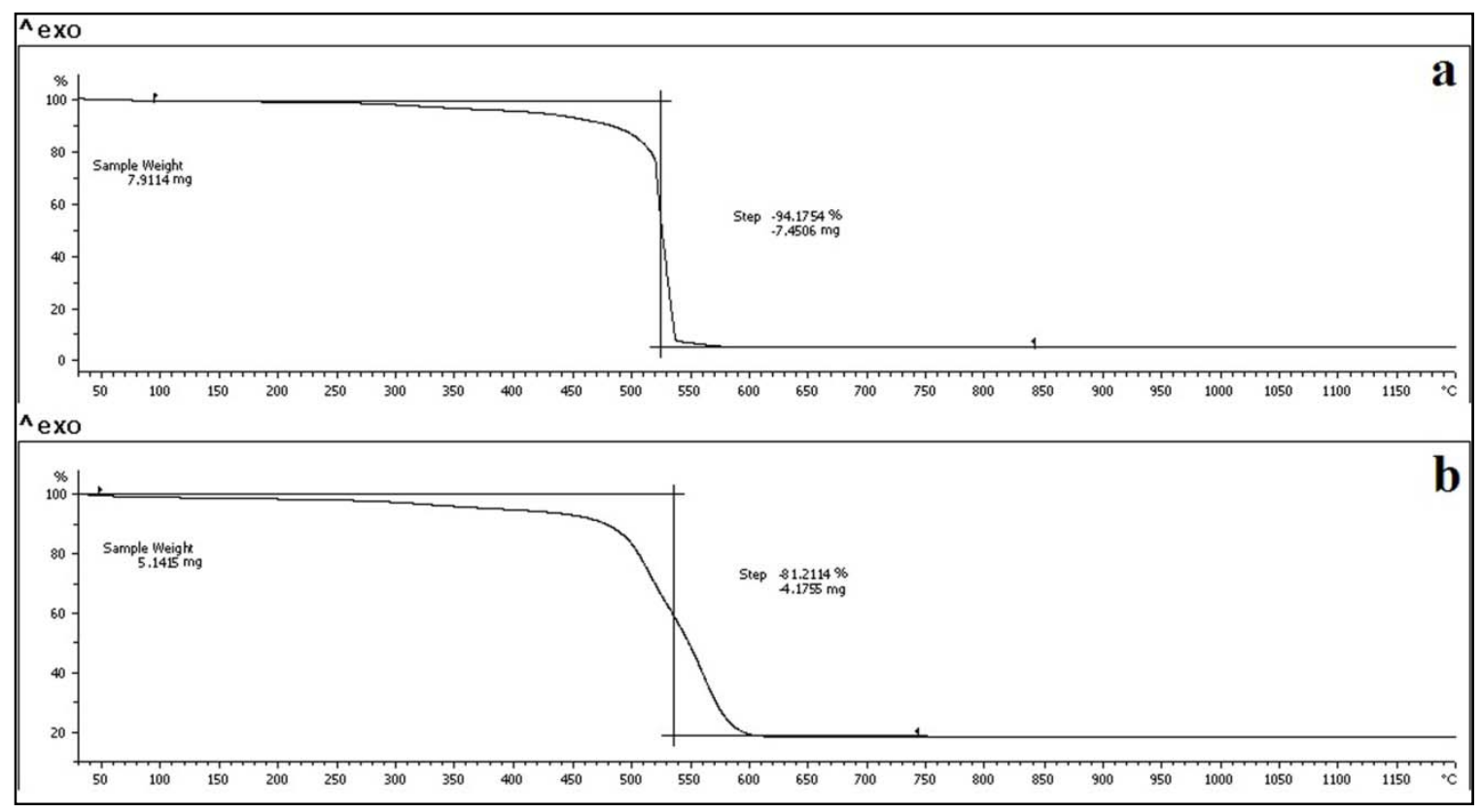

Figure 4.6 TGA analyses of $\mathrm{TiO}_{2} /$ Carbon synthetics TC1 (a) and TC2 (b)

BET analyses of $\mathrm{TC} 1$ and $\mathrm{TC} 2$ are given in Table 4.3. The BET surface area and micropore volume of $\mathrm{TC} 1$ are relatively larger than those of $\mathrm{TC} 2$. No heating process was involved in the preparation, resulting in synthetics with relative high surface area, which is favorable for hydrogen storage.

Electric resistivity data of $\mathrm{TC} 1$ and TC2 is given in Table 4.4. It is seen that the sample with a higher $\mathrm{TiO}_{2}$ content has a larger resistivity because of the better isolation of carbon particles. 
Table 4.3

BET analyses of chemically deposited $\mathrm{TiO}_{2} / \mathrm{Carbon}$ synthetics $\mathrm{TC1}$ and TC2

\begin{tabular}{ccc}
\hline Sample ID & BET surface area $\left(\mathbf{m}^{2} / \mathbf{g}\right)$ & Micropore $\mathbf{V ~}\left(\mathrm{cm}^{3} / \mathbf{g}\right)$ \\
\hline TC1 & 1563.2 & 0.15 \\
TC2 & 1248.3 & 0.07 \\
\hline
\end{tabular}

Table 4.4

Electrical resistivity of chemically deposited $\mathrm{TiO}_{2} /$ Carbon synthetics $\mathrm{TC} 1$ and $\mathrm{TC} 2$

\begin{tabular}{ccc}
\hline Sample ID & TC1 & TC2 \\
\hline Resistivity (M $\Omega)$ & 2.0 & $>50$ \\
\hline
\end{tabular}

\subsection{Characterizations of $\mathrm{MgO} / \mathrm{Carbon}$ species}

X-ray diffraction spectrum of synthesized $\mathrm{MgO} /$ Carbon sample is shown in Figure 4.7. Only $\mathrm{MgO}$ peaks were observed. SEM images of the species are displayed in Figure 4.8, which indicate cubic crystals with uniform size. BET analysis for $\mathrm{MC}$ showed that surface area is $538.3 \mathrm{~m}^{2} / \mathrm{g}$ and micropore volume is $0.04 \mathrm{~cm}^{3} / \mathrm{g}$. Electrical resistivity of $\mathrm{MC}$ is greater than $100 \mathrm{M} \Omega$. 


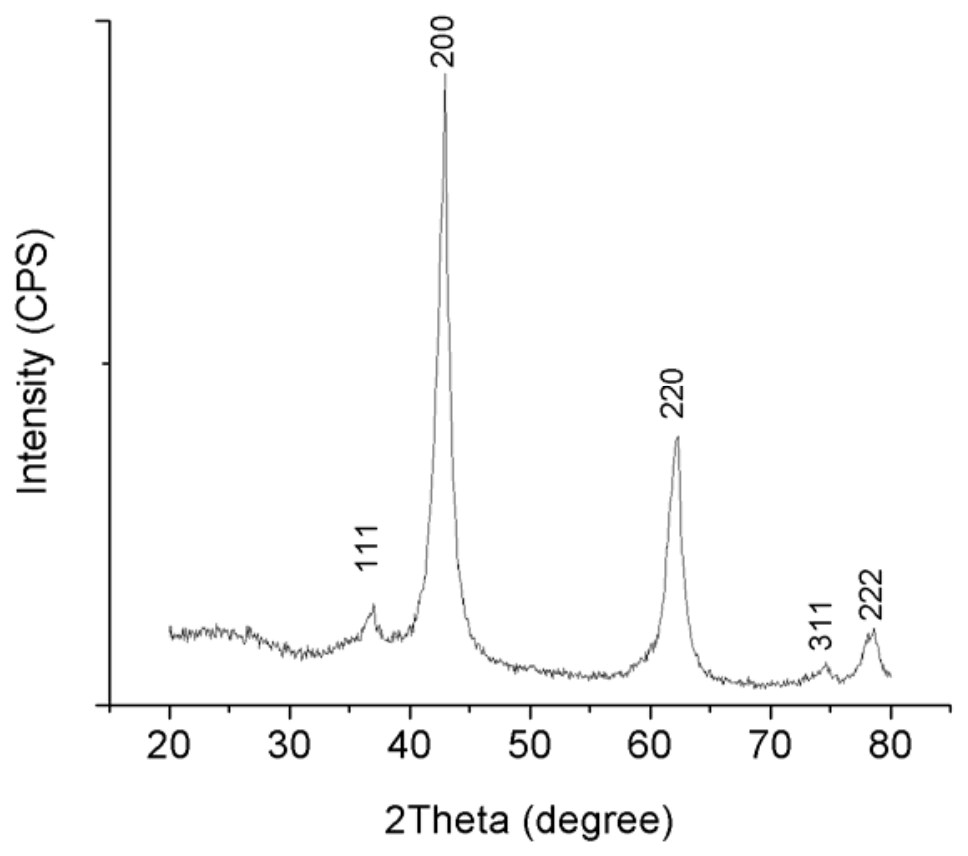

Figure 4.7 XRD pattern of MgO/Carbon synthetic MC
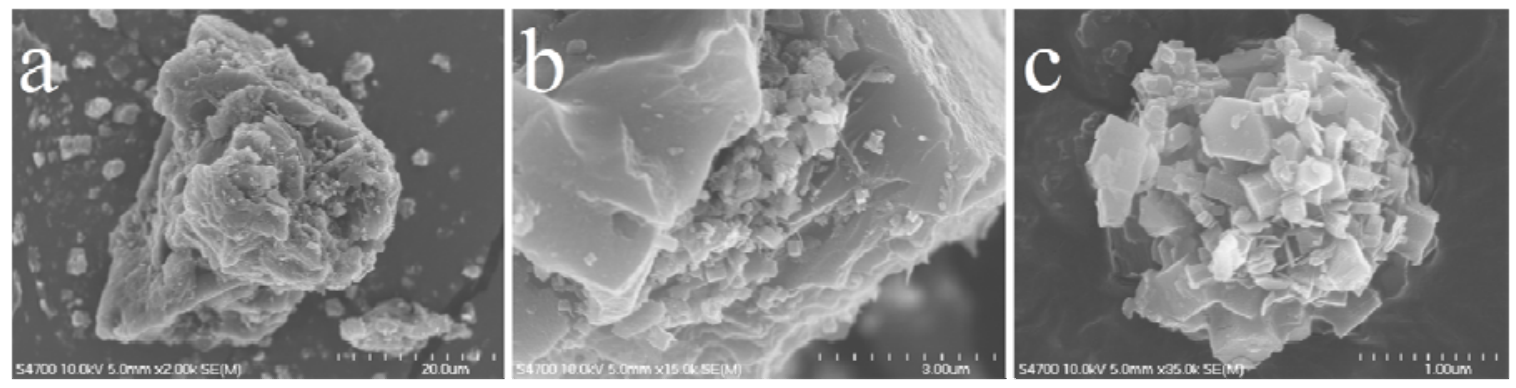

Figure 4.8 FE-SEM images of MgO/Carbon synthetic MC

For $\mathrm{ZC}$ and $\mathrm{BC}$, only resistivity measurement was carried out. The results showed that the resistivity is greater than $100 \mathrm{M} \Omega$ for both samples. 


\section{CHAPTER 5 EXAMINATION OF HYDROGEN ADSORPTION ON ACTIVATED CARBON UNDER ELECTRIC FIELD}

The study started with verifying the effect of electric field on carbon materials. Direction of electric potential as well as intensity was varied in the examination. The adsorption enhancement is defined as follows

$$
\text { ads. enhacement }(\%)=\frac{\text { ads. with Epotential }- \text { ads. } w / o \text { Epotential }}{\text { ads.w/o Epotential }} \times 100 \%
$$

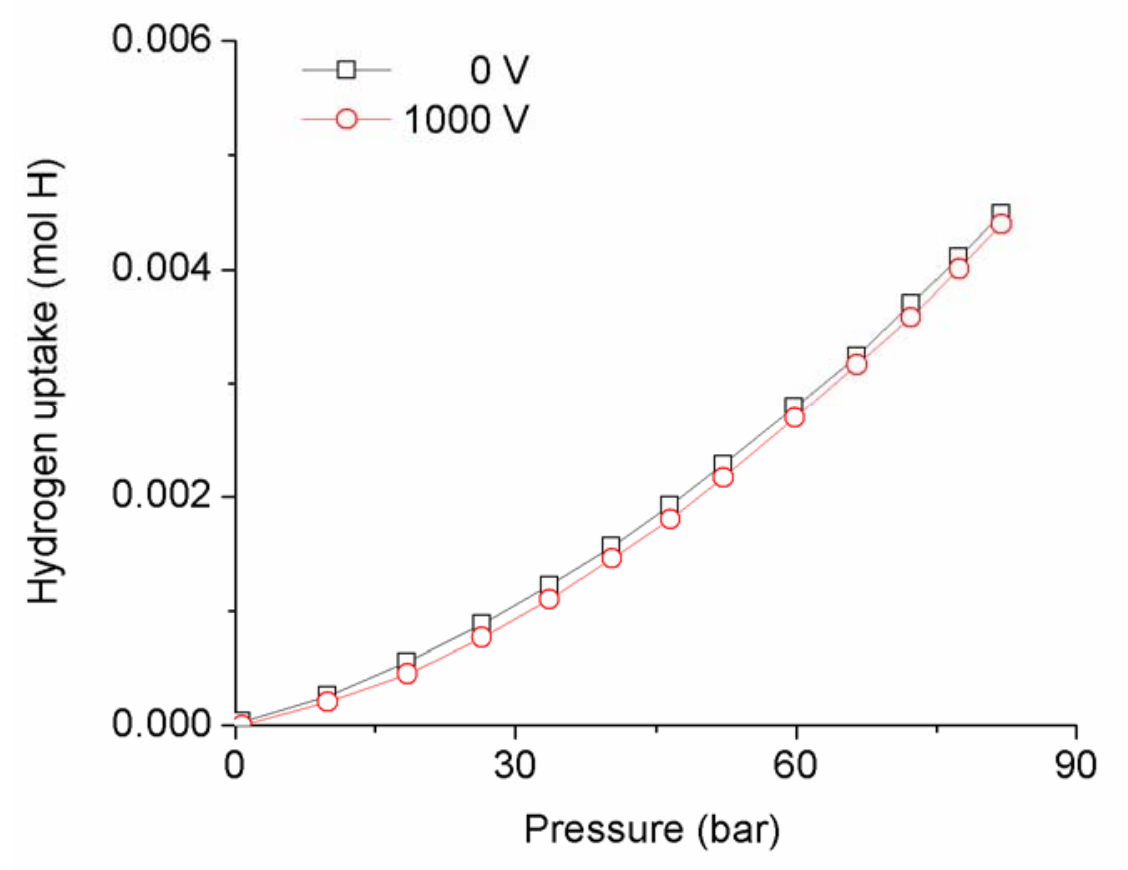

Figure 5.1 Hydrogen adsorption on blank sample holder with and without $1000 \mathrm{~V}$ electric potentials

Blank experiment was first addressed by applying $0 \mathrm{~V}$ and $1000 \mathrm{~V}$ electric potential to the blank sample holder, as shown in Figure 5.1. The adsorption curves indicate negligible difference between the two tests. It was therefore concluded that the electric potential does not affect the adsorption performance of the background. All the variations are due 
to the electric field effect on adsorption over the adsorbent.

\subsection{Hydrogen adsorption on pristine activated carbon}

\subsubsection{Positive electric potential}

Hydrogen adsorption measurements of pristine NAC with 0, 1000, 2000 and $3000 \mathrm{~V}$ electric potentials can be seen in Figure 5.2. The hydrogen uptake shown here was the net weight percentage of uptake after elimination of the adsorption on the blank sample holder. The error bars represent stand errors, which are $4-6 \%$ and $<3 \%$ for the measurements with and without voltage based on three repeated experiments. As shown in the picture, all the adsorption isotherms at room temperature have a linear trend and locate close to each other. Unlike previous findings ${ }^{90,93}$, applying an electric potential to the activated carbon led to no adsorption improvement but some decrease in this study. The hydrogen storage capacity of NAC reached 0.43 wt. $\%$ at 80 bar. With electric potentials of 1000,2000 and $3000 \mathrm{~V}$, the uptakes were $0.33,0.41$ and $0.36 \mathrm{wt} . \%$ at $80 \mathrm{bar}$, which meant $23 \%, 5 \%$ and $16 \%$ decreases, respectively. No specific correlation has been found between the potential intensity and the hydrogen adsorption in this case. 


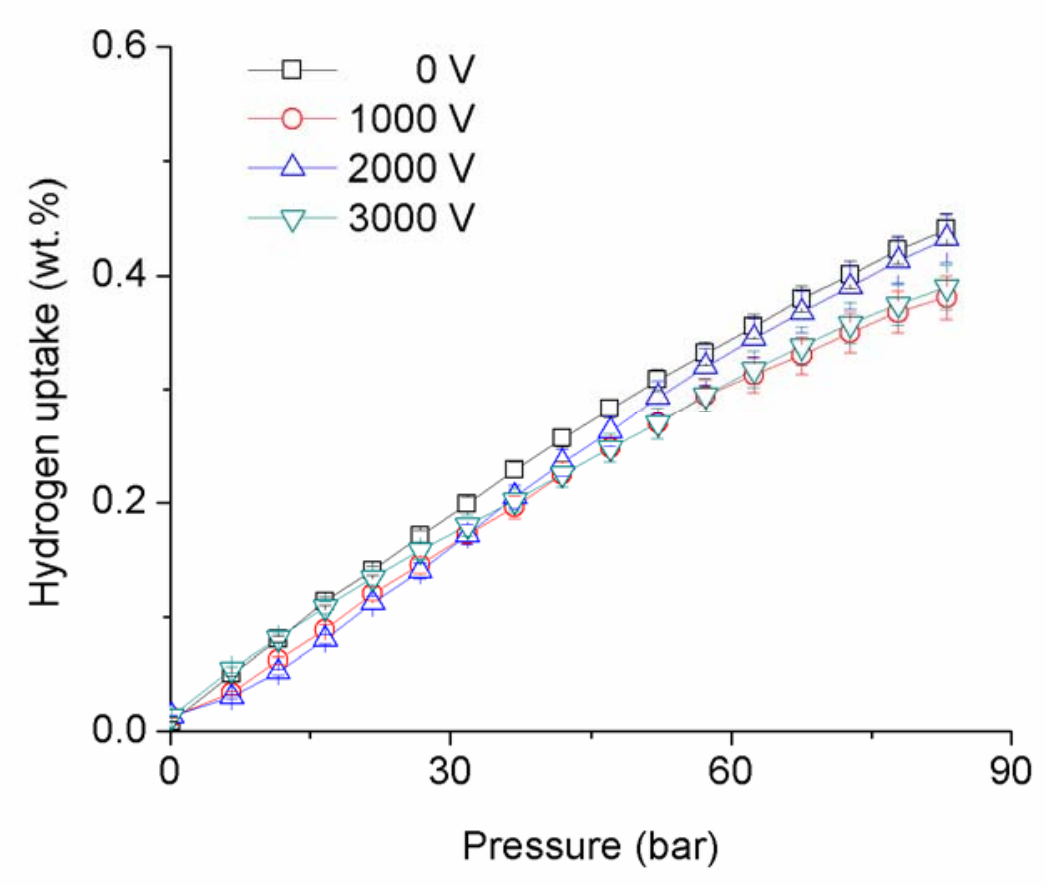

Figure 5.2 Hydrogen adsorption on NAC under various electric potentials

The interaction between activated carbon and hydrogen molecules is weak van der Waals force, leading to very low storage capacity at ambient temperature. Under a positive electric field, positive charges can be introduced to the carbon adsorbent and reside at the surface of carbon body when the system reaches equilibrium. Only hydrogen molecules located near to the charged area are possible to form stronger electrostatic interaction. Compared to the large surface area of activated carbon, the charged area takes up a very small proportion and thus the ratio of strongly bonded hydrogen is negligible. Moreover, the stronger bond between hydrogen and adsorbent can create longer H-H bond length, which indicates less stable state of hydrogen molecules. Under a sufficiently high electric field, dissociation and ionization of hydrogen molecules probably exist ${ }^{120,121}$. Movement of hydrogen ions in the electric field causes less adsorbed hydrogen. As no electricity was detected by the ammeter, ionized hydrogen molecules are not abundant. Besides, either increases of reported findings and decreases of our experimental results are not 
significant. Experimental errors caused by differences in experiment conditions may be another reason for the deviation of results.

\subsubsection{Negative electric potential}

Previous studies only examined adsorption behaviors with positive electric potential. To discover the effect of the direction of electric potential on adsorption, electric potential with opposite direction was applied to the sample. Hydrogen adsorption isotherm with negative electric potential of $1000 \mathrm{~V}$ is shown in Figure 5.3. The error for the measurement is around $10 \%$, much bigger than that with positive potential. A sharp decrease was observed in the presence of a negative potential. Hydrogen adsorption at 80 bar with $-1000 \mathrm{~V}$ voltage was 0.26 wt.\%, corresponding to $40 \%$ decrease. Current leak of around $0.1 \mathrm{~A}$ was detected by the incorporated ammeter of the power supply, indicating the transportation of electrons from the negative electrode to the ground. Moreover, the current continuously grew up as the voltage gradually increased. Measurement was not conducted at higher voltage due to the distinct current flow.

In the environment of a negative potential, some of hydrogen molecules will probably gain electrons from the electrode to form negative hydrogen ions $\left(\mathrm{H}^{-}\right)$or hydrogen ion clusters $\left(\mathrm{H}_{\mathrm{n}}{ }^{-}, \mathrm{n}=3,5,7,9 \ldots\right)$. However, the negative hydrogen ions or ion clusters are very unstable and impossible to form steady interaction with adsorbent surface ${ }^{106}$. The obtained electrons are about to be released in no time and run to the grounded electrode, resulting in a detected current. Additionally, the current flow would increase the temperature of the adsorbent, further reducing the adsorption capacity. 


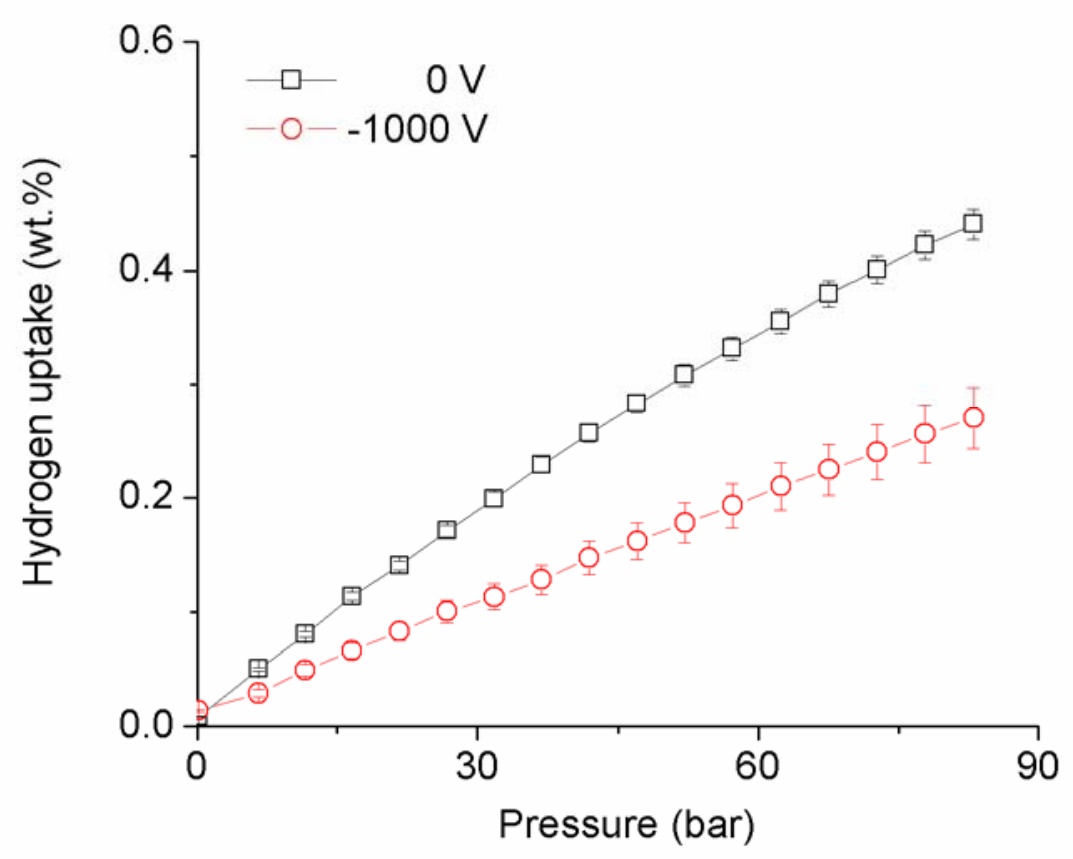

Figure 5.3 Hydrogen adsorption on NAC with and without $-1000 \mathrm{~V}$ electric potential

In the light of above observations, introducing an electric field to pristine carbon materials did not achieve any enhancement in hydrogen adsorption. Adsorbents with some specific characteristics may be required to form an effective system with the applied electric field.

\subsection{Hydrogen adsorption on Pt-doped activated carbon}

It has been demonstrated that Pt-doped activated carbon is able to dissociate hydrogen molecules and obtain improved adsorption through spillover. Experiment was carried out to determine the effect of an electric potential on the mixture of activated carbon and Pt-doped carbon (PAC). Hydrogen adsorption isotherms with and without a $2000 \mathrm{~V}$ electric potential are shown in Figure 5.4. Obvious enhancement was observed, even at low hydrogen pressure. At 80 bar, hydrogen adsorption capacities for $0 \mathrm{~V}$ and $2000 \mathrm{~V}$ applied potential were 0.42 and $0.51 \mathrm{wt} . \%$, resulting in a $21 \%$ increase. 


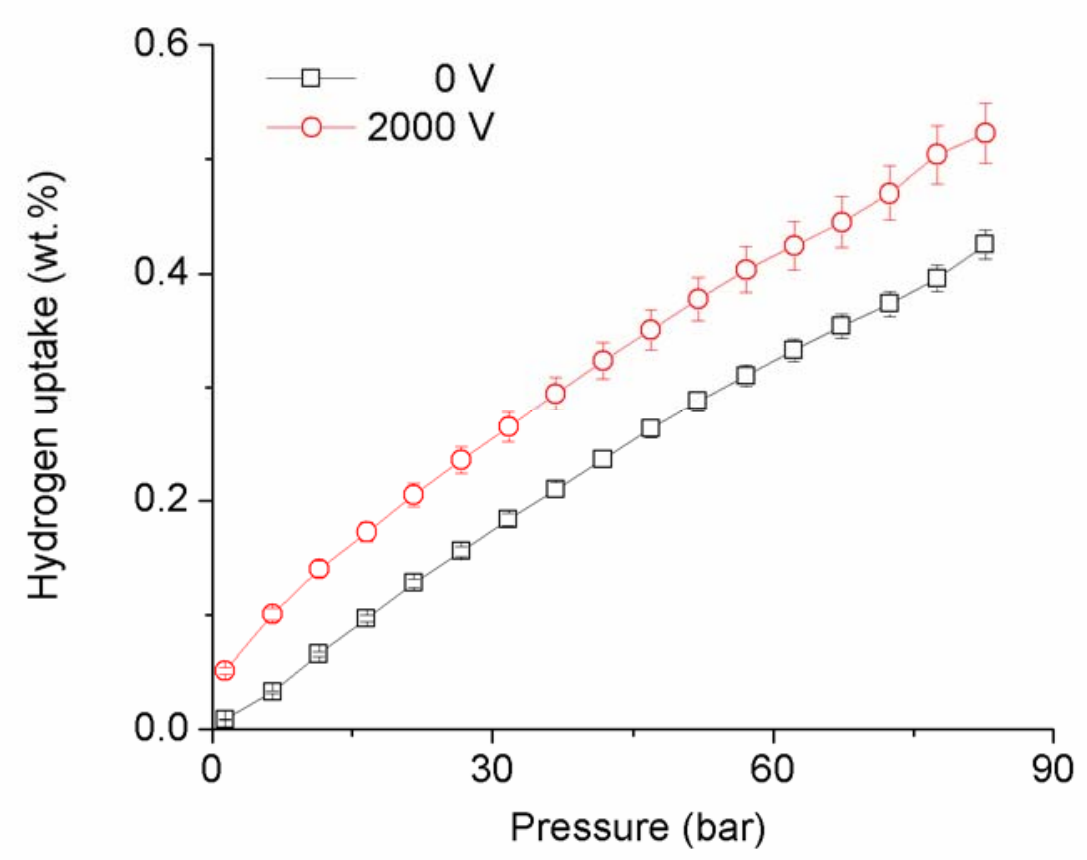

Figure 5.4 Hydrogen adsorption on PAC with and without $2000 \mathrm{~V}$ electric potential

In previous experiments, introduction of electric field did not lead to any adsorption enhancement over the activated carbon. The enhancement obtained on PAC could be ascribed to the existence of Pt particles. The mechanism may be illustrated by the following reasons. First, hydrogen molecules can be polarized by the electric field and the charges at adsorbent surface, facilitating the dissociation of hydrogen molecule on $\mathrm{Pt}$ particles. Also, the charges may accelerate the diffusion of $\mathrm{H}$ atoms into the bulk material. Therefore, more hydrogen can be adsorbed, indicating the application of electric field is capable of promoting the spillover effect. 


\section{CHAPTER 6 EXAMINATION OF HYDROGEN ADSORPTION ON ACTIVATED CARBON SEPARATED BY TITANIUM DIOXIDE}

\section{UNDER ELECTRIC FIELD}

\subsection{Hydrogen adsorption on mechanically mixed $\mathrm{TiO}_{2} /$ Carbon mixture}

Hydrogen uptakes of prepared TCM sample under $0 \mathrm{~V}$ and $2000 \mathrm{~V}$ are shown in Figure 6.1. The error for measurements is between $2 \%$ and $5 \%$. Using mixture of $\mathrm{NAC}$ and $\mathrm{TiO}_{2}$ nanopowder as adsorbent is a convenient way to check if introduction of electric field could affect hydrogen adsorption over activated carbon separated with dielectric material. It is told from the figure that introducing electric field could efficiently increase hydrogen storage over the mixture. For cases with and without electric field, 0.19 wt. $\%$ and 0.15 wt.\% uptakes were obtained at 80 bar and room temperature respectively, resulting in $26.7 \%$ improvement. However, compared to hydrogen adsorption on NAC, the adsorption without an electric field decreased remarkably. The platform of the adsorption curve at high hydrogen pressure indicated saturation of available adsorption sites.

The significant uptake reduction at $0 \mathrm{~V}$ was mainly caused by the addition of $\mathrm{TiO}_{2}$ powder, which is demonstrated as a very poor hydrogen storage material ${ }^{122}$. The enhancement with $2000 \mathrm{~V}$ applied electric potential is then considered primarily causing by enlarged charged zone. In this case, $\mathrm{TiO}_{2}$ particles would uniformly lie around carbon particles through mixing and could hold a large number of electrical charges generated at the interface of carbon and dielectric material. Then hydrogen molecules were possible to be polarized and form a stronger interaction with adsorbent, which was reflected as higher hydrogen uptake. Here we used a qualitative way to verify our hypothesis and agreeable results were obtained. However, the mechanism may be more complicated and 
further studies are needed.

\subsection{Hydrogen adsorption on $\mathrm{TiO}_{2} /$ Carbon synthetics prepared from $\mathrm{TiO}_{2}$ premix}

\subsubsection{Hydrogen adsorption with applied electric field}

$\mathrm{TiO}_{2}$-coated activated carbon samples with different content of $\mathrm{TiO}_{2}$ were prepared from the premix of $\mathrm{TiO}_{2}$ powder for investigating the effect of electric field on adsorption. The hydrogen adsorption isotherms of the prepared synthetics in the absence of an electric field are shown in Figure 6.2. For comparison, the measurement of pristine NAC is also included. It is found from the data that hydrogen uptake almost increases linearly with the growing pressure, while drops remarkably with increasing $\mathrm{TiO}_{2}$ content. The adsorption difference between $\mathrm{P} 3 \mathrm{H} 1$ and $\mathrm{P} 4 \mathrm{H} 1$ is very small. At 80 bar, the hydrogen storage capacity of NAC was 0.43 wt.\%, while uptakes of $\mathrm{P} 1 \mathrm{H} 1, \mathrm{P} 2 \mathrm{H} 1, \mathrm{P} 3 \mathrm{H} 1$ and $\mathrm{P} 4 \mathrm{H} 1$ were 0.35 wt. $\%, 0.28$ wt. $\%, 0.23$ wt. $\%$ and 0.23 wt. $\%$, respectively.

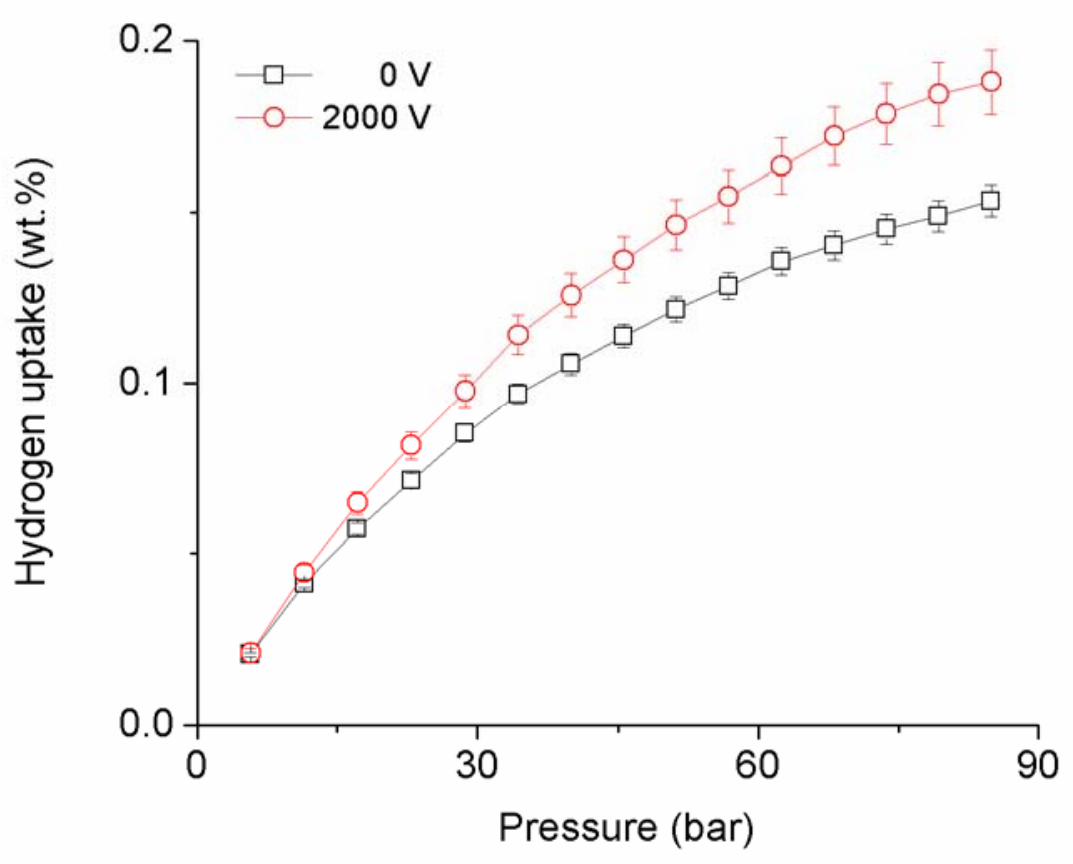

Figure 6.1 Hydrogen adsorption on sample MM with and without $2000 \mathrm{~V}$ electric potential 


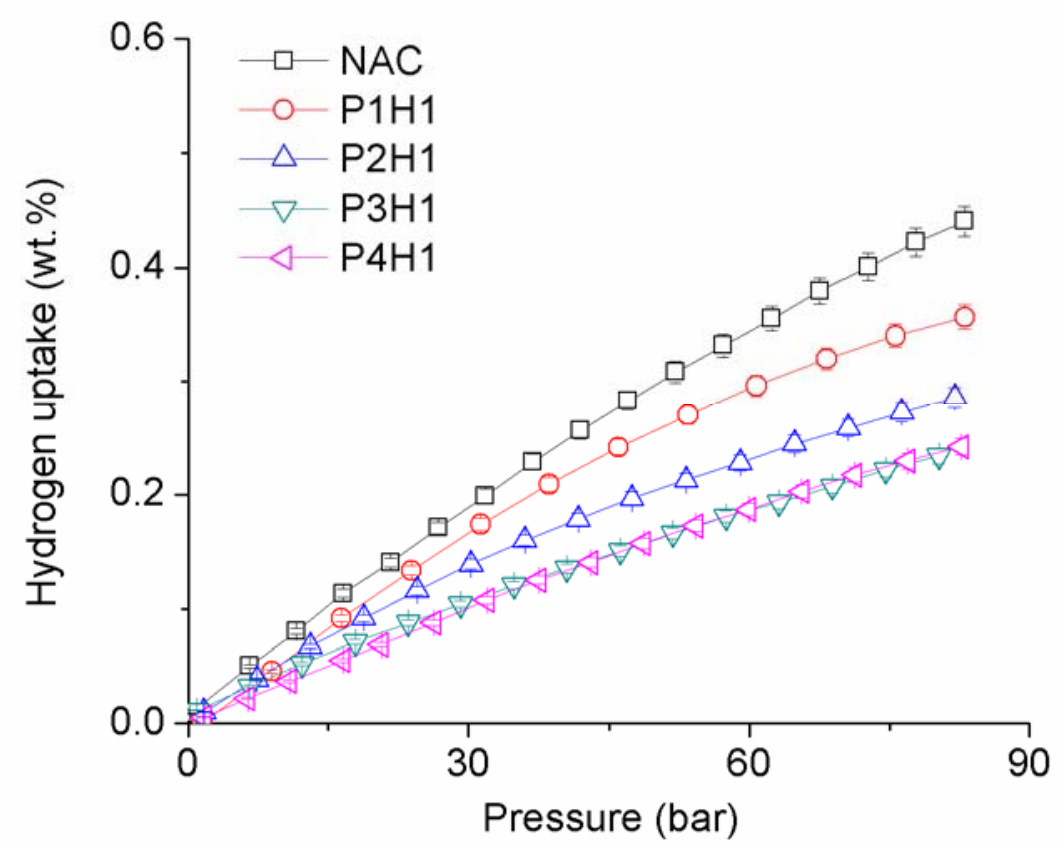

Figure 6.2 Hydrogen adsorption on $\mathrm{TiO}_{2} /$ Carbon synthetics P1H1, P2H1, P3H1, P4H1 and NAC

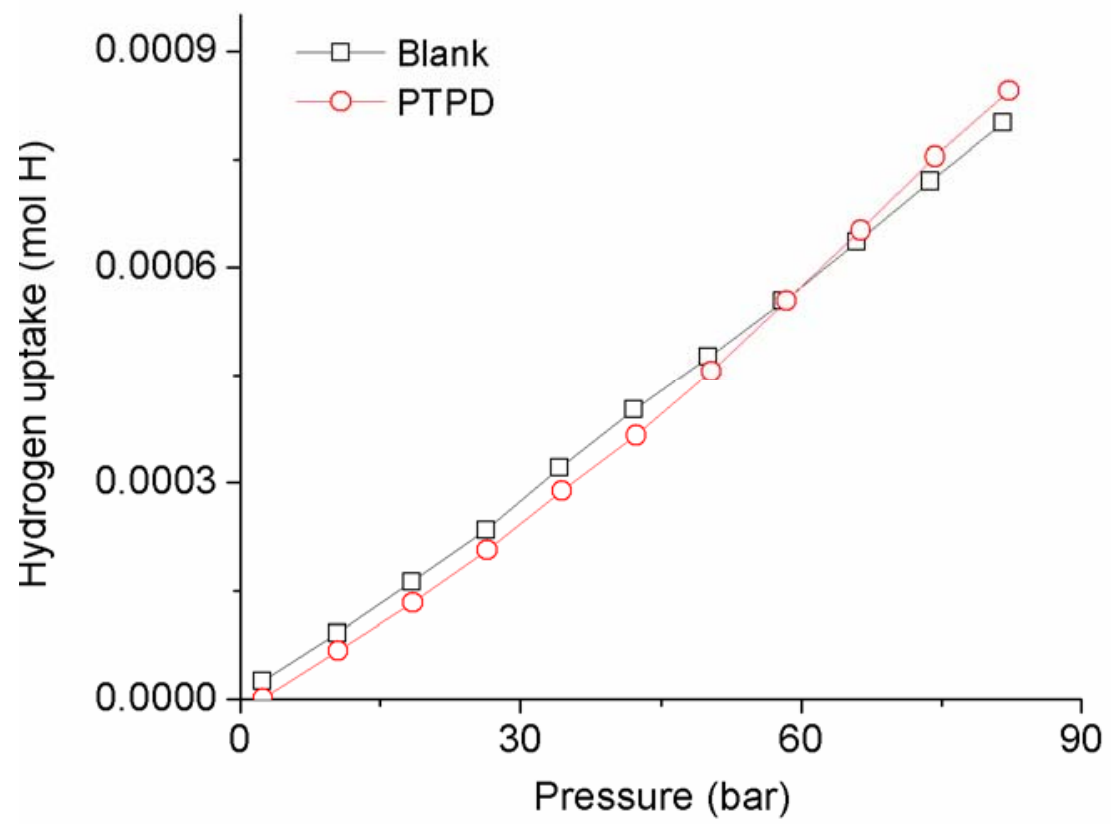

Figure 6.3 Hydrogen adsorption isotherms of PTPD and blank test 
Figure 6.3 shows the adsorption isotherms of PTPD and blank test. A negligible difference between the two experiments reveals that the PTPD itself adsorb little hydrogen.

An electric potential of $1000 \mathrm{~V}$ was then introduced to the testing samples and the results are shown in Figure 6.4. The error for this set of tests is around 5\%. Measurements for samples without voltage are also included for comparison. As shown in Figure 6.4a, for sample P1H1, suspected adsorption increase was observed under low pressure but was replaced by a slight decrease with pressure over 30 bar. Figure $6.4 \mathrm{~b}$ shows an enhancement for $\mathrm{P} 2 \mathrm{H} 1$, a sample with higher $\mathrm{TiO}_{2}$ content, which was very obvious even at very low hydrogen pressure. As for P3H1 in Figure 6.4c, the gap between the two data curves become larger, indicating even higher adsorption improvement. P4H1 showed a nice adsorption jump under electric field in Figure $6.4 \mathrm{~d}$, which meant a remarkable increase in adsorption capacity. At 80 bar of hydrogen pressure, the adsorption capacities of $\mathrm{P} 2 \mathrm{H} 1, \mathrm{P} 3 \mathrm{H} 1$ and $\mathrm{P} 4 \mathrm{H} 1$ under electric field were $0.36,0.33$ and 0.38 wt.\% and corresponding increases were $29 \%, 43 \%$ and $65 \%$, respectively. The results revealed that adsorption enhancement increases with the increasing of $\mathrm{TiO}_{2}$ content. It should be noted that the dehydrated PTP alone has little adsorption. Such adsorption increases are considered to occur on the activated carbon substrate. 

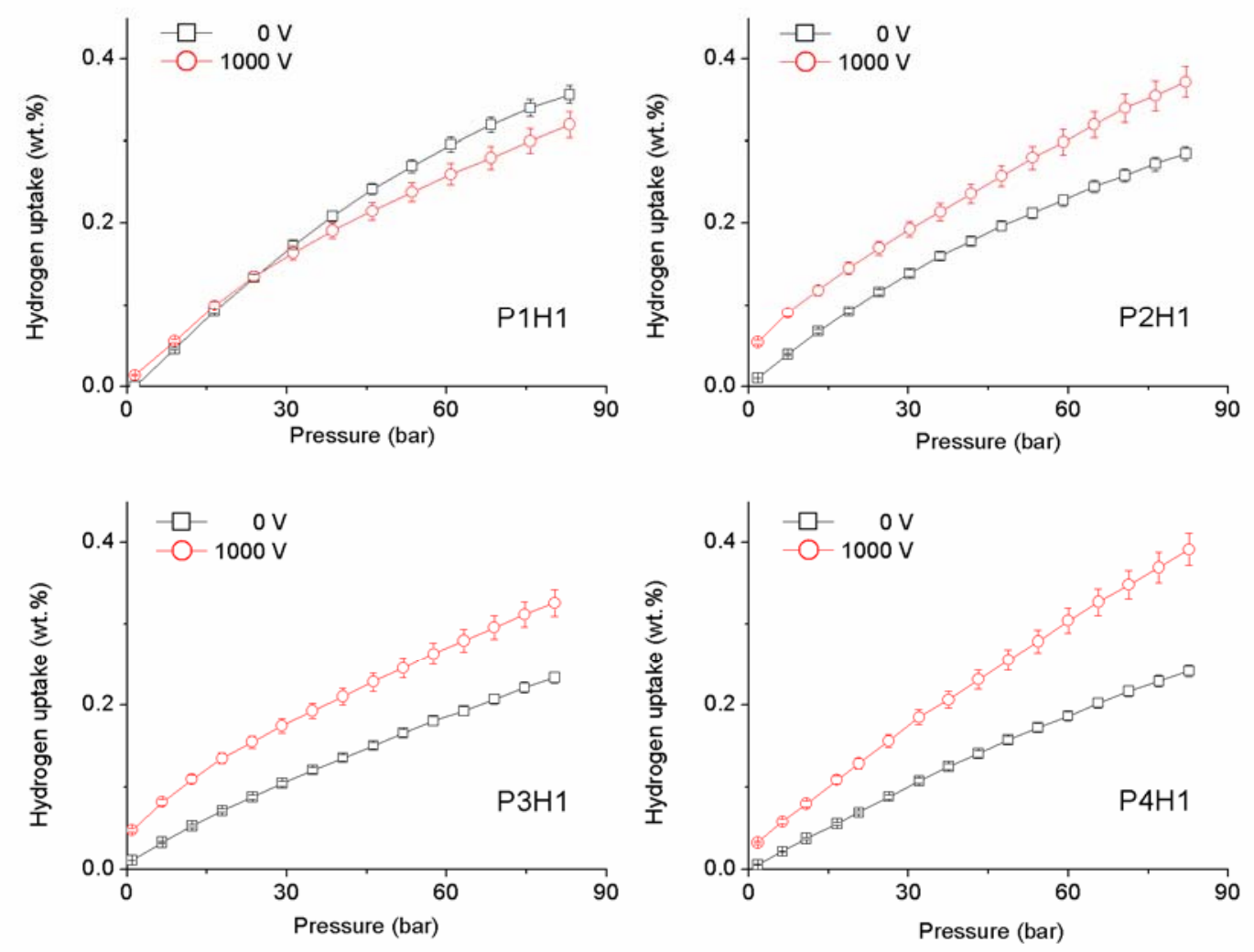

Figure 6.4 Hydrogen adsorption on $\mathrm{TiO}_{2} /$ Carbon synthetics P1H1, P2H1, P3H1 and P4H1 with and without $1000 \mathrm{~V}$ electric potential

As the surface area of the synthetics varies greatly, it is insufficient to simply compare hydrogen uptakes on different samples. We normalized the adsorption capacity with the BET surface area, as shown in Figure 6.5. It is indicated that application of an electric field enabled more hydrogen to be adsorbed on unit area for $\mathrm{P} 2 \mathrm{H} 1, \mathrm{P} 3 \mathrm{H} 1$ and $\mathrm{P} 4 \mathrm{H} 1$. Among all the results, P4H1 under $1000 \mathrm{~V}$ voltage had the highest normalized uptake. Additionally, under an electric field the amount of hydrogen adsorbed on equivalent area increased with the increasing $\mathrm{TiO}_{2}$ content in the species. 


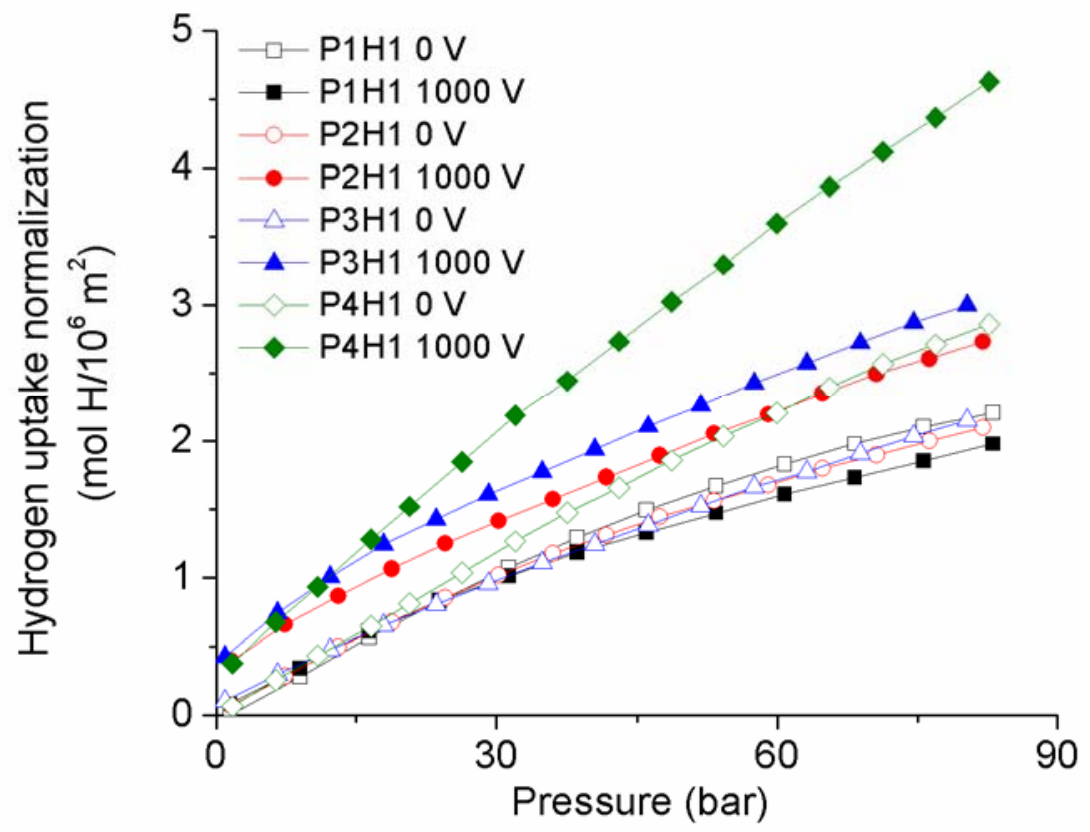

Figure 6.5 Hydrogen adsorption normalized by BET surface area

A higher storage capacity is in fact due to larger adsorption energy. The adsorption process between carbon and hydrogen is primarily weak van der Waals attraction between the $\pi$ bonds of aromatic rings and the $\sigma$ bonds of hydrogen molecules. After decorating activated carbon with $\mathrm{TiO}_{2}$ particles, hydrogen molecules may dissociate and migrate onto carbon host, which is known as spillover. However, Mishra and co-workers ${ }^{68}$ found reversible hydrogen storage (more than $90 \%$ ) over $\mathrm{TiO}_{2} /$ Carbon composite at room temperature, which indicated the adsorption mainly depended on physisorption. In addition, according to the report of Lim et al. ${ }^{70}$, around $25 \%$ of the $\mathrm{H}_{2}$ was chemisorped to the self-prepared $\mathrm{TiO}_{2}$ nanotubes due to spillover, in which half was weakly chemisorbed and reversible. Moreover, the supported $\mathrm{TiO}_{2}$ particles are relatively large and poorly distributed on carbon surface, and thus largely limit spillover. It is therefore considered that the spillover effect could be ignored in this case and the changes in adsorption were primarily attributed to the presence of electric field. According to the 
experimental observations, no obvious loss in adsorption capacity was found after several repeated experiments, indicating approximately complete desorption of hydrogen.

When an electric potential is applied, dielectric $\mathrm{TiO}_{2}$ coated on carbon surface will be polarized and induced charges can be generated in carbon. The coating allows charges induced to stay at the interface of carbon particles and dielectric materials, resulting in an enlarged charged zone. Hydrogen molecules and charged carbon surface can then build electrostatic interactions, which are stronger than van der Waals forces. Shi et al. also mentioned that orbital defects may be produced in adsorbent with an applied electric field, resulting in intensified orbital interactions ${ }^{92}$.

As $\mathrm{TiO}_{2}$ content varied in samples, carbon particles were isolated at different levels, or in other words, charged zones were different in size. Resistivity is a reflection of isolation. Higher resistivity corresponds to better isolation. P1H1 has a low resistivity due to the small amount of $\mathrm{TiO}_{2}$, exhibiting similar phenomenon as pristine carbon adsorbent under electric field. On the other hand, the sample holder can be treated as a capacitor with applied electric potential. The relationship of related parameters in a capacitor can be expressed using the following equations

$$
\begin{gathered}
C=\varepsilon_{r} \varepsilon_{o} \frac{s}{d} \\
Q=C V
\end{gathered}
$$

where $C$ is the capacitance, $\varepsilon_{r}$ is dielectric constant of the material between the two electrodes of the capacitor, $\varepsilon_{o}$ is the electric constant $\left(\varepsilon_{o} \approx 8.854 \times 10^{-12} \mathrm{~F} / \mathrm{m}\right), S$ is the area of overlap of the two electrodes, $d$ is the separation of the electrodes, $Q$ is the amount of induced charges and $V$ is the electric potential applied. The dielectric constant of 
synthetics rises with a growing ratio of dielectric materials until conductor-insulator transition is approached ${ }^{123}$. With other conditions unchanged, more charges would be generated as $\mathrm{TiO}_{2}$ content goes up. Therefore, both the enlarged charged zone and increased charge amounts are responsible for more intensified hydrogen polarization, leading to improved hydrogen adsorption increase on $\mathrm{P} 2 \mathrm{H} 1, \mathrm{P} 3 \mathrm{H} 1$ and $\mathrm{P} 4 \mathrm{H} 1$ samples.

In previous experiment, adsorption increase has been observed on mixture of activated carbon and anatase powder under electric field. Also, electric field enhanced adsorption was demonstrated when rutile particles was introduced to the carbon. The results indicate that the phase of $\mathrm{TiO}_{2}$ does not play a very important role in the adsorption enhancement with an applied electric potential.

\subsubsection{Hydrogen adsorption with the presence of piezoelectric element}

Hydrogen adsorption isotherms with one side insulated PMN-PTs are shown in Figure 6.6. Since a small difference in free volume would result in a big effect on hydrogen uptake via volumetric measurement, experiments have been carefully carried out with $<$ $0.1 \%$ volume differences. Standard error for the measurements with the presence of PMN-PT is around $5 \%$. The obtained results indicated that the addition of positive side insulted PMN-PT (denoted as PMN-PT(-)) could lead to significant hydrogen adsorption enhancement while the presence of PMN-PT with the negative side insulated (dentoed as PMN-PT $(+)$ ) caused reduction in storage capacity. In other words, introduction of negative charges was able to strengthen the interaction between hydrogen and adsorbent, but positive charges would weaken the interaction. 


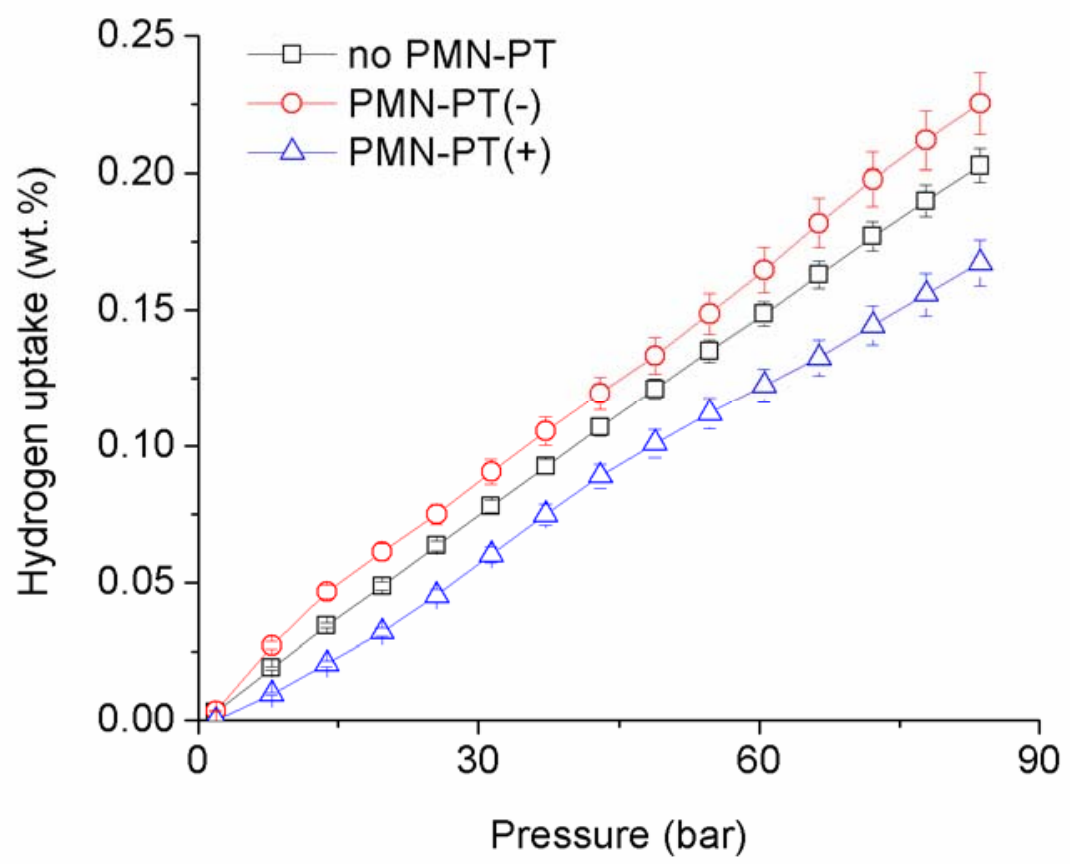

Figure 6.6 Hydrogen adsorption on P4 with the presence of a PMN-PT

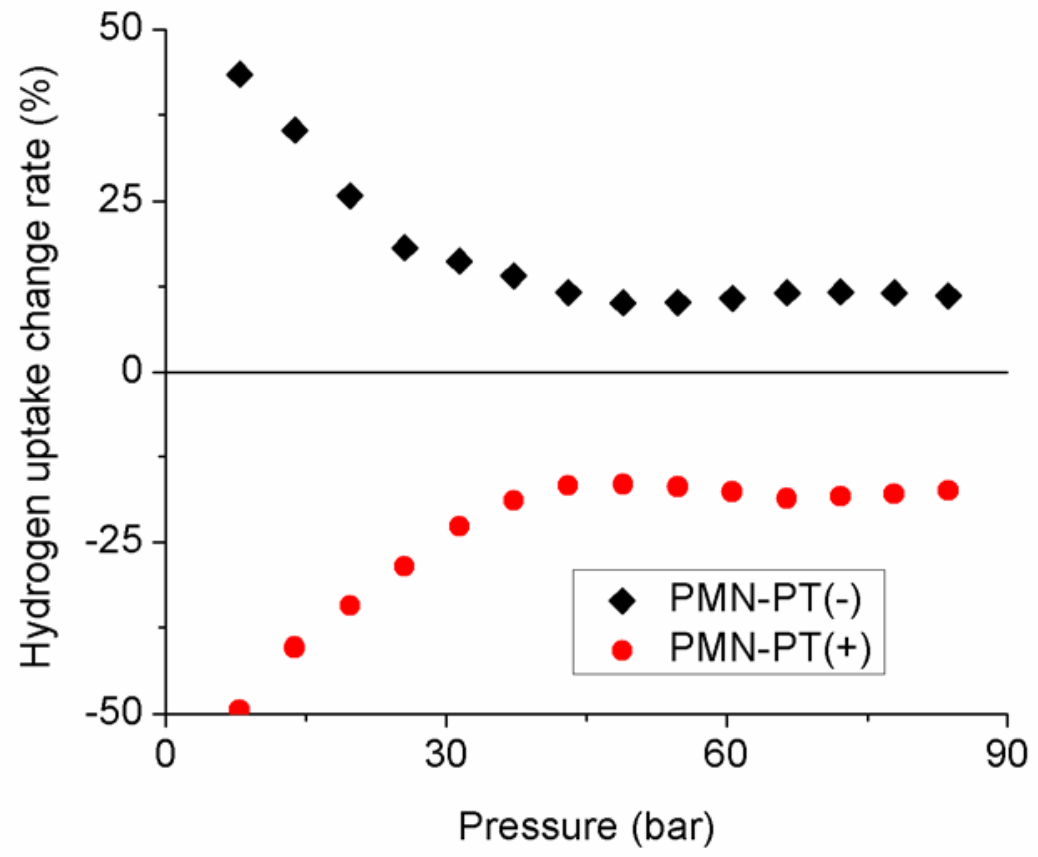

Figure 6.7 Change rate of hydrogen adsorption with the presence of a PMN-PT 
Change rates of hydrogen adsorption with two kinds of PMN-PT are shown in Figure 6.7. Hydrogen adsorption with PMN-PT(-) and PMN-PT(+) at 80 bar were 0.22 and 0.16 wt. $\%$, corresponding to $10 \%$ increase and $20 \%$ decrease. In hydrogen atmosphere, chargers will be generated and stay around the piezoelectric element due to the high electric resistivity of the adsorbent. Unlike an applied electric field, the charges generated by PMN-PT would not be capable of dissociating or ionizing hydrogen molecules. The adsorption takes place in the form of hydrogen molecule. The accumulated charges can be considered as a big point charge. As the field intensity of point charge falls off as the square of the distance from the charge, only the $\mathrm{TiO}_{2}$ particles locating near to the PMN-PT can be efficiently polarized. Charge distribution with the presence of PMN-PT(+) is described in Figure 6.8. Given the low surface area of the $\mathrm{TiO}_{2}$, it contributes few adsorption sites for hydrogen. Hydrogen is stored directly in activated carbon at the carbon- $\mathrm{TiO}_{2}$ interface or by initial binding on $\mathrm{TiO}_{2}$ and subsequent spillover in activated carbon ${ }^{69,75}$. The experimental results reflected that hydrogen molecules have stronger interaction with negatively charged $\mathrm{TiO}_{2}$ than positively charged $\mathrm{TiO}_{2}$. The principle of the phenomenon is attributed to the difference in binding energy. Computational calculations in the following chapter will provide more detailed explanation. 


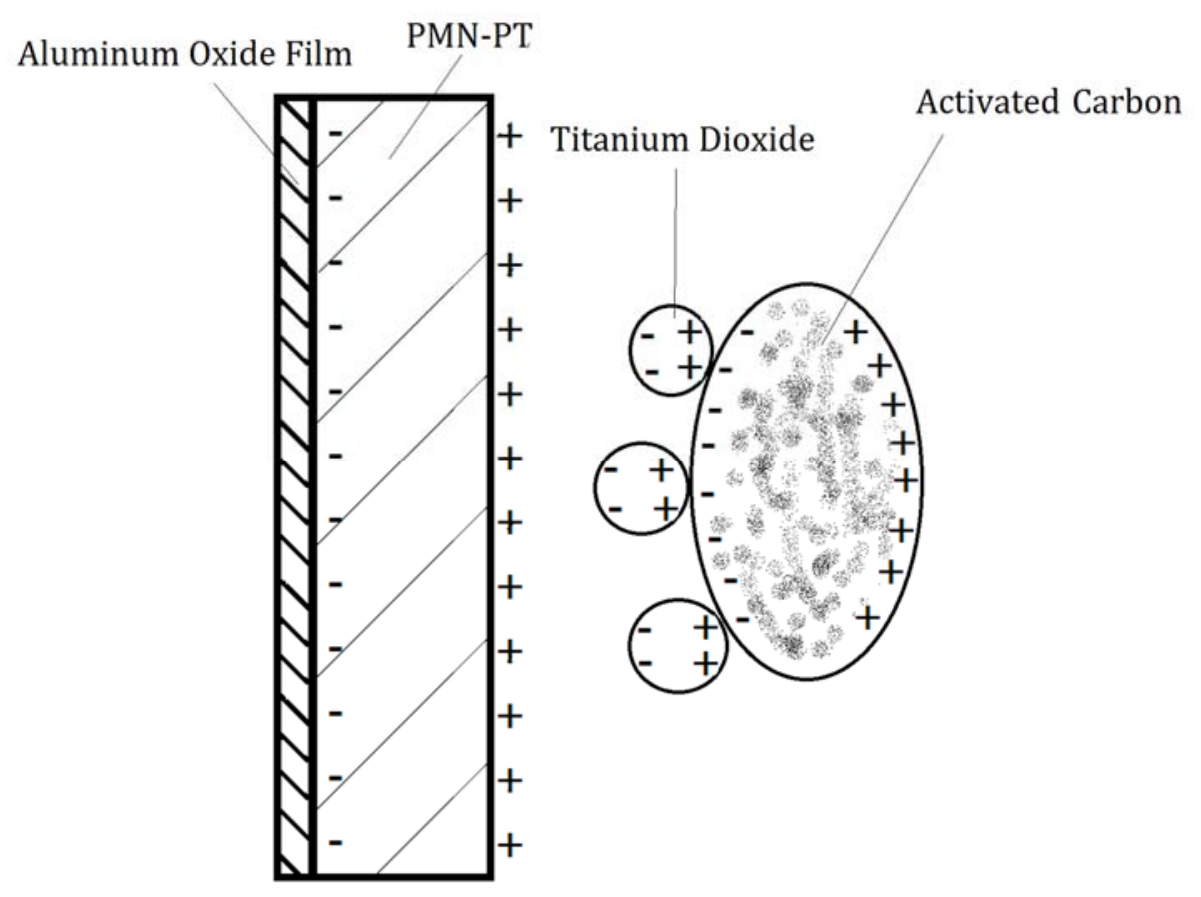

Figure 6.8 Schematic of charge distribution with the presence of PMN-PT(+)

It is also noted that for both measurements the rate of change went down as the pressure went up at low pressure $(<30 \mathrm{bar})$, and then became stable as the pressure further increased. According to Equation 3-1, relation between chargers generated from PMN-PT and hydrogen pressure can be described in Figure $6.9\left(\mathrm{~d}_{33}=1800 \mathrm{pC} / \mathrm{N}\right)$, which indicates the amount of charges linearly increases with the pressure. At low pressure, the amount of hydrogen molecules is small and thus the adsorption related to the generated charges would take up a considerable portion of total hydrogen adsorbed. As the pressure goes higher, the portion of influenced molecules falls down, leading to a reduction in either increase or decrease. 


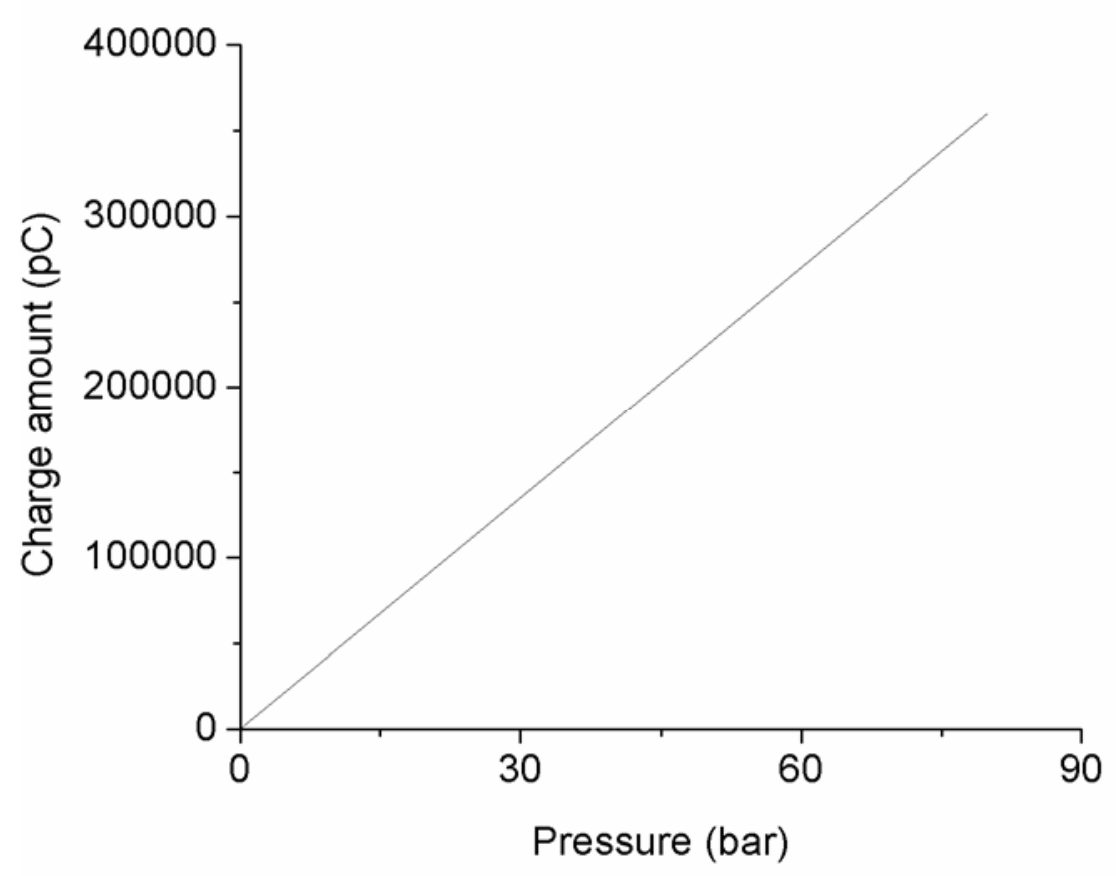

Figure 6.9 Relationship between hydrogen pressure and charges generated

The introduction of PMN-PT is a very convenient way to obtain storage enhancement based on current material processing techniques. However, the method merely affects the adsorption occurring around PMN-PT and the effect is not obvious. Bigger size or increased number of piezoelectric element is needed for large scale applications.

\subsection{Hydrogen adsorption on chemically deposited $\mathrm{TiO}_{2} /$ Carbon synthetics}

The hydrogen adsorption isotherms of prepared $\mathrm{TiO}_{2} /$ Carbon species in the absence of an electric field are shown in Figure 6.10. The measurement of pristine NAC is also included for comparison. At 80 bar, the hydrogen adsorption capacity of NAC was 0.43 wt.\%, while uptakes of TC1 and TC2 were 0.40 wt.\% and 0.37 wt.\%, respectively. 


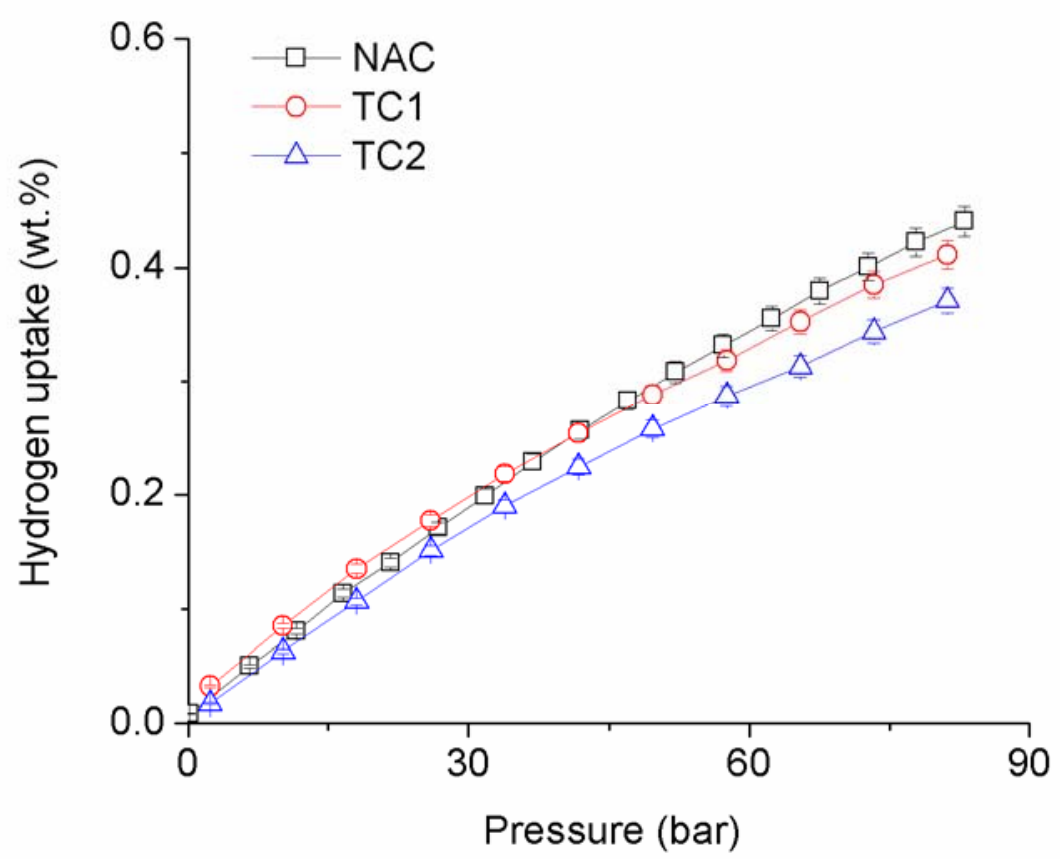

Figure 6.10 Hydrogen adsorption on TC1, TC2 and NAC

An electric potential of $1000 \mathrm{~V}$ was then introduced to TC1 and TC2 and the results are shown in Figure 6.11. For comparison, measurements for samples without voltage are also included. It is clear that both adsorbents have obtained adsorption enhancements with a $1000 \mathrm{~V}$ voltage. Adsorption capacities of TC1 and TC2 at 80 bar were 0.45 and 0.56 wt. $\%$, corresponding to $13 \%$ and $51 \%$ increase, respectively. A greater enhancement has been expectedly achieved by $\mathrm{TC} 2$, the sample with higher $\mathrm{TiO}_{2}$ content, which is consistent with our proposed theory. It is also noted that at 80 bar adsorption capacities of both TC1 and TC2 under electric field exceed that of NAC (0.43 wt.\%). 

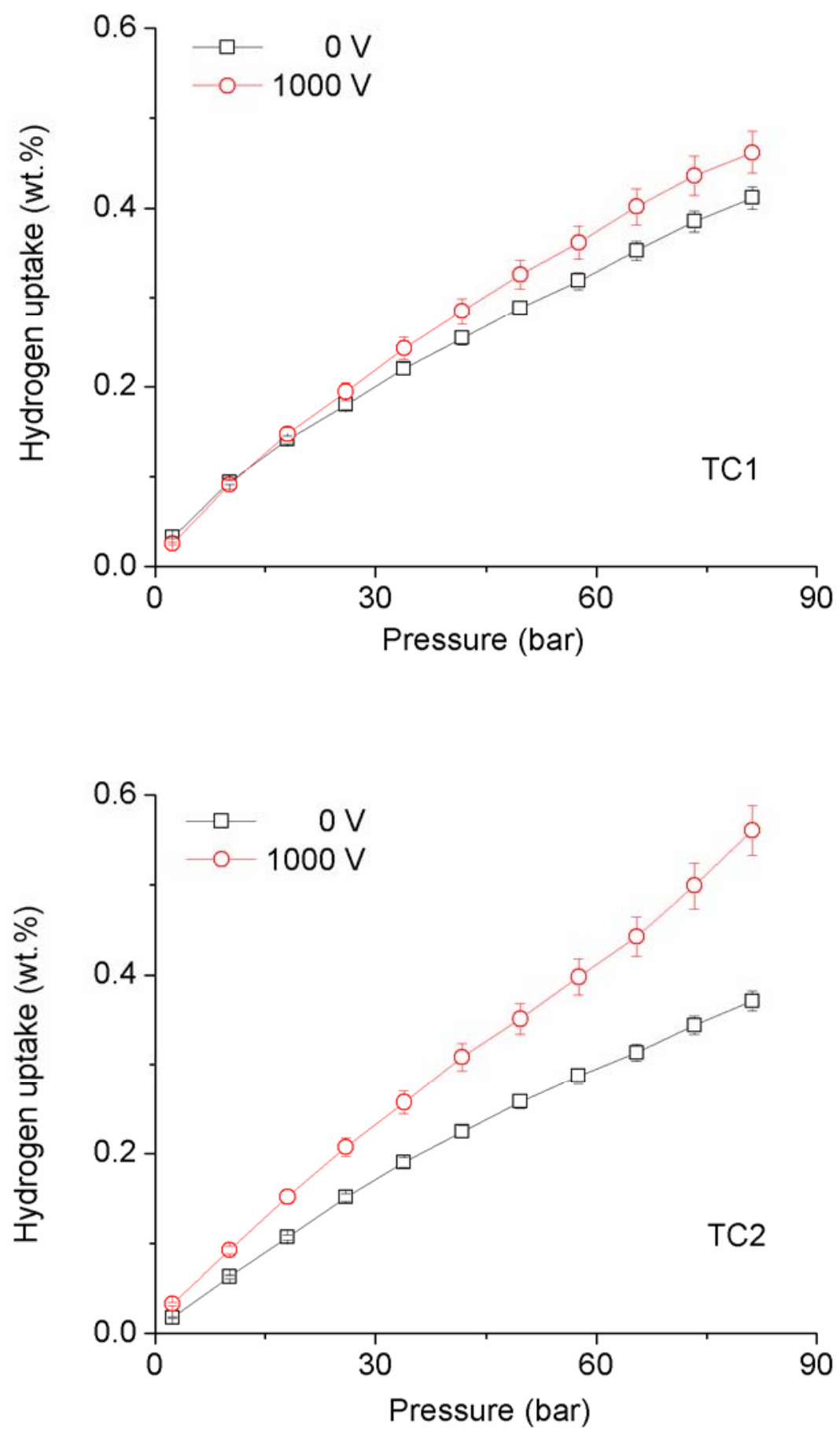

Figure 6.11 Hydrogen adsorption on TC1 and TC2 with and without $1000 \mathrm{~V}$ electric potential 


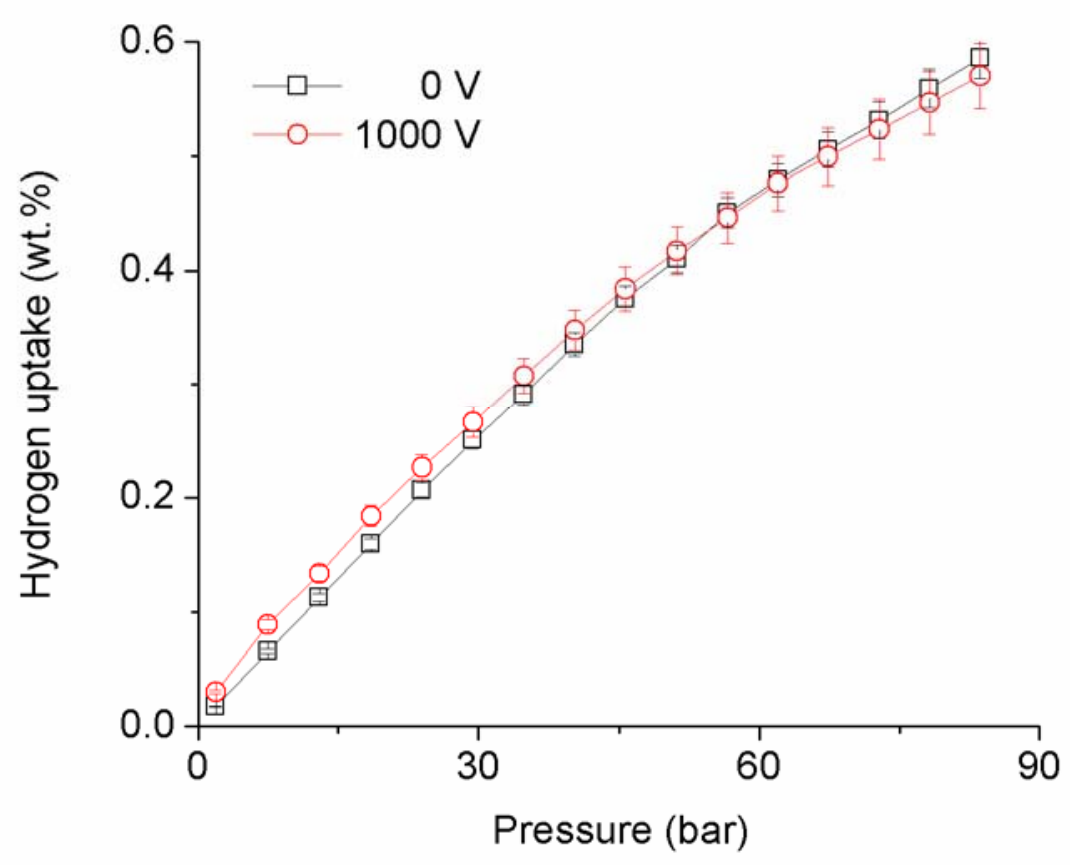

Figure 6.12 Hydrogen adsorption on HCl/NAC with and without $1000 \mathrm{~V}$ electric potential

To exclude the possible effect of $\mathrm{Cl}^{-}$ions, adsorption experiments with or without $1000 \mathrm{~V}$ electric potential were carried out on $\mathrm{HCl} / \mathrm{NAC}$, as shown in Figure 6.12. The data curves showed a negligible difference between the two experiments. It could be concluded that the presence of $\mathrm{Cl}^{-}$ions did not affect hydrogen uptake during the measurement. Adsorption enhancement was attributed to the introduction of $\mathrm{TiO}_{2}$ particles.

As TC2 possesses uniform $\mathrm{TiO}_{2}$ coating and has achieved significant adsorption enhancement with applied electric field, it was chosen as the object to study the effect of field intensity on adsorption performance over $\mathrm{TiO}_{2} /$ Carbon synthesis. Hydrogen adsorption measurements with different electric potentials were conducted on TC2 and the results are shown in Figure 6.13. Within the range of applied potential from 0 to 3000 $\mathrm{V}$, the highest storage capacity was obtained at $1000 \mathrm{~V}$, while the lowest was gotten at 


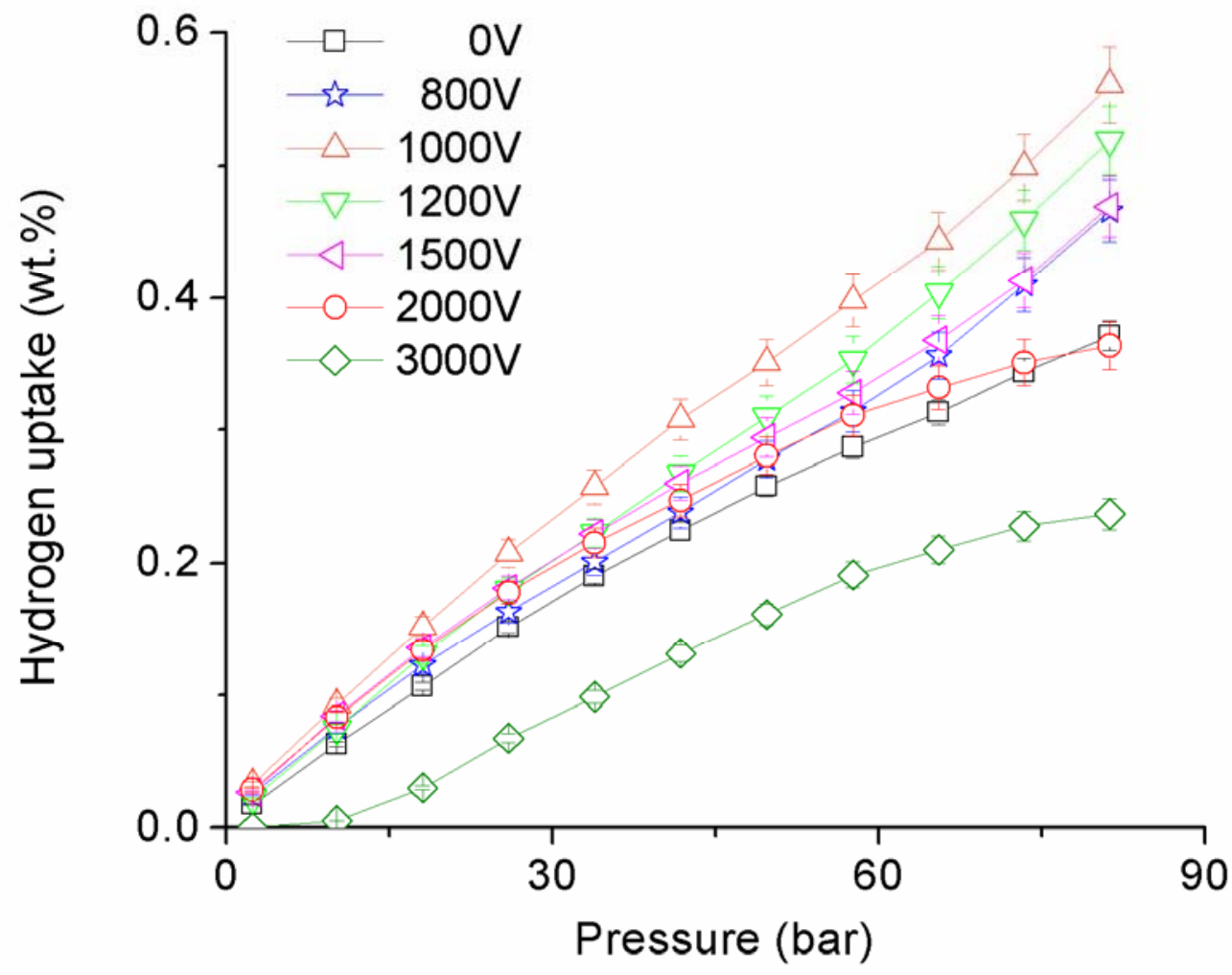

Figure 6.13 Hydrogen adsorption on $\mathrm{TiO}_{2} / \mathrm{Carbon}$ synthetics $\mathrm{TC} 2$ under various electric potentials

3000 V. Additionally, as shown in Figure 6.14, the incorporated ammeter showed an electricity of around $0.1 \mathrm{~mA}$ at $3000 \mathrm{~V}$, while no electricity was detected at other voltages. 


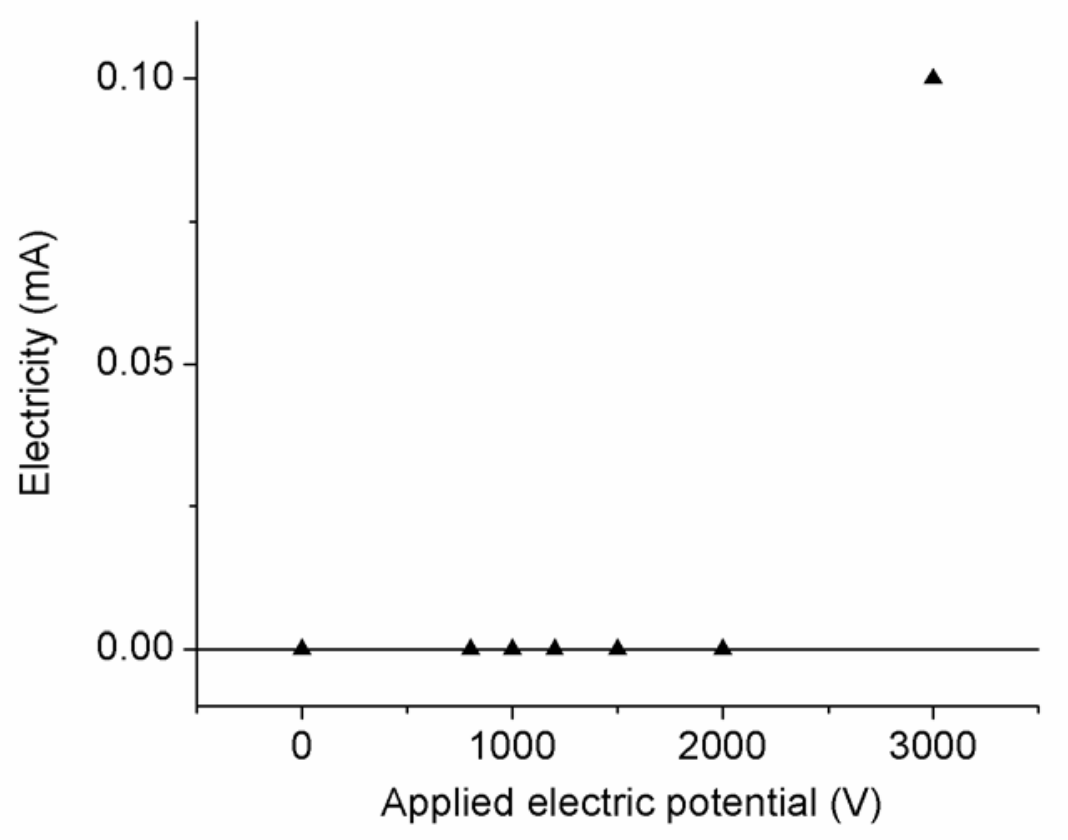

Figure 6.14 Electricity detected by ammeter under various electric potentials

To provide a more obvious comparison, variance ratios of hydrogen uptake at 20, 50 and 80 bar under different electric potential were given in Figure 6.15. Hydrogen adsorption at 20,50 and 80 bar in the absence of an electric field were $0.12,0.26$ and 0.37 wt.\%. As the potential increased, the storage capacity at each selected pressure first increased and then decreased. Enhanced hydrogen adsorptions were observed when applied potentials were less than $2000 \mathrm{~V}$. The most significant adsorption enhancements were achieved at $1000 \mathrm{~V}$, which were $42 \%, 35 \%$, and $51 \%$ for 20,50 and 80 bar. At $2000 \mathrm{~V}$, improvements become less obvious, and even a little decrease (3\%) was found at 80 bar. When the potential was raised to $3000 \mathrm{~V}$, a sharp decrease occurred. Hydrogen uptakes at 20, 50 and 80 bar with a $3000 \mathrm{~V}$ voltage were $0.04,0.16$ and 0.24 wt.\% respectively, corresponding to decreases of $66 \%, 38 \%$ and $35 \%$. 


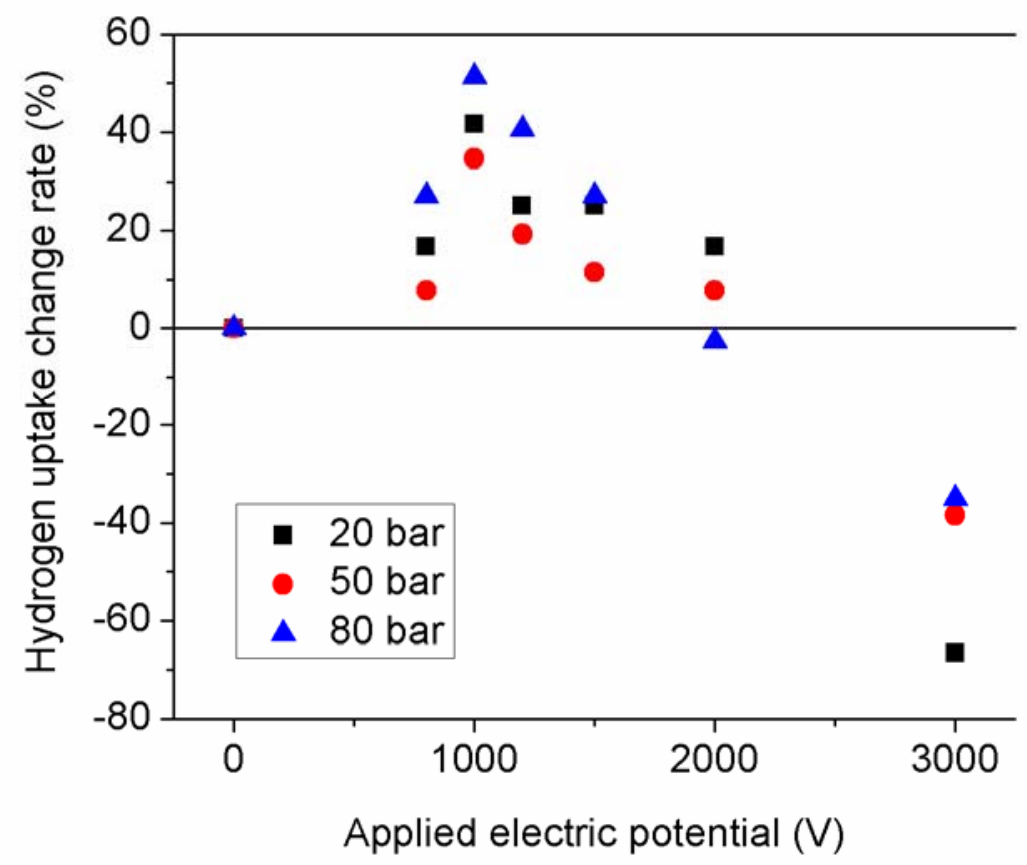

Figure 6.15 Adsorption change rate of TC2 at 20, 50 and 80 bar under various electric potentials

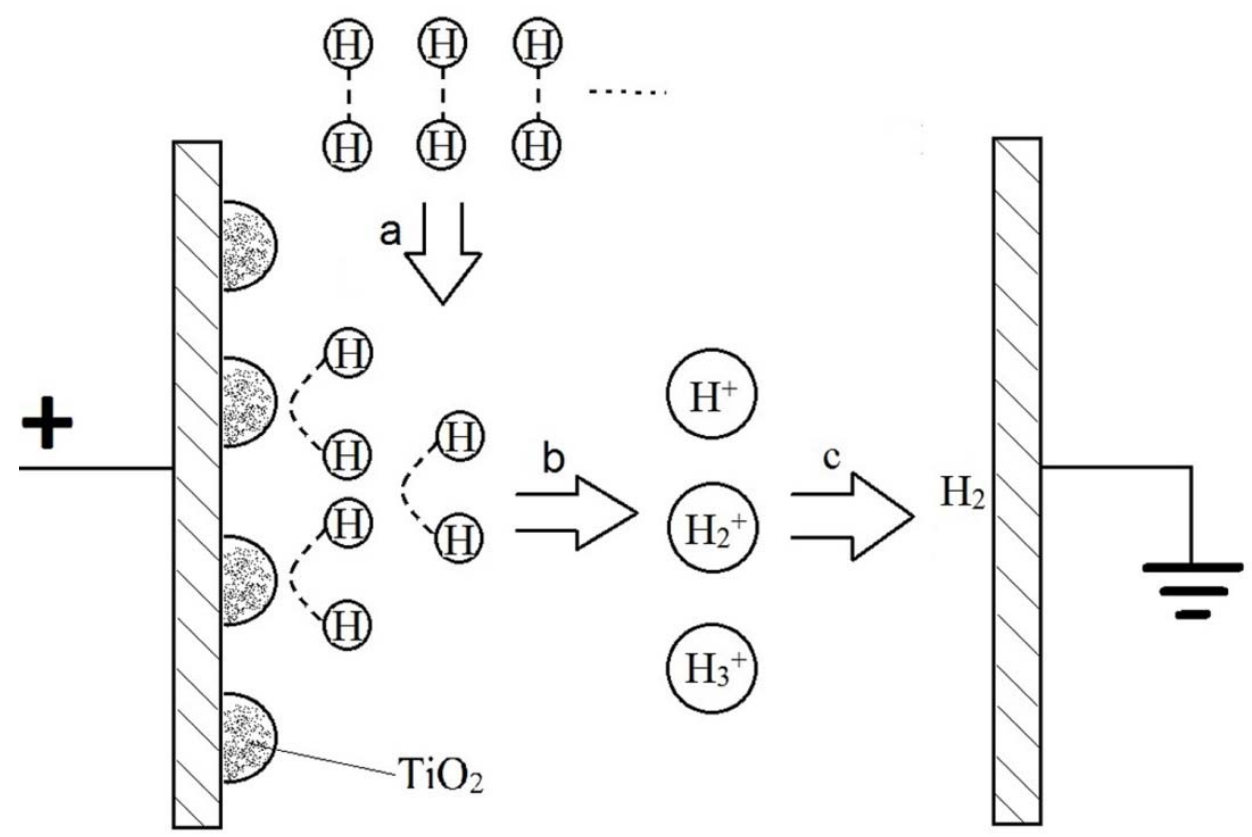

Figure 6.16 Illustration of hydrogen adsorption mechanism under electric field 
As discussed before, the application of an external electric field can polarize the dielectric $\mathrm{TiO}_{2}$ coating and induce charges on carbon. The coating also ensures the charges stay on carbon, leading to stronger electrostatic interactions between hydrogen and adsorbent. Increasing the field strength is expected to intensify the polarization and facilitate the attraction, resulting in a higher storage capacity. However, the results showed that further increase of electric potential adversely decreased the hydrogen uptake. There must be a reason for the phenomenon.

Hydrogen ions $\left(\mathrm{H}^{+}\right.$and $\left.\mathrm{H}_{2}{ }^{+}\right)$were reported to be formed under a strong electric field due to field ionization and field induced dissociation of $\mathrm{H}_{2}{ }^{121}$, which can be described by the following reactions 124

$$
\mathrm{H}_{2} \rightarrow \mathrm{H}_{2}^{+} \rightarrow \mathrm{H}^{+}+\mathrm{H} \rightarrow \mathrm{H}^{+}+\mathrm{H}^{+}
$$

Another kind of hydrogen ion, $\mathrm{H}_{3}{ }^{+}$, was also detected by mass spectrum. Its formation is generally accepted as ${ }^{125}$

$$
\mathrm{H}_{2}^{+}+\mathrm{H}_{2} \rightarrow \mathrm{H}_{3}^{+}+\mathrm{H}
$$

According to Clements and Müller ${ }^{124}, \mathrm{H}_{2}^{+}$is predominant at low fields, but with increasing filed the contributions of protons to the total ions increases. Field condition of $\mathrm{H}_{3}{ }^{+}$is difficult to determine. As a result, the positive charged hydrogen ions will move towards the grounded electrode and release their charges there. The observed electricity at $3000 \mathrm{~V}$ was an indication of the activity. Moreover, it is noticed that no current flow and remarkable decrease in adsorption were detected when a $3000 \mathrm{~V}$ electric potential was applied to activated carbon sample. The reason should be that $\mathrm{TiO}_{2}$ is a kind of 
material with intrinsic dipole moment. The external electric field could further enhance the dipole moment, so that the nearby hydrogen molecules would be strongly polarized and easily ionized.

Therefore, the measured hydrogen uptakes were the reflection of strengthened binding between hydrogen and adsorbent, accompanied by the influence of hydrogen ions transportation, as illustrated in Figure 6.16. Enhanced hydrogen storage obtained under a low electric potential $(<2000 \mathrm{~V})$ indicated electrostatic interaction plays the leading role. A high applied potential $(>2000 \mathrm{~V})$ created more hydrogen ions and an even larger electric force exerted on the ions made the ions transportation very violent, resulting in a reduced storage capacity and current flow. Moreover, the current flow would create heat in the adsorbent, which is not favorable for adsorption. To obtain an ideal storage capacity, an electric field with optimized strength is needed. For different samples, the strength may be different.

\subsection{Hydrogen adsorption on $\mathrm{TiO}_{2}$-coated $\mathrm{Pt} / \mathrm{AC}$}

As the effects of electric field on $\mathrm{TiO}_{2}$-coated activated carbon and Pt-doped carbon have been demonstrated, experiments were conducted to examine the hydrogen adsorption on $\mathrm{TiO}_{2}$-coated $\mathrm{Pt} / \mathrm{AC}$ under electric field. Figure 6.16 shows the hydrogen uptakes on $\mathrm{TiO}_{2}$-coated $\mathrm{Pt} / \mathrm{AC}$ with and without a $2000 \mathrm{~V}$ electric potential. Error for the measurement with voltage is about $8 \%$. It is seen in the picture that exceptionally high enhancement in adsorption has been achieved during the entire measurement process. The adsorption capacity at 80 bar of hydrogen pressure increased from 0.13 wt. $\%$ to 0.37 wt. $\%$ with the presence of electric field, corresponding to a $185 \%$ enhancement. 


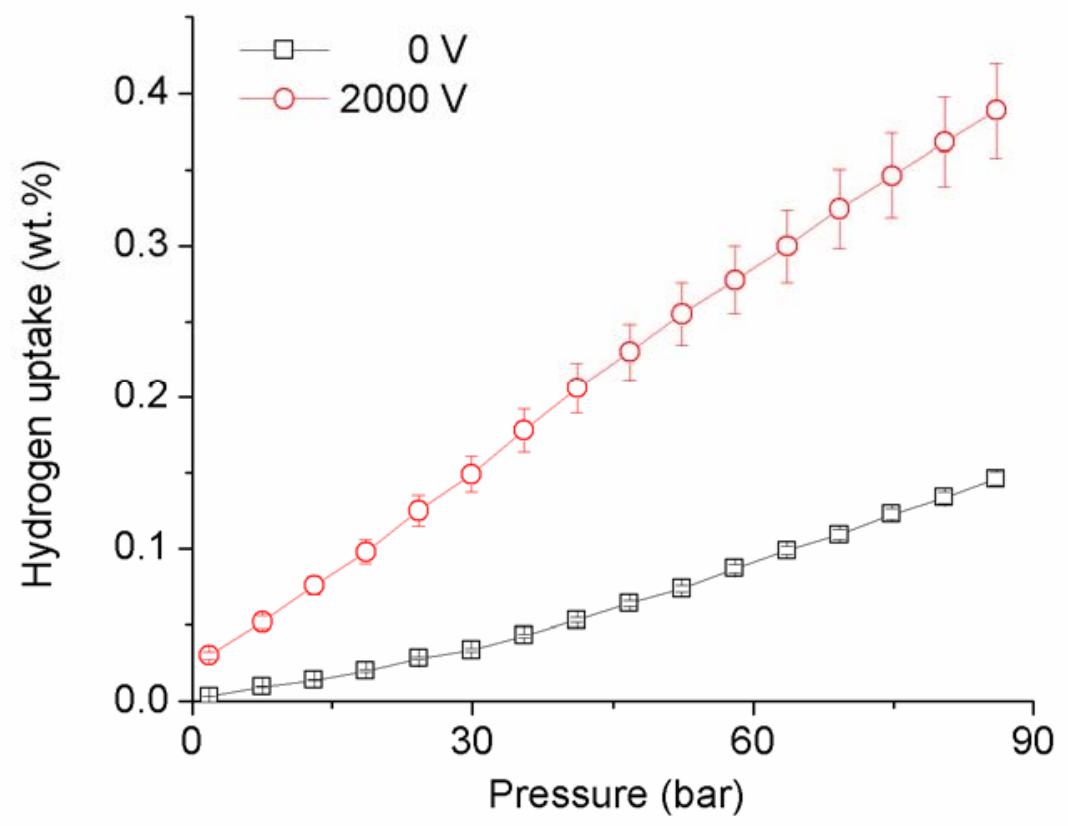

Figure 6.17 Hydrogen adsorption on $\mathrm{TiO}_{2}$-coated $\mathrm{Pt} / \mathrm{AC}$ synthetic TPC under electric potential

The adsorption enhancement over PAC demonstrated that spillover can be facilitated by applied electric field. Introduction of $\mathrm{TiO}_{2}$ particles to the $\mathrm{Pt} / \mathrm{AC}$ would result in more charges, further promoting the dissociation of hydrogen molecules. In addition, the Pt particles interacted with both carbon and $\mathrm{TiO}_{2}$ particles. Hydrogen adsorption on $\mathrm{TiO}_{2}$ particles might also be increased due to the spillover mechanism. 


\section{CHAPTER 7 EXAMINATION OF HYDROGEN ADSORTPION ON ACTIVATED CARBON SEPARATED BY OTHER DIELEDTRIC MATERIALS UNDER ELECTRIC FIELD}

Hydrogen adsorption enhancement over $\mathrm{TiO}_{2}$-coated activated carbon under proper electric field has been demonstrated by previous experimental work. The increased adsorption is considered primarily due to the enhanced dipole moment of dielectric $\mathrm{TiO}_{2}$. $\mathrm{TiO}_{2}$ is a material with good dielectric properties and its dielectric constant is $\sim 100^{126,127}$. In this chapter, hydrogen adsorption performances over activated carbon separated by three other dielectric materials $\left(\mathrm{MgO}, \mathrm{ZnO}\right.$ and $\left.\mathrm{BaTiO}_{3}\right)$ are investigated. Compared to $\mathrm{TiO}_{2}, \mathrm{MgO}$ and $\mathrm{ZnO}$ have much smaller dielectric constants, which are $\sim 10$ and 8-10,

respectively ${ }^{128-130}$. $\mathrm{BaTiO}_{3}$ was selected because of the unusually high dielectric constant up to several thousand ${ }^{131}$. The study was initiated to reveal the effect of dielectric degree on hydrogen adsorption.

\subsection{Hydrogen adsorption on $\mathrm{MgO} / \mathrm{Carbon}$ species}

Hydrogen adsorption isotherms of MC with and without an electric potential are shown in Figure 7.1. Electric fields with two different strengths were applied to the testing sample. Unlike the species coated with $\mathrm{TiO}_{2}$, negligible difference was shown among the tests, indicating no influence of electric field on hydrogen adsorption over activated carbon separated by $\mathrm{MgO}$. Given the relative small dielectric constant of $\mathrm{MgO}$, the applied electric field may not be sufficient to polarize $\mathrm{MgO}$, or the degree of polarization is not enough to form stronger electrostatic interaction between hydrogen and adsorbent. Ionization of hydrogen molecule certainly becomes less probable. Therefore, no obvious enhancement or decline was found in adsorption capacity. 


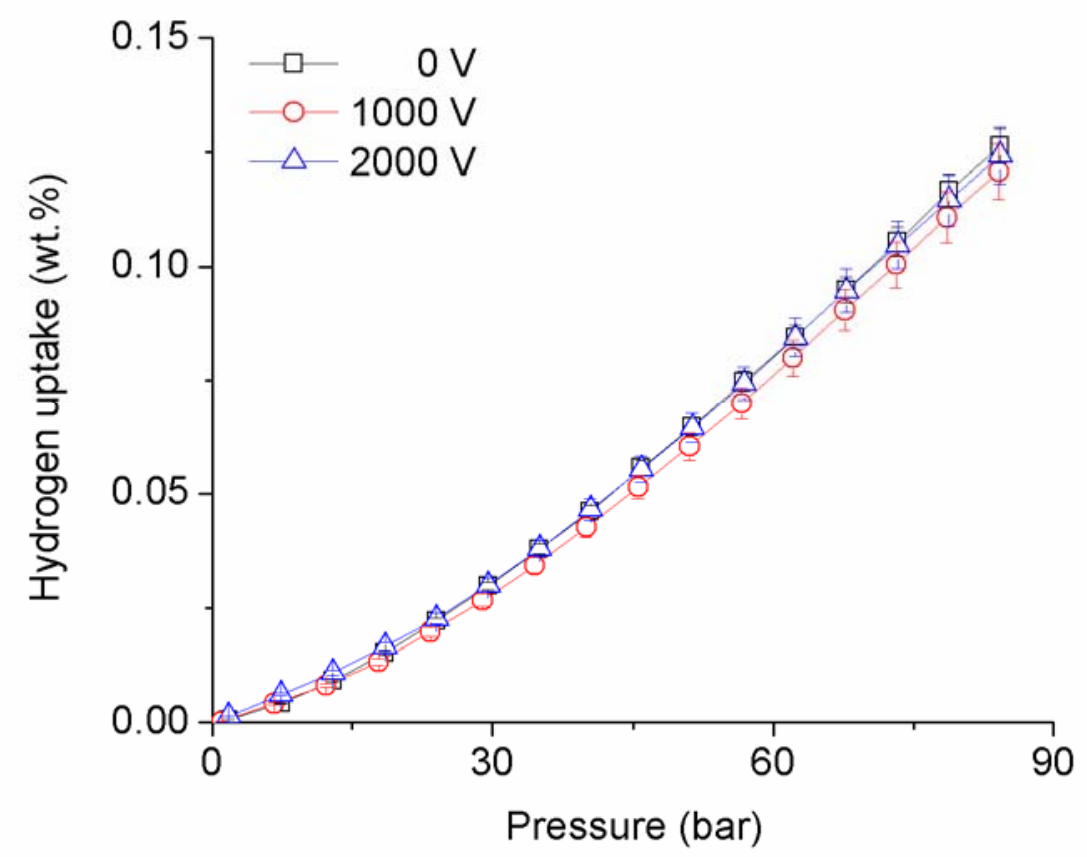

Figure 7.1 Hydrogen adsorption on MgO/Carbon synthesis MC with and without electric potential

\subsection{Hydrogen adsorption on $\mathrm{ZnO} /$ Carbon species}

Hydrogen adsorption on $\mathrm{ZC}$ with and without a $2000 \mathrm{~V}$ electric potential is given in Figure 7.2. Overlap of the error bars of the two data sets indicates no distinctive increase or decrease with an applied electric field. A slight decrease under electric field may be caused by ionization of a small amount of hydrogen. $\mathrm{ZnO}$ has a dielectric constant quite close to $\mathrm{MgO}$, resulting in a similar adsorption phenomenon as that of $\mathrm{MC}$. 


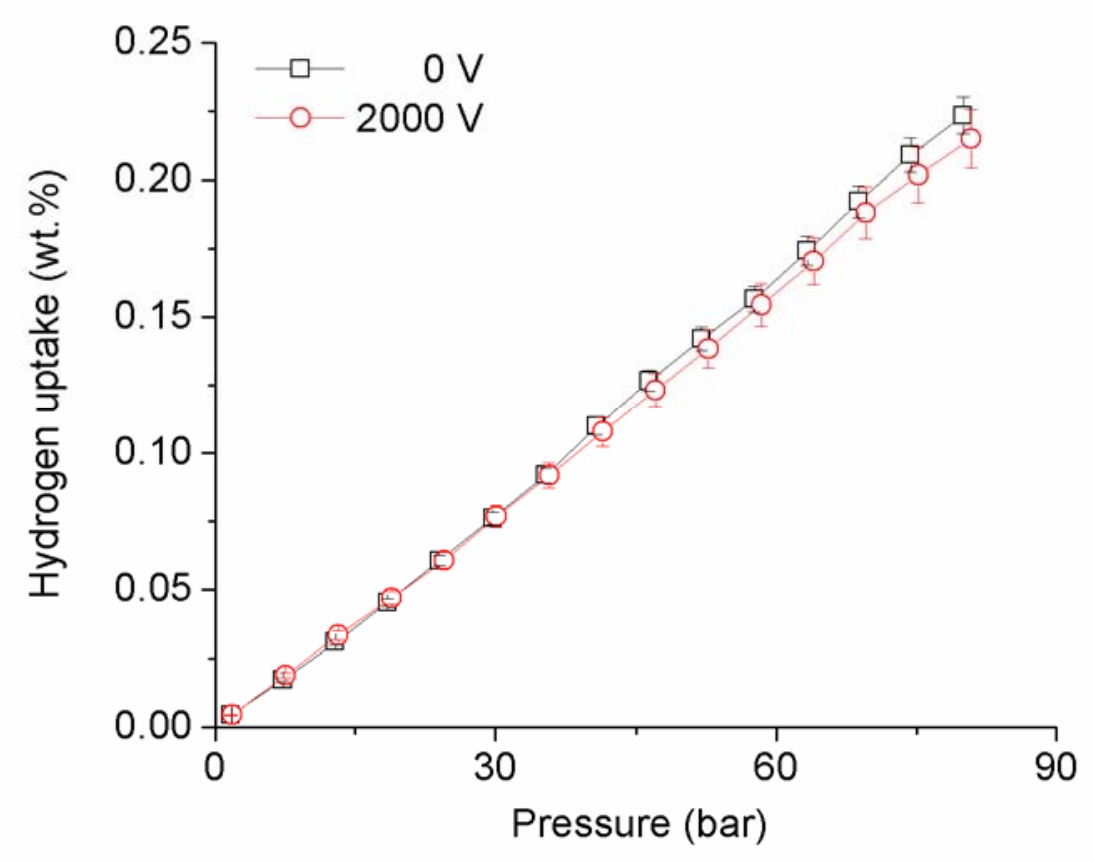

Figure 7.2 Hydrogen adsorption on $\mathrm{ZnO} / \mathrm{Carbon}$ mixture $\mathrm{ZC}$ with and without electric potential

\subsection{Hydrogen adsorption on $\mathrm{BaTiO}_{3} /$ Carbon species}

Figure 7.3 shows the hydrogen adsorption on BC in the presence of absence of a $2000 \mathrm{~V}$ electric potential, respectively. It can be seen that adsorption enhancement showed up under very low hydrogen pressure, and the gap between the curves increase with the increase of the pressure. At 80 bar of hydrogen pressure, adsorption capacities with and without an electric filed were 0.19 and 0.21 wt.\%, indicating $10 \%$ increase. Although the adsorption enhancement is not impressive, it confirms that the adsorption enhancement under electric field is related to separation of activated carbon with material involving high dielectric constant. However, $\mathrm{TiO}_{2}$ and $\mathrm{BaTiO}_{3}$ are materials with relatively large molecular weight, which is not favorable for hydrogen storage with high weight percentage. Many light polymer-based composites with high dielectric constant, such as polyvinylidene fluoride (PVDF) with conductive additive ${ }^{132}$, have been well investigated and can be considered as alternatives in further study. 


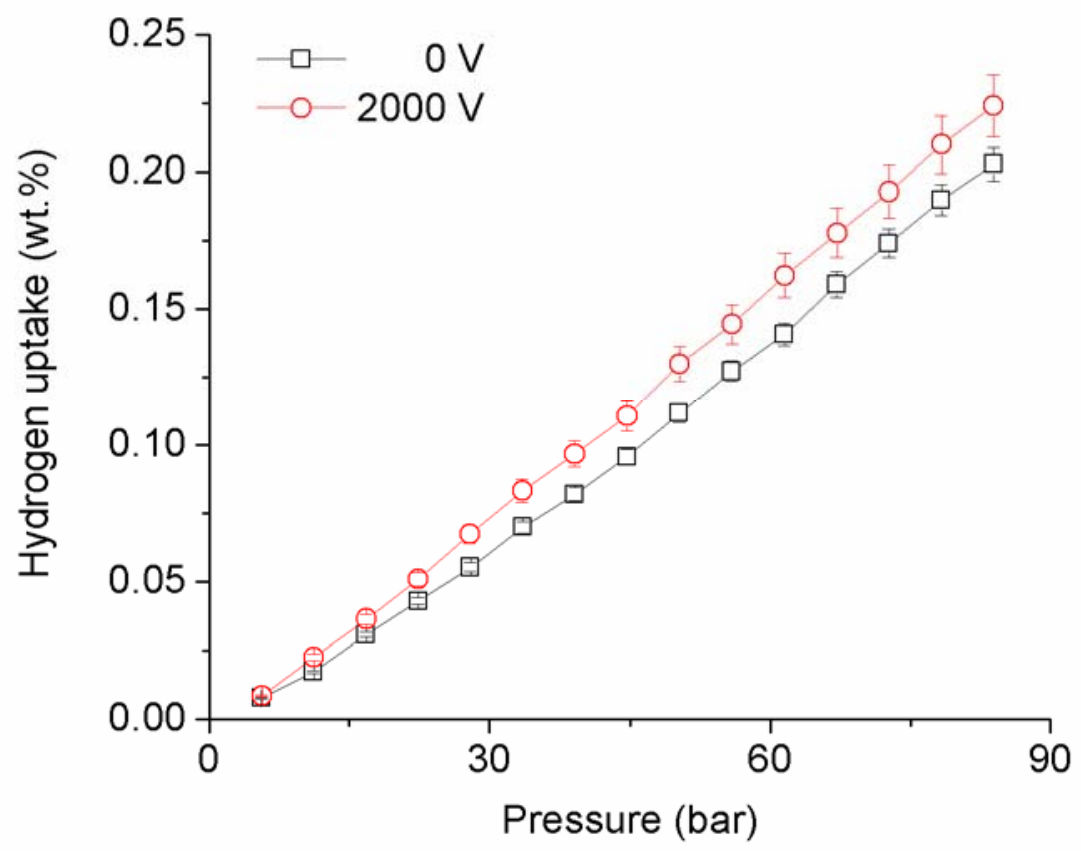

Figure 7.3 Hydrogen adsorption on $\mathrm{BaTiO}_{3} / \mathrm{Carbon}$ mixture $\mathrm{BC}$ with and without electric potential 


\section{CHAPTER 8 COMPUTATIONAL CALCULATIONS}

\subsection{Introduction}

Compared to huge amount lab work, computer modeling is an easier approach to find and evaluate suitable substances for hydrogen storage. For a generic Hydrogen adsorption process, it can be presented using a schematic equation like the one below

$$
n H_{2}+M \rightarrow M\left(H_{2}\right)_{n}
$$

where $\mathrm{M}$ is the substrate for Hydrogen adsorption. Commonly used models with the function of adsorbing $\mathrm{H}_{2}$ molecules include graphitic carbon-based materials ${ }^{133,134}$, metal ${ }^{82}$, metal oxides ${ }^{64,82}$ and combined structures ${ }^{82,135}$.

For theoretical study for the adsorption process outlined in Equation 8.1 under constant temperature and pressure, we will need to evaluate the association (or binding) Gibbs free energy, which can be expressed by

$$
\Delta_{r} G=G\left[M\left(H_{2}\right)_{n}\right]-\left[n G\left(H_{2}\right)+G(M)\right]
$$

In this equation, all Gs on the right hand side are the Gibbs free energy of all species relative the zero point of the state, in which all nuclei and electrons are apart to infinite distance and at rest. So these quantities are different from those normally used in thermal chemistry, in which we usually use quantities like Gibbs free energy of formation. The free energies listed on the right side of equation can be computed theoretically using ab initio methods. 
In order to obtain the association Gibbs free energy $\Delta_{\mathrm{r}} \mathrm{G}$ accurately, it is ideal that the reaction represented by Equation 8.2 would be the one so called "isodesmic", which means that the number of various bonds and lone pairs on both sides of the equation are exactly identical. The reason is that with identical chemical bonds and lone pairs on both sides, the error arising from calculating electronic correlation will mainly be cancelled out by making use of Equation 8.2. And all processes in this project are close to be isodesmic since we expect no intensive chemical bond overlap interaction taking place during the process of hydrogen adsorption, although there are some reports claiming the covalent force involvement.

By definition, association Gibbs free energy $\mathrm{G}$ is calculated according to equations below

$$
\begin{aligned}
& G=H-T S \\
& H=U+P V
\end{aligned}
$$

Here, $\mathrm{P}$ and $\mathrm{V}$ are temperature and volume. $\mathrm{H}, \mathrm{U}$ and $\mathrm{S}$ are enthalpy, internal energy and entropy with the same relative point as $\mathrm{G}$ defined above. $\mathrm{U}$ and $\mathrm{S}$ can be directly computed based on Statistic Mechanics principles, given that energy levels for all energy components are known. The relevant energy components are electronic, vibrational, rotational and translational parts. The latter three are often referred as thermal contribution and have been ignored in many computational works. Electronic energy is necessary to compute total internal energy and entropy and thus enthalpy and Gibbs free energy. Quantum mechanics computations are needed to obtain the electronic energy.

For quantum mechanics computations (ab initio computations), we need to solve the Schrödinger equation for the system with a Hamiltonian given below ${ }^{136}$ 


$$
\begin{aligned}
& H=-\sum_{\mu}^{m} \frac{\hbar^{2}}{2 m_{e}} \nabla_{\mu}^{2}-\sum_{K}^{N} \frac{\hbar^{2}}{2 M_{K}} \nabla_{K}^{2}-\sum_{\mu}^{m} \sum_{K}^{N} \frac{e^{2} Z_{K}}{R_{i K}} \\
& +\sum_{\mu<v} \frac{e^{2}}{R_{\mu \nu}}+\sum_{K<L} \frac{e^{2} Z_{K} Z_{L}}{R_{K L}}
\end{aligned}
$$

On the right hand side of the equation, we have the terms in the order given for the kinetic energy for the $\mathrm{m}$ electrons, kinetic energy for $\mathrm{N}$ nuclei, nuclear-electron attraction, electron-electron repulsion and nuclear-nuclear repulsion. $M_{K}$ is the mass of kth nucleus, $\mathrm{m}_{\mathrm{e}}$ is the electronic mass, $R_{\mu K}$ is the distance between the $\mu$ th electron and Kth nucleus, $R_{\mu v}$ is the distance between the $\mu$ th and vth electrons, and $R_{K L}$ is the distance between the Kth and Lth nuclei. And e is the electronic charge and $Z_{K}$ and $Z_{L}$ are the atomic numbers for Kth and Lth nuclei.

Usually the solution to Schrödinger equation is started with separating electrons from nuclei by invoking so called "Born-Oppenheimer Approximation", which is based on the fact that that protons and neutrons are about 1800 times heavier than electrons ${ }^{136}$. Because of the enormous mass difference, we can assume at any moment, the electrons move in an environment where all nuclear positions are fixed. This makes it possible to separate the motion of the electrons from that of the nuclei. At each specific nuclear configuration, all nuclear coordinates are treated as constants and the electronic wave-function is solved according to the nuclear configuration, so all electronic wave-functions have nuclear coordinates in it as parameters. Then we change the nuclear configuration according to certain algorithm and compute the electronic wave-function again. And this is repeated until the lowest possible electronic energy is reached. The nuclear configuration (nuclei position relative to one another) corresponding to the electronic wave-function with lowest energy is called equilibrium structure. The whole 
process illustrated here is called "geometry optimization" since it a process seeking for the structure with lowest electronic energy.

There are many methods for solving for the electronic wave functions and vibrational analysis, such as RHF (Restricted Hartree-Fock), DFT (Density Functional Theory), MPn ( $\mathrm{n}=1,2,3 \ldots)$ (Meller-Plesset perturbation calculation), CI (Configuration Interaction) and CC (Coupled-/Cluster theory) etc. Usually we expand the wave-function as a series of certain set of known mathematic functions with unknown coefficients. Then the problem is converted to solve for the coefficients, which is normally completed using variation theorem. Those known mathematic functions are often referred as basis sets. For more information please refer to relevant literatures ${ }^{136}$.

In this section, Density Functional Theory investigations corresponding to the experiments have been carried out for more detailed explanations on adsorption mechanisms. Simulations were first performed on interaction of $\mathrm{H}_{2}$ with charged $\mathrm{TiO}_{2}$ molecule. Then, effects of electric field on $\mathrm{H}_{2}$ adsorption over $\mathrm{TiO}_{2}$ molecule, graphene and $\mathrm{TiO}_{2}$-doped graphene were studied.

\subsection{Computational methods}

DFT calculations in this section were all performed with the program Gaussian $09^{137}$, using the B3LYP functional and the LANL2DZ basis sets for all atom types. LANL2DZ has been widely used in quantum chemistry, particularly in the calculations of transition metal compounds ${ }^{138,139}$. The coronene molecule $\left(\mathrm{C}_{24} \mathrm{H}_{12}\right)$ was chosen as the model for graphite surface, as shown in Figure 8.1. Previous studies have shown that coronene is a reliable model for the graphite (0001) surface ${ }^{140,141}$. A $\mathrm{TiO}_{2}$ molecule was used to represent the metal oxide phase. 


\section{top view}

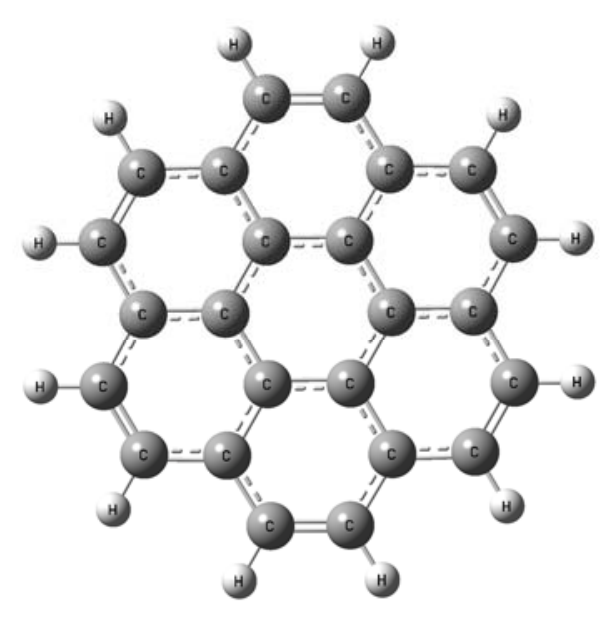

front view

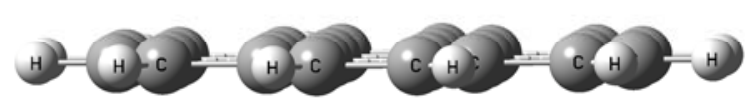

Figure 8.1 Structure of coronene

The total adsorption energy under an electric filed (f) was calculated by the difference between the total energy of the whole adsorption system and the total energy of the separate objects before combination, as presented in flowing equation:

$$
E_{a d}=E_{f}\left(H_{2}+S\right)-E_{f}(S)-E_{f}\left(H_{2}\right)
$$

where $E_{a d}$ is the adsorption energy, $E_{f}\left(S+H_{2}\right)$ is the total energy of the whole adsorption system in the presence of an electric field (f), $\mathrm{E}_{\mathrm{f}}(\mathrm{S})$ and $\mathrm{E}_{\mathrm{f}}\left(\mathrm{H}_{2}\right)$ stand for the energy of the substrate $\mathrm{H}_{2}$ and the $\mathrm{H}_{2}$ molecule under the intensity field $\mathrm{f}$. The negative value of $\mathrm{E}_{\mathrm{ad}}$ indicates that the adsorption is exothermic, while the positive means endothermic. 


\subsection{Results and discussion}

\subsubsection{Hydrogen adsorption on charged $\mathrm{TiO}_{2}$ molecule}

The simulations on $\mathrm{H}_{2}$ adsorption with charged $\mathrm{TiO}_{2}$ molecule were first addressed, starting with the structure shown in Figure 8.2. The optimized geometries and adsorption energies are readily seen in Table 8.1. The free hydrogen molecule optimized by B3LYP/LANL2DZ possesses an H-H bond length of $0.7435 \AA$. The interaction of $\mathrm{H}_{2}$ and neutral $\mathrm{TiO}_{2}$ molecule shows a slightly enlongated $\mathrm{H}-\mathrm{H}$ bond, indicating a small perturbation from the $\mathrm{TiO}_{2}$ molecule. When $\mathrm{H}_{2}$ interacts with negatively charged $\mathrm{TiO}_{2}$ molecule, the shorter bond distance of $4 \mathrm{H}-2 \mathrm{Ti}$ and $5 \mathrm{H}-2 \mathrm{Ti}$ illustrate that the $\mathrm{H}_{2}$ has been attracted closer to the $\mathrm{TiO}_{2}$. As a result, the binding energy increases dramatically to $-7.8838 \mathrm{~kJ} / \mathrm{mol}$, which is almost three times that of $\mathrm{H}_{2}$ and neutral $\mathrm{TiO}_{2}$. For the case of positively charged $\mathrm{TiO}_{2}$ molecule as the adsorption substrate, the hydrogen molecule is less perturbed due to a shorter $\mathrm{H}-\mathrm{H}$ bond and thus weakly tied to the $\mathrm{TiO}_{2}$. These phenomena are consistent with the experimental observations.

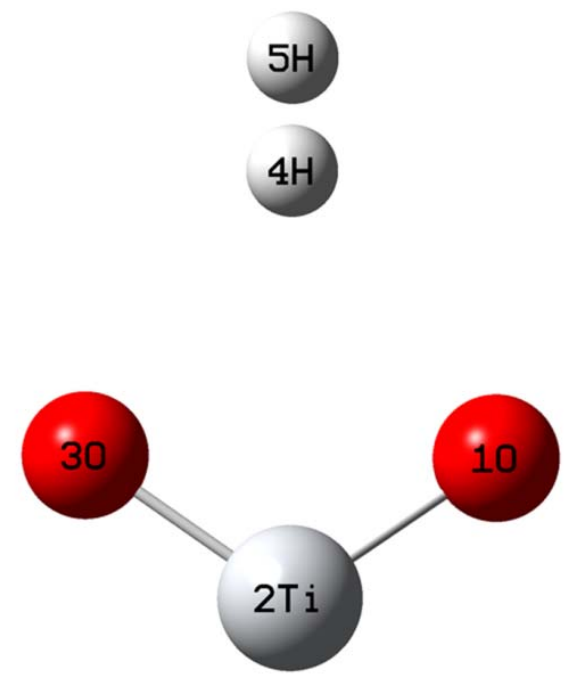

Figure 8.2 Initial state of $\mathrm{H}_{2}-\mathrm{TiO}_{2}$ system 
Table 8.1

Geometric parameters and binding energies of $\mathrm{H}_{2}$ and charged $\mathrm{TiO}_{2}$

\begin{tabular}{lllll}
\hline \multirow{2}{*}{ Charge } & \multicolumn{3}{c}{ Bond length $(\AA)$} & Binding energy \\
\cline { 2 - 4 } & $4 \mathrm{H}-5 \mathrm{H}$ & $4 \mathrm{H}-2 \mathrm{Ti}$ & $5 \mathrm{H}-2 \mathrm{Ti}$ & $\mathbf{( k J / m o l )}$ \\
\hline 0 & 0.7451 & 3.6233 & 4.3685 & -2.8597 \\
-1 & 0.7483 & 3.3640 & 4.1123 & -7.8838 \\
1 & 0.7441 & 4.0795 & 4.8236 & -1.1762 \\
\hline
\end{tabular}

\subsubsection{Hydrogen adsorption on $\mathrm{TiO}_{2}$ molecule under electric field}

Initial state $\mathrm{H}_{2}$ and $\mathrm{TiO}_{2}$ molecule is the same as the structure shown in Figure 8.2. Electric field is parallel to the plane that all the atoms locate. The positive direction of electric field is defined as upward and the negative is downward. The optimized geometries and binding results of $\mathrm{H}_{2}$ and $\mathrm{TiO}_{2}$ in the presence of an electric field are listed in Table 8.2. As shown in the table, in the field range of $\mathrm{f}=0-+0.06 \mathrm{au}, \mathrm{H}-\mathrm{H}$ bond length increases with the increasing electric field strength, and meanwhile the distance between $\mathrm{H}$ atoms and Ti decreases with the increasing field. With applied electric fields of +0.05 and +0.06 au, the binding affinities lie between $20-40 \mathrm{~kJ} / \mathrm{mol}$, indicating reversible hydrogen storage. The calculations confirm that a positive field can evidently improve the interaction between $\mathrm{H}_{2}$ and $\mathrm{TiO}_{2}$. In contrast, opposite binding trends are observed when direction of the field is reversed although the decreases are not significant.

Simulations with stronger electric field have not been conducted. However, it is reasonable to predict that $\mathrm{H}-\mathrm{H}$ bond would be further elongated under stronger field. As a result, hydrogen molecule becomes unstable and is prone to get ionized or broken when electric field is strong enough. This deduction can be confirmed in the light of findings from Zhou et al. ${ }^{95}$, which illustrated molecular hydrogen adsorption is achieved only 
below a certain critical electric field. Hydrogen atoms or ions can be more easily captured than molecules, leading to a promising storage capacity.

Table 8.2

Geometric parameters and binding energies of $\mathrm{H}_{2}$ and $\mathrm{TiO}_{2}$ under electric field

\begin{tabular}{llllr}
\hline \multirow{2}{*}{$\begin{array}{c}\text { E field f } \\
(\mathbf{a u})\end{array}$} & $4 \mathrm{H}-5 \mathrm{H}$ & $4 \mathrm{H}-2 \mathrm{Ti}$ & $5 \mathrm{H}-2 \mathrm{Ti}$ & $\begin{array}{c}\text { Binding energy } \\
(\mathbf{k J} / \mathbf{m o l})\end{array}$ \\
\cline { 2 - 4 } 0 & 0.7451 & 3.6233 & 4.3685 & -2.8597 \\
+0.01 & 0.7469 & 3.5002 & 4.2471 & -4.6790 \\
+0.02 & 0.7504 & 3.4082 & 4.1586 & -7.4171 \\
+0.03 & 0.7564 & 3.3060 & 4.0623 & -11.3564 \\
+0.04 & 0.7655 & 3.2207 & 3.9861 & -16.9582 \\
+0.05 & 0.7793 & 3.1499 & 3.9292 & -24.9291 \\
+0.06 & 0.8014 & 3.0915 & 3.8929 & -36.5103 \\
\hline-0.01 & 0.7449 & 3.7413 & 4.4862 & -1.8387 \\
-0.02 & 0.7461 & 3.9400 & 4.6862 & -1.6179 \\
\hline
\end{tabular}

\subsubsection{Hydrogen adsorption on coronene under electric field}

The initial state of $\mathrm{H}_{2}$-coronene system is shown in Figure 8.3. Electric fields were applied perpendicular to the coronene plane, in the upward (+) or downward (-).The optimized geometries and adsorption energies of $\mathrm{H}_{2}$ and coronene are given in Table 8.3. Little bonding energy is obtained between hydrogen molecule and coronene plane without the presence of electric field, which can be taken as the reason of the negligible adsorption capacity over carbon materials at ambient temperature. Compared to $\mathrm{H}-\mathrm{H}$ bond of free hydrogen molecule $(0.7435 \AA)$, only a tiny perturbation occurs to hydrogen molecule. When a positive electric field is applied, an improvement in adsorption energy and an increase in $\mathrm{H}-\mathrm{H}$ bond length are observed, which indicate a stronger interaction. 
An electric field with a higher intensity further strengthens the binding between $\mathrm{H}_{2}$ and coronene. Additionally, the application of negative field also leads to some increase in binding energy. However, it is noted that the improvements are very small and corresponding influences in hydrogen adsorption capacity should be negligible. As discussed in previous chapter, our experimental observations did not show any increase in storage capacity. Furthermore, Shi et al. ${ }^{93}$ reported a slight adsorption enhancement over activated carbon with a $2000 \mathrm{~V}$ applied voltage. Therefore, introduction of electric field to pristine carbon materials is unlikely to efficiently improve the hydrogen adsorption capacities.

top view

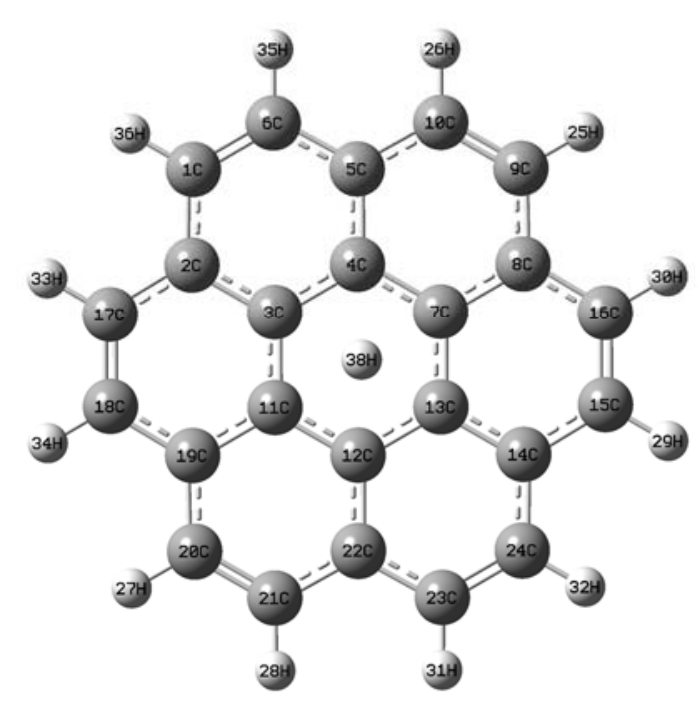

front view

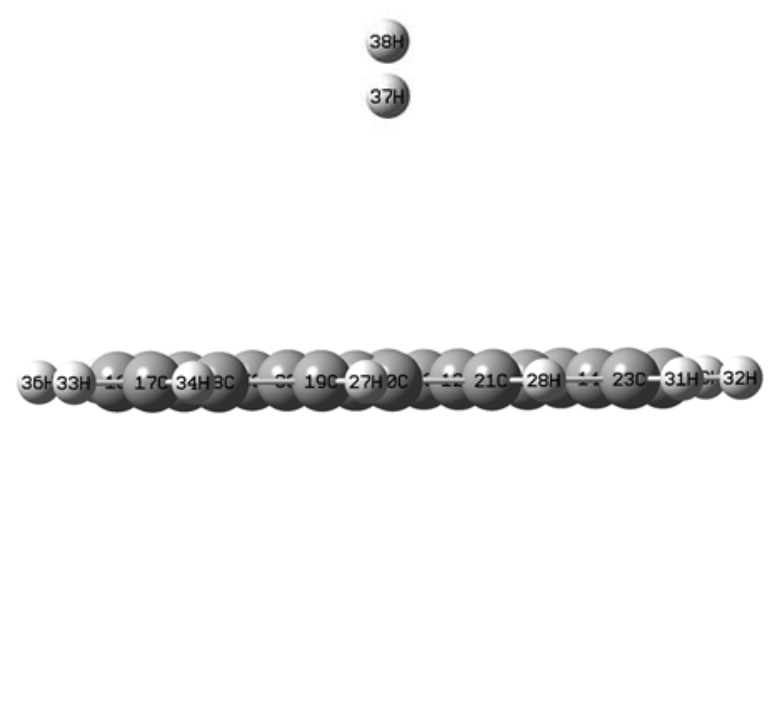

Figure 8.3 Initial state of $\mathbf{H}_{2}$-coronene system 
Table 8.3

Geometric parameters and binding energies of $\mathrm{H}_{2}$ and coronene under electric field

\begin{tabular}{llllr}
\hline \multicolumn{1}{c}{$\begin{array}{c}\text { E field f } \\
\text { (au) }\end{array}$} & \multicolumn{3}{c}{ Bond length $(\AA)$} & Binding energy \\
\cline { 2 - 4 } & $37 \mathrm{H}-38 \mathrm{H}$ & $37 \mathrm{H}-3 \mathrm{C}$ & $38 \mathrm{H}-3 \mathrm{C}$ & \multicolumn{1}{c}{$(\mathbf{k J} / \mathbf{m o l})$} \\
\hline 0 & 0.7436 & 4.1462 & 4.8503 & 0.0667 \\
+0.01 & 0.7443 & 4.0530 & 4.7559 & -0.4895 \\
+0.02 & 0.7465 & 3.5700 & 3.5729 & -1.7870 \\
\hline-0.01 & 0.7439 & 11.1292 & 11.8672 & 0.0005 \\
-0.02 & 0.7455 & 3.7363 & 4.4333 & -0.1639 \\
\hline
\end{tabular}

\subsubsection{Hydrogen adsorption on $\mathrm{TiO}_{2}$-doped coronene under electric field}

The initial state of $\mathrm{H}_{2}-\mathrm{TiO}_{2}$-coronene system is shown in Figure 8.4. Electric fields were also applied perpendicular to the coronene plane, in the upward (+) or downward (-). Considering different doping sites, our simulations showed that the most stable position for $\mathrm{TiO}_{2}$ is perpendicularly lying above the center of the middle ring. Optimized geometries and adsorption energies of $\mathrm{H}_{2}$ and $\mathrm{TiO}_{2}$-doped coronene are given in Table 8.4. Calculations with $\mathrm{TiO}_{2}$ doping showed a much higher binding energy in the absence of a field than that of pristine coronene. Given the weak adsorption energy for hydrogen on pristine coronene, the hydrogen storage capacity can be significantly increased via $\mathrm{TiO}_{2}$ doping. However, $\mathrm{TiO}_{2}$ itself has a large molecular weight, which is not beneficial to a high storage capacity. When a 0.005 au electric field is introduced, binding energy increases by $2.44 \mathrm{~kJ} / \mathrm{mol}$, corresponding to a $38 \%$ binding enhancement. Moreover, an approximate $100 \%$ enhancement of binding energy is achieved with the presence of a 0.01 au field. It is also found in the table that the $\mathrm{H}-\mathrm{H}$ bond increases with the increasing strength of electric field, which is identical to the energy data.

The simulations show that a stronger electric field can lead to more intensive interactions 
between $\mathrm{H}_{2}$ and $\mathrm{TiO}_{2}$-doped graphene. The phenomenon seems very different from the experimental results, which indicated a decreased storage capacity with $3000 \mathrm{~V}$ electric potential. As discussed before, the strong interaction between $\mathrm{H}_{2}$ and $\mathrm{TiO}_{2}$ under electric field makes $\mathrm{H}_{2}$ ionized. The formation and transportation of hydrogen ions is responsible for a reduced adsorption under relatively strong electric field. Although the calculations here failed to show the formation and transportation of hydrogen ions, they provided the reason of a stronger interaction between adsorbate and adsorbent under field, which is consistent with our experimental observations.

top view

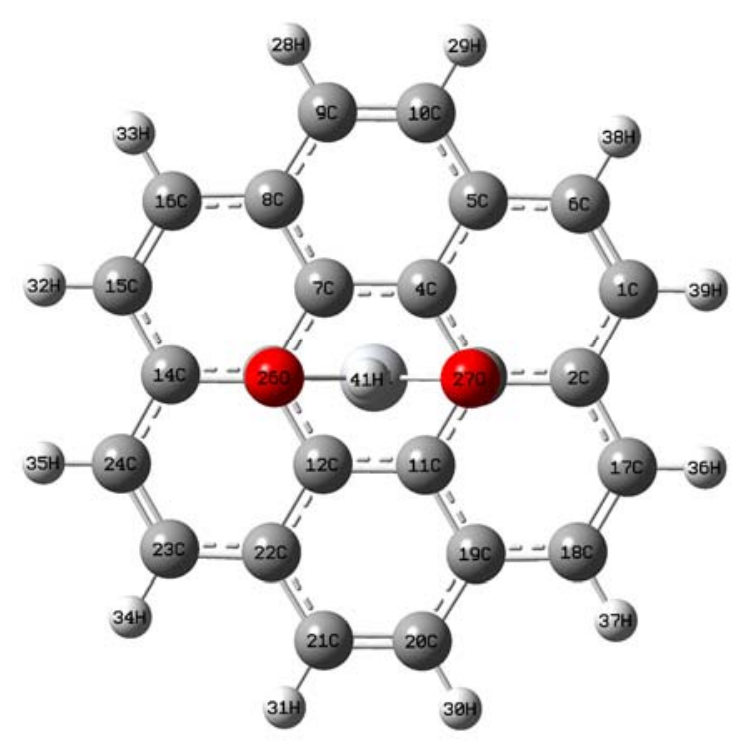

front view

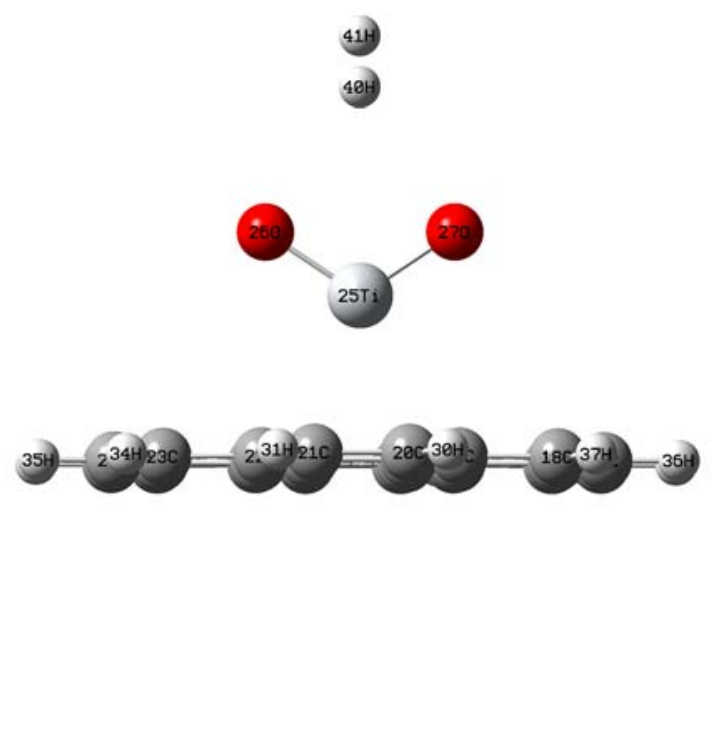

Figure 8.4 Initial state of $\mathrm{H}_{2}$-TiO - -coronene system 
Table 8.4

Geometric parameters and binding energies of hydrogen and $\mathrm{TiO}_{2}$-doped coronene under electric field

\begin{tabular}{|c|c|c|c|c|c|}
\hline \multirow{2}{*}{$\begin{array}{c}\text { E field f } \\
\text { (au) }\end{array}$} & \multicolumn{4}{|c|}{ Bond length (Å) } & \multirow{2}{*}{$\begin{array}{c}\text { Binding energy } \\
(\mathrm{kJ} / \mathrm{mol})\end{array}$} \\
\hline & $40 \mathrm{H}-41 \mathrm{H}$ & $40 \mathrm{H}-25 \mathrm{Ti}$ & $41 \mathrm{H}-25 \mathrm{Ti}$ & $40 \mathrm{H}-3 \mathrm{C}$ & \\
\hline 0 & 0.7485 & 4.0083 & 4.7545 & 5.5529 & -6.4592 \\
\hline 0.005 & 0.7511 & 3.8474 & 4.5857 & 5.6476 & -8.9008 \\
\hline 0.01 & 0.7552 & 3.7337 & 4.4699 & 6.9294 & -12.6368 \\
\hline
\end{tabular}




\section{CHAPTER 9 SUMMARY AND CONCLUSIONS}

In this project, a hydrogen storage system has been developed and used to investigate the effect of an applied electric field on hydrogen adsorption over activated carbon separated by different dielectric materials. The experimental results indicated that introducing an electric field to the activated carbon materials partitioned with high dielectric materials, such as $\mathrm{TiO}_{2}$ and $\mathrm{BaTiO}_{3}$, could efficiently improve the hydrogen adsorption at ambient temperature.

Intensive experimental studies have been performed on $\mathrm{TiO}_{2}$-coated activated carbon. A $1000 \mathrm{~V}$ electric potential was applied to synthetics with different $\mathrm{TiO}_{2}$ contents. Increasing enhancements of $29 \%, 43 \%$ and $65 \%$ were obtained at 80 bar for the samples containing 4.8, 9.1 and $13.0 \mathrm{wt} . \% \mathrm{TiO}_{2}$, respectively. No improvement was observed for the sample with $1.0 \mathrm{wt} . \%$ due to the poor isolation of carbon particles. Normalized adsorption by the BET surface area further revealed that, under an electric field, the amount of hydrogen adsorbed on a specific area increased with the increasing $\mathrm{TiO}_{2}$ content. Electric fields with various strengths were subsequently introduced to a carbon sample coated with 18.8 wt.\% $\mathrm{TiO}_{2}$ nanoparticles. The results showed the hydrogen uptake first increased and then decreased with the increasing strength of electric field. Enhanced storage capacities were observed when the applied electric potentials were no greater than $2000 \mathrm{~V}$. The most significant adsorption enhancement was obtained at 1000 $\mathrm{V}$, which showed a $51 \%$ increase at 80 bar. Experiment was also carried out on $\mathrm{TiO}_{2}$ coated Pt/AC. Exceptionally high enhancement of $185 \%$ was achieved at 80 bar with a $2000 \mathrm{~V}$ applied electric potential.

The addition of dielectric $\mathrm{TiO}_{2}$ to carbon isolates carbon particles, resulting in an 
enlarged charged zone and increased charges with applied electric field. The charges are responsible for the stronger electrostatic interaction between hydrogen and the solid surface. A large amount of hydrogen molecules may be ionized under a sufficiently high electric field, resulting in a reduced hydrogen uptake.

Density Functional Theory calculations related to the experiments were also conducted and consistent with the observations. It was found that, under an external electric field, adsorption energy between hydrogen and $\mathrm{TiO}_{2}$-doped coronene is much higher than that in the absence of a field, leading to the enhancement in adsorption capacity.

The findings from this work indicated a potential for developing high-capacity hydrogen storage system. Further studies can be focused on the search of a light weight dielectric phase, which is an ideal hydrogen adsorbent. Limitation of current devices for hydrogen adsorption testing is also a big issue needing attentions. 


\section{REFERENCES}

1. Davis SC, Diegel SW, Boundy RG. U.S. Transportation Energy Data Book. $29^{\text {th }}$ Ed. Washington, D.C.: Department of Energy Press; 2010.

2. Environment News Service. New York: Environment News Service. Bush Hydrogen Initiative Faces Many Obstacles; 2003 [updated 2003 Feb 6, cited 2012 Mar 22].

Available from:

http://www.ens-newswire.com/ens/feb2003/2003-02-06-10.html

3. National Research Council (U.S.), National Academy of Engineering (U.S.). 2004.

The Hydrogen Economy: Opportunities, Costs, Barriers, and R\&D Needs. Washington D.C.: National Academies Press.

4. $\mathrm{Hu}$ YH. 2010. Materials for Energy Applications (Courseware). Houghton, MI: Michigan Technological University.

5. Haryanto A, Fernando S, Murali N, Adhikari S. Current status of hydrogen production techniques by steam reforming of ethanol: a review. Energy Fuels. 2005;19:2098-2106.

6. U.S. Department of Energy. A national vision of Amreica's transition to a hydrogen economy to 2030 and beyond. Washington, DC: U.S. Department of Energy Press; 2002.

7. Ohi J. Hydrogen energy cycle: an overview. Journal of Materials Research. $2005 ; 20: 3180-3187$.

8. EERE Information Center - U.S. Department of Energy. Washington, DC: U.S. Department of Energy. Comparison of fuel cell technologies; 2011[updated 2011 Feb, cited 2012 Mar 22].

Available from: 
http://www1.eere.energy.gov/hydrogenandfuelcells/fuelcells/pdfs/fc_comparison chart.pdf

9. EERE Information Center - U.S. Department of Energy. Washington, DC: U.S. Department of Energy. Types of fuel cells; 2011[updated 2011 Mar 8, cited 2012 Mar 22].

Available from:

http://www1.eere.energy.gov/hydrogenandfuelcells/fuelcells/fc types.html\#pem

10. Zhou L. Progress and problems in hydrogen storage methods. Renewable \& Sustainable Energy Reviews. 2005;9:395-408.

11. Fichtner M. Nanotechnological aspects in materials for hydrogen storage. Advanced Engineering Materials. 2005;7(6):443-455.

12. Züttel A. Materials for hydrogen storage. Materialstoday. 2003;6(9):23-33.

13. EERE Information Center - U.S. Department of Energy. Washington, DC: U.S. Department of Energy. 2011interim update: Technical plan - storage; 2011 [updated 2011, cited 2012 Mar 22].

Available from:

http://www1.eere.energy.gov/hydrogenandfuelcells/mypp/pdfs/storage.pdf

14. Züttel A. Hydrogen storage methods. Naturwissenschaften. 2004;91:157-172.

15. Eberle U, Felderhoff M, Schüth. Chemical and Physical solutions for hydrogen storage. Angewandte Chemie International Edition. 2009;48:6608-6630.

16. Selvam P, Visvanathan B, Swamy CS, Srinivasan V. Magnesium and magnesium alloy hydrides. International Journal of Hydrogen Energy. 1986;11(3):169-192.

17. Libowitz GG, Hayes HF, Gibb TRP Jr. The system zircoium-nickel and hydrogen. Journal of Physical Chemistry. 1958;62(1):76-79.

18. Reilly JJ Jr, Wiswall RH Jr. Reaction of hydrogen with alloys of magnesium and 
nickel and the formation of $\mathrm{Mg}_{2} \mathrm{NiH}_{4}$. Inorganic Chemistry. $1968 ; 7(11): 2254-2256$.

19. Reilly JJ Jr, Wiswall RH Jr. Formation and properties of iron titanium hydride. Inorganic Chemistry. 1974;13(1):218-222.

20. Sakintuna B, Lamari-Darkim F, Hirscher M. Metal hydride materials for solid hydrogen storage: a review. International Journal of Hydrogen Energy. 2007;32(9):1121-1140.

21. Bogdanovic B, Schwickardi M. Ti-doped alkali metal aluminium hydrides as potential novel reversible hydrogen storage materials. Journal of Alloys and Compounds. 1997;253-254:1-9.

22. Orimo S, Nakamori Y, Eliseo JR, Züttle A, Jensen CM. Complex hydrides for hydrogen storage. Chemical Reviews. 2007;107(10):4111-4132.

23. Dafert FW, Miklauz R. Über einige neue Verbindungen von Stickstoff und Wasserstoff mit Lithium. Monatshefte für Chemie. 1910;31:981-996.

24. Graetz J. New approach to hydrogen storage. Chemical Society Reviews. 2009;38:73-82.

25. Yurum Y, Taralp A, Veziroglu TN. Storage of hydrogen in nanostructured carbon materials. International Journal of Hydrogen Energy. 2009;34:3784-3798.

26. Gupta BK, Tiwari RS, Srivastava ON. Studies on synthesis and hydrogenation behaviour of graphitic nanofibres prepared through palladium catalyst assisted thermal cracking of acetylene. Journal of Alloys and Compounds. 2004;381(1-2):301-308.

27. de la Casa-Lillo MA, Lamari-Darkrim F, Cazorla-Amorós D, Linares-Solano A. Hydrogen storage in activated carbons and activated carbon fibers. Journal of Physical Chemistry B. 2002;106(42):10930-10934.

28. Bauqhman RH, Zakhidov AA, de Heer WA. Carbon nanotubes - the route toward 
applications. Science. 2002;297(5582):787-792.

29. Ansón A, Callejas MA, Benito AM, Maser WK, Lzquierdo MT, Rubio B, Jagiello J, Thommes M, Parra JB, Martínez MT. Hydrogen adsorption studies on single wall carbon nanotubles. Carbon. 2004;42(7):1243-1248.

30. Cao D, Feng P, Wu J. Molecular simulation of novel carbonaceous materials for hydrogen storage. Nano Letters. 2004;4(8):1489-1492.

31. Dillon AC, Heben MJ. Hydrogen storage using carbon adsorbents: past, present and future. Applied Physics A: Materials Science \& Processing. 2001;72(2):133-142.

32. Yang Z, Xia Y, Mokaya R. Enhanced hydrogen storage capacity of high surface area zeolite-like carbon materials. Journal of the American Chemical Society. 2007;129(6):1673-1679.

33. Kayiran SB, Lamari FD, Levesque D. Adsorption properties and structural characterization of activated carbons and nanocarbons. Journal of Physical Chemistry B. 2004;108(39):15211-15215.

34. Wang LF, Yang RT. New sorbent for hydrogen storage by hydrogen spillover -- a review. Energy \& Environmental Science. 2008;1(2):268-279.

35. Dillon AC, Jones KM, Bekkedahl TA, Kiang $\mathrm{CH}$, Bethune DS, Heben MJ. Storage of hydrogen in single-walled carbon nanotubes. Nature. 1997;386:377-379.

36. Pandey SK, Singh RK, Srivastava ON. Investigations on hydrogenation behavior of CNT admixed $\mathrm{Mg}_{2} \mathrm{Ni}$.Internaltional Journal of Hydrogen Energy. 2009;34:9378-9384.

37. Heine T, Zhechkov L, Seifert G. Hydrogen storage by physisorption on nanostructured graphite platelets. Physical Chemistry Chemical Physics. 2004;6:980-984. 
38. Chen $\mathrm{P}, \mathrm{Wu} \mathrm{X}$, Lin J, Tan KL. High $\mathrm{H}_{2}$ uptake by alkali-doped carbon nanotubes under ambient pressure and moderate temperatures. Science. 1999;285:91-93.

39. Tibbetts GG, Meisner GP, Olk CH. Hydrogen storage capacity of carbon nanotubes, filaments, and vapor grown fibers. Carbon. 2001;39(15):2291-2301.

40. Yang RT. Hydrogen storage by alkali-doped carbon nanotubes - revisited. Carbon. 2000;38:623-641.

41. Shiraishi M, Takenobu T, Kataura H, Ata M. Hydrogen adsorption and desorption in carbon nanotube systems and its mechanisms. Applied Physics A. 2004;78:947-954.

42. Kayiran SB, Lamari FD, Levesque D. Adsorption properties and structural characterization of activated carbons and nanocarbons. Journal of Physical Chemistry B. 2004;108(39):15211-15215.

43. Jin H, Lee YS, Hong I. Hydrogen adsorption characteristics of activated carbon. Catalysis Today. 2007;120(3-4):399-406.

44. Züttel A, Nützenadel Ch, Sudan P, Mauron Ph, Emmenegger Ch, Rentsch S, Schlapbach L, Weidenkaff A, Kiyobayashi T. Hydrogen sorption by carbon nanotubes and other carbon nanostructures. Journal of Alloys and Compounds. 2002;330-332:676-682.

45. Zheng $\mathrm{Q}, \mathrm{Gu} \mathrm{A}, \mathrm{Lu} \mathrm{X}$, Lin W. Temperature-dependent state of hydrogen molecules within the nanopore of multi-walled carbon nanotubes. International Journal of Hydrogen Energy. 2004;29(5):481-489.

46. Thomas KM. Hydrogen adsorption and storage on porous materials. Catalysis Today. 2007;120(3-4):389-398.

47. Ye Y, Ahn CC, Witham C, Fultz B, Liu J, Rinzler AG. Hydrogen adsorption and cohesive energy of single-walled carbon nanotubes. Applied Physics Letters. 1999;74:2307-2309. 
48. Rosi NL, Eckert J, Eddaoudi M, Vodak DT, Kim J, O’Keeffe M, Yaghi OM. Hydrogen storage in microporous metal-organic frameworks. Science. 2003;300(5622):1127-1129.

49. Yildirim T, Hartman MR. Direct observation of hydrogen adsorption sites and nanocage formation in metal-organic frameworks. Physical Review Letters. 2005;95(21):215504 1-4.

50. Li H, Eddaoudi M, O’Keeffe M, Yaghi OM. Design and synthesis of an exceptionally stable and highly porous metal -organic framework. Nature. 1999;402:276-279.

51. Hirscher M, Panella B, Schmitz B. Metal-organic frameworks for hydrogen storage. Microporous and Mesoporous Materials. 2010;129:335-339.

52. $\mathrm{Hu} \mathrm{YH}$, Zhang L. Hydrogen storage in metal-organic frameworks. Advanced Energy Materials. 2010;22:E117-E130.

53. Yang Q, Zhong C. Molecular simulation of adsorption and diffusion of hydrogen in metal-organic frameworks. Journal of Physical Chemistry B. 2005;109(24):11862-11864.

54. Rowsell JLC, Eckert J, Yaghi OM. Characterization of $\mathrm{H}_{2}$ binding sites in prototypical metal-organic frameworks by inelastic neutron scattering. Journal of the American Chemical Society. 2005;127(42):14904-14910.

55. Rowsell JLC, Millward AR, Park KS, Yaghi OM. Hydrogen sorption in functionalized metal-organic frameworks. Journal of the American Chemical Society. 2004;126:5666-5667.

56. Rowsell JLC, Yaghi OM. Effects of functionalization, catenation, and variation of the metal oxide and organic linking units on the low-pressure hydrogen adsorption properties of metal-organic frameworks. Journal of the American Chemical Society. 2006;128:1304-1315. 
57. Chae H, Siberio-Perez DY, Kim J, Go Y, Eddaoudi M, Matzger AJ, O'Keeffe M, Yaghi OM. A route to high surface area, porosity and inclusion of large molecules in crystals. Nature. 2004, 427, 523-527.

58. Furukawa H, Miller M, Yaghi OM. Independent verification of the saturation hydrogen uptake in MOF-177 and establishment of a benchmark for hydrogen adsorption in metal-organic frameworks. Journal of Materials Chemistry. 2007; 17:3197-3204.

59. Berman A, Karn RK, Epstein M. Steam reforming of methane on a $\mathrm{Ru} / \mathrm{Al}_{2} \mathrm{O}_{3}$ catalyst promoted with $\mathrm{Mn}$ oxides for solar hydrogen production. Green Chemistry. 2007;9(6):626-631.

60. $\mathrm{Hu} \mathrm{YH}$, Ruckenstein E. Catalytic conversion of methane to synthesis gas by partial oxidation and $\mathrm{CO}_{2}$ reforming. Advances in Catalysis. 2004;48:297-345.

61. Li Y, Li X, Li J, Yin J. Photocatalytic degradation of methyl orange by $\mathrm{TiO}_{2}$-coated activated carbon and kinetic study. Water Research. 2006;40:1119-1126.

62. Wang J, Wang L, Ma Li, Zhao J, Wang B, Wang G. Structures, electronic properties, and hydrogen-storage capacity of single-wall $\mathrm{TiO}_{2}$ nanotubes. Physica E. 2009;41:838-842.

63. Dai XP, Li RJ, Yu CC, Hao ZP. Unsteady-state direct partial oxidation of methane to synthesis gas in a fixed-bed reactor using $\mathrm{AFeO}_{3}(\mathrm{~A}=\mathrm{La}, \mathrm{Nd}, \mathrm{Eu})$ perovskite-type oxides as oxygen storage. Journal of Physical Chemistry B. 2006;110(45):22525-22531.

64. Sun X, Hwang JY, Shi SZ. Hydrogen storage in mesoporous metal oxide with catalyst and external electric field. Journal of Physical Chemistry C. 2010;114(15):7178-7184.

65. Korotcenkov G. Metal oxides for solid-state gas sensors: What determines our 
choice? Materials Science and Engineering B. 2007;139(1):1-23.

66. Bushnell JE, Kemper PR, Maitre P, Bowers MT. Insertion of $\mathrm{Sc}^{+}$into $\mathrm{H}_{2}$ : The first example of cluster-mediated $\sigma$-bond activation by a transition metal center. Journal of the American Chemical Society. 1994;116(21):9710-9718.

67. Manard MJ, Bushnell JE, Bernstein SL, Bowers MT. Origin of bonding interactions in $\mathrm{Cu}_{2}^{+}\left(\mathrm{H}_{2}\right)_{\mathrm{n}}$ clusters: An experimental and theoretical investigation. Journal of Physical Chemistry A. 2002;106(42):10027-10032.

68. Mishra A, Banerjee S, Mohapatra SK, Graeve OA, Misra M. Synthesis of carbon nanotube- $\mathrm{TiO}_{2}$ nanotubular material for reversible hydrogen storage. Nanotechnology. 2008;19(44):445607-445613.

69. Rather S, Mehraj-ud-din N, Zacharia R, Hwang SW, Kim AR, Nahm KS. Hydrogen storage of nanostructured $\mathrm{TiO}_{2}$-impregnated carbon nanotubes. International Journal of Hydrogen Energy. 2009;34(2):961-966.

70. Lim SH, Luo J, Zhong Z, Ji W, Lin J. Room-temperature hydrogen uptake by $\mathrm{TiO}_{2}$ nanotubes. Inorganic Chemistry. 2005;44(12):4124-4126.

71. Bavykin DV, Lapkin AA, Plucinski PK, Friedrich JM, Walsh FC. Reversible storage of molecular hydrogen by sorption into multilayered $\mathrm{TiO}_{2}$ nanotubes. Journal of Physical Chemistry B. 2005;109(41):19422-19427.

72. Pan H, Luo J, Sun H, Feng Y, Poh C, Lin J. Hydrogen storage of ZnO and Mg doped ZnO nanowires. Nanotechnology. 2006;17:2963-2967.

73. Ahmad M, Rafi-ud-Din, Pan C, Zhu J. Investigation of hydrogen storage capacities of ZnO-based nanostructures. Physical Chemistry C. 2010;114(6):2560-2565.

74. Dag S, Ozturk Y, Ciraci S, Yildirim T. Adsorption and dissociation of hydrogen molecules on bare and functionalized carbon nanotubes. Physical Review B. 2005;72 (15):155404-155411. 
75. Lueking AD, Yang RT. Hydrogen spillover from a metal oxide catalyst onto carbon nanotubes -- implications for hydrogen storage. Journal of Catalysis. 2002;206(1):165-168.

76. Lueking AD, Yang RT. Hydrogen spillover to enhance hydrogen storage - study of the effect of carbon physicochemical properties. Applied Catalysis A. 2004;265:259-268.

77. Yang FH, Lachawiec AJ, Yang RT. Adsorption of spillover hydrogen atoms on single-wall carbon nanotubes. Journal of Physical Chemistry B. 2006;110(12):6236-6244.

78. Lachawiec AJ, Qi G, Yang RT. Hydrogen storage in nanostructured carbons by spillover: bridge-building enhancement. Langmuir. 2005;21(24):11418-11424.

79. Li Y, Yang RT. Hydrogen storage on platinum nanoparticles doped on superactivated carbon. Journal of Physical Chemistry C. 2007;111(29):11086-11094.

80. Li Y, Yang RT. Significantly enhanced hydrogen storage in metal-organic frameworks via spillover. Journal of the American Chemical Society. 2006;128(3):726-727.

81. Li Y, Yang RT. Hydrogen storage in metal-organic frameworks by bridged hydrogen spillover. Journal of the American Chemical Society. 2006;128(25):8136-8137.

82. Cheng H, Chen L, Cooper CA, Sha X, Pez GP. Hydrogen spillover in the context of hydrogen storage using solid-state materials. Energy \& Environmental Science. 2008;1(3):338-354.

83. Adelhelm P, de Jongh PE. The impact of carbon materials on the hydrogen storage properties of light metal hydrides. Journal of Materials Chemistry. 2010;21:2417-2427. 
84. Bouaricha S, Dodelet JP, Guay D, Huot J, Schulz R. Study of the activation process of Mg-based hydrogenstorage materials modified by graphite and other carbonaceous compounds. Journal of Materials Research. 2001;16(10):2893-2905.

85. Bouaricha S, Dodelet JP, Guay D, Huot J, Schulz R. Activation characteristics of graphite modified hydrogen absorbing materials. Journal of Alloys and Compounds. 2001;325(1):245-251.

86. Amirkhiz BS, Danaie M, Barnes M, Simard B, Mitlin D. Hydrogen sorption cycling kinetic stability and microstructure of single-walled carbon nanotube (SWCNT) magnesium hydride $\left(\mathrm{MgH}_{2}\right)$ nanocomposites. Journal of Physical Chemistry C. 2010;114(7):3265-3275.

87. Imamura H, Usui Y, Takashima M. Preparation and hydriding properties of magnesium-containing hydrogen storage materials chemically deposited from a homogeneous phase. Journal of the Less Common Metals. 1991;175(1):171-176.

88. Liang JJ, Kung WCP. Confinement of $\mathrm{Mg}-\mathrm{MgH}_{2}$ systems into carbon nanotubes changes hydrogen sorption energetics. Journal of Physical Chemistry C. 2005;109(38):17837-17841.

89. Baldé CP, Hereijgers BPC, Bitter JH, de Jong KP. Sodium alanate nanoparticles linking size to hydrogen storage properties. Journal of the American Chemical Society. 2008;130 (21):6761-6765.

90. Li X, Hwang JY, Shi S, Sun X, Zhang Z. Effect of electric potential on hydrogen adsorption. Carbon. 2010;48(3):876-880.

91. Li X, Hwang JY, Shi S, Sun X, Zhang Z. Effect of piezoelectric material on hydrogen adsorption. Fuel Processing Technology. 2010;91(9):1087-1089. 
92. Shi S, Hwang JY, Li X, Sun X. Enhanced hydrogen sorption on carbon and NiO in the presence of a piezoelectric element. Energy \& Fuels. 2009;23(12):6085-6088.

93. Shi S, Hwang JY, Li X, Sun X, Lee BI. Enhanced hydrogen sorption on carbonaceous sorbents under electric field. International Journal of Hydrogen Energy. 2010;35(2):629-631.

94. Liu W, Zhao YH, Nguyen J, Li Y, Jiang Q, Lavernia EJ. Electric field induced reversible switch in hydrogen storage based on single-layer and bilayer graphenes. Carbon 2009;47(15):3452-3460.

95. Zhou J, Wang Q, Sun Q, Jena P, Chen XS. Electric field enhanced hydrogen storage on polarizable materials substrates. Proceedings of the National Academy of Science of the United States of America. 2010;107(7):2801-2806.

96. Kubas GJ. 2001. Metal Dihydrogen and $\sigma$-bond Complexes: Structure, Theory, and Reactivity. New York: Kluwer Academic/Plenum Publishers.

97. Lochan RC, Head-Gordon M. Computational studies of molecular hydrogen binding affinities: The role of dispersion forces, electrostatics, and orbital interactions. Physical Chemistry Chemical Physics. 2006,8(12):1357-1370.

98. Froudakis GE. Why alkali-metal-doped carbon nanotubes possess high hydrogen uptake. Nano Letters. 2001;1(10):531-533.

99. Zhao YL, Zhang RQ, Wang RS. The role of lithium in hydrogen storage in aromatic carbon materials. Chemical Physics Letters. 2004;398(1-3):62-67.

100. Paul W, Lucke B, Schlemmer S, Gerlich D. International Journal of Mass Spectrometry and Ion Processes. On the dynamics of the reaction of positive hydrogen cluster ions $\left(\mathrm{H}_{5}{ }^{+}\right.$to $\left.\mathrm{H}_{23}{ }^{+}\right)$with para and normal hydrogen at $10 \mathrm{~K}$. 1995;149-150:373-387.

101. Thomson JJ. Further experiments on positive rays. Philosophical Magazine Series 
6. 1912;24(140):209-253.

102. Kurosaki Y, Takayanagi T. An ab initio molecular orbital study of even-membered hydrogen cluster cations: $\mathrm{H}_{6}{ }^{+}, \mathrm{H}_{8}{ }^{+}, \mathrm{H}_{10}{ }^{+}, \mathrm{H}_{12}{ }^{+}$, and $\mathrm{H}_{14}{ }^{+}$. Journal of Chemical Physics. 1998;109(11):4327-4334.

103. Dykstra CE, Gaylord AS, Gwinn WD, Swope WC, Schaefer HF III. The uncoupled symmetric stretching frequency of $\mathrm{H}_{3}{ }^{+}$. Journal of Chemical Physics. 1978;68(8):3951-3952.

104. Hiraoka K, Kebarle P. A determination of the stabilities of $\mathrm{H}_{5}^{+}, \mathrm{H}_{7}^{+}, \mathrm{H}_{9}{ }^{+}$, and $\mathrm{H}_{11}{ }^{+}$ from measurement of the gas phase ion equilibria $\mathrm{H}_{n}^{+}+\mathrm{H}_{2}=\mathrm{H}_{n+2}{ }^{+}(n=3,5,7,9)$. Journal of Chemical Physics. 1975;62(6):2267-2270.

105. Mills RL. Novel hydrogen compounds from a potassium carbonate electrolytic cell. Fusion Science and Technology. 2000;37(2):157-182.

106. Hirao K, Yamabe S. Theoretical study on the structure and stability of hydrogen-ion clusters $\mathrm{H}_{\mathrm{n}}^{+}$and $\mathrm{H}_{\mathrm{n}}{ }^{-}(\mathrm{n}=3,5,7,9,11,13)$. Chemical Physics. $1983 ; 80(3): 237-243$.

107. Kubas GJ, Ryan RR, Swanson BI, Vergamini PJ, Wasserman HJ. Characterization of the first examples of isolable molecular hydrogen complexes, $\mathrm{M}(\mathrm{CO})_{3}(\mathrm{PR} 3)_{2}\left(\mathrm{H}_{2}\right) \quad(\mathrm{M}=$ molybdenum or tungsten; $\mathrm{R}=\mathrm{Cy}$ or isopropyl $)$. Evidence for a side-on bonded dihydrogen ligand. Journal of the American Chemical Society. 1984;106(2):451-452.

108. Long JR, Dincă M. Hydrogen storage in microporous metal-organic frameworks with exposed metal sites. Angewandte Chemie International Edition (English). 2008;47(36):6766-6779.

109. Bushnell JE, Maitre P, Kemper PR, Bowers MT. Binding energies of $\operatorname{Ti}^{+}\left(\mathrm{H}_{2}\right)_{1-6}$ clusters: theory and experiment. Journal of Chemical Physics. 1997;106:10153-10167. 
110. Weis P, Kemper PR, Bowers MT. $\mathrm{Mn}^{+}\left(\mathrm{H}_{2}\right)_{\mathrm{n}}$ and $\mathrm{Zn}^{+}\left(\mathrm{H}_{2}\right)_{\mathrm{n}}$ clusters: Influence of $3 \mathrm{~d}$ and $4 \mathrm{~s}$ orbitals on metal-ligand bonding. Journal of Physical Chemistry A. 1997;101(15):2809-2816.

111. Zhao XB, Xiao B, Fletcher AJ, Thomas KM. Hydrogen adsorption on functionalized nanoporous activated carbons. Journal of Physical Chemistry B. 2005;109(18):8880-8888.

112. Lin CJ, Tu WK, Kuo CK, Chien SH. Single-step fabrication of phase-controllable nanocrystalline $\mathrm{TiO}_{2}$ films for enhanced photoelectrochemical water splitting and dye-sensitized solar cells. Journal of Power Sources. 2011;196:4865-4869.

113. Yacob AR, Mustajab MKAA, Samadi NS. Calcination temperature of nano MgO effect on base transesterification of palm oil. World Academy Science, Engineering and Technology. 2009;56:408-412.

114. Hy-Energy LLC. 2007. PCT-Pro 2000 User Guide. Newark, CA: Hy-Energy LLC.

115. Uršič H, Zarnik MS, Kosec M. Pb( $\left.\mathrm{Mg}_{1 / 3} \mathrm{Nb}_{2 / 3}\right) \mathrm{O}_{3}-\mathrm{PbTiO}_{3}(\mathrm{PMN}-\mathrm{PT})$ material for actuator applications. Smart Material Research. 2011;2011:452901 1-6.

116. van Randeraat J, Setterington RE. 1974. Piezoelectric Ceramics. London, UK: Mullard Ltd.

117. Brunauer S, Emmett PH, Teller EE. Adsorption of gases in multimolecular layers. Journal of the American Chemical Society. 1938;60(2):309-319.

118. Harkins WD, Jura G. Surfaces of solids. XIII. A vapor and adsorption method for the determination of the area of a solid without the assumption of a molecular area, and the areas occupied by nitrogen and other molecules on the surface of a solid. Journal of the American Chemical Society. 1944;66:1366-1373.

119. Wen C. 2010. Enhancement of Hydrogen Adsorption with Titanium Dioxide Coated Carbon. Houghton, MI: Michigan Technological University. 
120. Glab WL, Hessler JP. Ionization and dissociation of $\mathrm{H}_{2}$ in a static electric field: Levels near the ionization threshold. Physical Review A. 1990(9);42:5486-5498.

121. Ernst N, Block JH. Electron-stimulated field desorption of diatomic and triatomic hydrogen. Physical Review B. 1984;29(12):7092-7095.

122. $\mathrm{Hu} \mathrm{X}$, Skadtchenko BO, Trudeau M, Antonelli DM. Hydrogen storage in chemically reducible mesoporous and microporous Ti oxides. Journal of the American Chemical Society. 2006;128(36):11740.

123. Ahmad K, Pan W, Shi SL. Electrical conductivity and dielectric properties of multiwalled carbon nanotube and alumina composites. Applied Physics Letters. 2006;89(13):133122-133124.

124. Clements TC, Müller EW. Occurrence of $\mathrm{H}_{3}{ }^{+}$in the field ionization of hydrogen. Journal of Chemical Physics. 1962;37(11):2684-2687.

125. Eyring H, Hirschfelder JO, Taylor HS. The theoretical treatment of chemical reactions produced by ionization processes Part I. The ortho-para hydrogen conversion by alpha-particles. Journal of Chemical Physics. 1936;4:479-91.

126. Breckenridge RG, Hosler WR. Electrical properties of titanium dioxide semiconductors. Physical Review. 1953;91(4):793-802.

127. Lundstrom JM, Rinehart LF, Pate RC, Smith TL. Measurement of the dielectric strength of titanium dioxide ceramics.IEEE. 1999. 1489-1491.

128. Subramanian MA, Shannon RD, Chai BHT, Abraham MM, Wintersgill MC. Dielectric constants of $\mathrm{BeO}, \mathrm{MgO}$, and $\mathrm{CaO}$ using the two-terminal method. Physics and Chemistry of Minerals. 1989;16(8):741-746.

129. Yang Y, Guo W, Wang X, Wang Z, Qi J, Zhang Y. Size dependence of dielectric constant in a single pencil-like $\mathrm{ZnO}$ nanowire. Nano Letters. Proceeding.

130. Langton NH, Matthews D. The dielectric constant of zinc oxide over a range of frequencies. British Journal of Applied Physics. 1958;9:453-456. 
131. Hoshina T, Takizawa K, Li J, Kasama T, Kakemoto H, Tsurumi T. Domain size effect on dielectric properties of barium titanate ceramics. Japanese Journal of Applied Physics. 2008;47(9):7607-7611.

132. Chen Q, Du P, Jin L, Weng W, Han G. Percolative conductor/polymer composite film with significant dielectric properties. Applied Physics Letters. 2007;91:0022912 1-3.

133. Park N, Hong S, Kim G, Jhi SH. Computational study of hydrogen storage characteristics of covalent-bonded graphenes. Journal of the American Chemical Society. 2007;129:8999-9003.

134. Han SS, Lee HM. Adsorption properties of hydrogen on $(10,0)$ single-walled carbon nanotube through density functional theory. Carbon. 2004:42:2169-2177.

135. Psofogiannakis GM, Froudakis GE. DFT study of the hydrogen spillover mechanism on Pt-Doped graphite. Journal of Physical Chemisty C. 2009;113:14908-14915.

136. Cramer CJ. 2004. Essentials of Computational Chemistry: Theories and Models. Second Edition. Chichester, England: John Wiley \& Sons Ltd.

137. Frisch, M. J.; Trucks, G. W.; Schlegel, H. B.; Scuseria, G. E.; Robb, M. A.; Cheeseman, J. R.; Scalmani, G.; Barone, V.; Mennucci, B.; Petersson, G. A.; Nakatsuji, H.; Caricato, M.; Li, X.; Hratchian, H. P.; Izmaylov, A. F.; Bloino, J.; Zheng, G.; Sonnenberg, J. L.; Hada, M.; Ehara, M.; Toyota, K.; Fukuda, R.; Hasegawa, J.; Ishida, M.; Nakajima, T.; Honda, Y.; Kitao, O.; Nakai, H.; Vreven, T.; Montgomery, Jr., J. A.; Peralta, J. E.; Ogliaro, F.; Bearpark, M.; Heyd, J. J.; Brothers, E.; Kudin, K. N.; Staroverov, V. N.; Kobayashi, R.; Normand, J.; Raghavachari, K.; Rendell, A.; Burant, J. C.; Iyengar, S. S.; Tomasi, J.; Cossi, M.; Rega, N.; Millam, N. J.; Klene, M.; Knox, J. E.; Cross, J. B.; Bakken, V.; Adamo, C.; Jaramillo, J.; Gomperts, R.; Stratmann, R. E.; Yazyev, O.; Austin, A. J.; 
Cammi, R.; Pomelli, C.; Ochterski, J. W.; Martin, R. L.; Morokuma, K.; Zakrzewski, V. G.; Voth, G. A.; Salvador, P.; Dannenberg, J. J.; Dapprich, S.; Daniels, A. D.; Farkas, Ö.; Foresman, J. B.; Ortiz, J. V.; Cioslowski, J.; Fox, D. J. Gaussian 09, Revision B.01. Gaussian, Inc., Wallingford CT, 2009.

138. Chiodo S, Russo N, Sicilia E. LANL2DZ basis sets recontracted in the framework of density functional theory. Journal of Chemical Physics. 2006;125(104107):1-8.

139. Cao $\mathrm{Y}$, Zhao X, Xin B, Xiong S, Tang Z. Reactions of $\mathrm{M}^{+}$and $\mathrm{MO}^{+}(\mathrm{M}=\mathrm{V}, \mathrm{Nb}$, Ta) with methanol. Journal of Molecular Structure. 2004;683(1-3):141-146.

140. Jeloaica L, Sidis V. DFT investigation of the adsorption of atomic hydrogen on a cluster-model graphite surface. Chemical Physics Letters. 1999;300(1-2):157-162.

141. Bonfanti M, Martinazzo R, Tantardini GF, Ponti A. Physisorption and diffusion of hydrogen atoms on graphite from correlated calculations on the H-Coronene model system. Journal of Physical Chemistry C. 2007;111(16):5825-5829. 


\section{APPENDIX A}

Figure 1.1 used in this dissertation was originally published in Transportation Energy Data Book (29 ${ }^{\text {th }}$ Edition) by DOE. The work was sponsored by the U.S. Government. The U.S. Government retains a nonexclusive, royalty-free license to publish or reproduce these documents, or to allow other s to do so. These documents may be freely distributed and used for non-commercial, scientific and education purpose. 


\section{APPENDIX B}

Figure 1.2 used in this dissertation was originally published on EERE web site. Materials on the EERE Web site are in the public domain. EERE requests that it be acknowledged as the source in any subsequent use of its information. 


\section{APPENDIX C}

Table 1.3 used in this dissertation was originally published on EERE web site. Materials on the EERE Web site are in the public domain. EERE requests that it be acknowledged as the source in any subsequent use of its information. 


\section{APPENDIX D}

Figure 1.3 used in this dissertation was originally published on EERE web site. Materials on the EERE Web site are in the public domain. EERE requests that it be acknowledged as the source in any subsequent use of its information. 


\section{$\underline{\text { APPENDIX E }}$}

Figure 2.1 used in this dissertation was originally published in the Catalysis Today, Elsevier, "Hydrogen adsorption and storage on porous materials", Volume 120, 2007, 389-398. Permission to reuse material from the published work was obtained with kind permission from Elsevier. A copy of the granting permission for reproduction is shown below.

This is a License Agreement between Zheng Zhang ("You") and Elsevier ("Elsevier") provided by Copyright Clearance Center ("CCC"). The license consists of your order details, the terms and conditions provided by Elsevier, and the payment terms and conditions.

Customer name: Zheng Zhang

Customer organization: Michigan Technological University

License number: 2926140534926

License date: JUN 11, 2012

Publication: Catalysis Today

Article title: Hydrogen adsorption and storage on porous materials

Author: Thomas KM

DOI: 10.1016/J.CATTOD.2006.09.015

Date: Feb 28, 2007

ISSN: 0920-5861

Publication type: Journal

Volume: 120

Issue: $3-4$ 
Start Page: 389

Publisher: ELSEVIER BV

Permission status: Granted

Permission type: Republish or display content

Type of use: reuse in a thesis/dissertation

Number of page: 10

Portion: figures/tables/illustrations

Number of figures/tables/illustrations: 2

Format: both print and electronic

Are you the author of this Elsevier article? No

Will you be translating? No

Order reference number:

Title of your thesis/dissertation: Effect of External Electric Field on Hydrogen Adsorption over Activated Carbon Separated by Dielectric Materials

Expected completion date: JUN 2012

Estimated size (number of pages): 120

Elsevier VAT number: GB 494627212

Permissions price: 0.00 USD

VAT/Local Sales Tax: 0.0 USD / 0.0 GBP

Total: 0.00 USD 


\section{$\underline{\text { APPENDIX F }}$}

Figure 2.2 used in this dissertation was originally published in the Journal of Physical Chemistry B, "Hydrogen adsorption on functionalized nanoporous activated carbons", Volume 109, 2005, 8880-8888. Permission to reuse material from the published work was obtained with kind permission from American Chemical Society. A copy of the granting permission for reproduction is shown below.

This is a License Agreement between Zheng Zhang ("You") and American Chemical Society ("American Chemical Society") provided by Copyright Clearance Center ("CCC"). The license consists of your order details, the terms and conditions provided by American Chemical Society, and the payment terms and conditions.

Permission is granted for your request in both print and electronic formats, and translations. If figures and/or tables were requested, they may be adapted or used in part. Please print this page for your records and send a copy of it to your publisher/graduate school. Appropriate credit for the requested material should be given as follows: "Reprinted (adapted) with permission from (COMPLETE REFERENCE CITATION). Copyright (YEAR) American Chemical Society." Insert appropriate information in place of the capitalized words. One-time permission is granted only for the use specified in your request. No additional uses are granted (such as derivative works or other editions). For any other uses, please submit a new request.

Customer name: Zheng Zhang

Customer organization: Michigan Technological University

License date: JUN 11, 2012 
Publication: Journal of Physical Chemistry B

Licensed content ISSN: 1520-6106

Publication year(s): 1997 - present

Author/Editor: American Chemical Society

Publication type: Journal

Publisher: AMERICAN CHEMICAL SOCIETY

Language: English

Country of publication: United States of America

Rightsholder: AMERICAN CHEMICAL SOCIETY

Permission type selected: Republish or display content

Type of use selected: reuse in a Thesis/Dissertation

Article title: Hydrogen Adsorption on Functionalized Nanoporous Activated Carbons

Author(s): Zhao XB; et al

DOI: $10.1021 / \mathrm{JP} 050080 \mathrm{Z}$

Date: May 1, 2005

Volume: 109

Issue: 18 


\section{APPENDIX G}

Figure 3.2 used in this dissertation was originally published in the Installation and Operations Manual for PCT-Pro 2000. Permission to reuse material from the published work was obtained with kind permission from Hy-Energy LLC. 


\section{$\underline{\text { APPENDIX H }}$}

Figure 3.5 used in this dissertation was originally published in the Journal of Carbon, "Effect of electric potential on hydrogen adsorption", Volume 48, 2010, 876-880. Permission to reuse material from the published work was obtained with kind permission from American Carbon Committee. A copy of the granting permission for reproduction is shown below.

This is a License Agreement between Zheng Zhang ("You") and American Carbon Committee ("American Carbon Committee") provided by Copyright Clearance Center ("CCC"). The license consists of your order details, the terms and conditions provided by American Carbon Committee, and the payment terms and conditions.

Customer name: Zheng Zhang

Customer organization: Michigan Technological University

License number: 2926170557059

License date: JUN 11, 2012

Publication: Carbon

Article title: Hydrogen adsorption and storage on porous materials

Author: Li X; et al

DOI: $10.1016 /$ J.CARBON.2009.10.042

Date: Mar 01, 2010

ISSN: 0008-6223

Publication type: Journal

Volume: 48

Issue: 3 
Start Page: 876

Publisher: PERGAMON

Author/Editor: AMERICAN CARBON COMMITTEE

Permission status: Granted

Permission type: Republish or display content

Type of use: reuse in a thesis/dissertation

Number of page: 5

Portion: figures/tables/illustrations

Number of figures/tables/illustrations: 1

Format: both print and electronic

Are you the author of this Elsevier article? Yes

Will you be translating? No

Order reference number:

Title of your thesis/dissertation: Effect of External Electric Field on Hydrogen Adsorption over Activated Carbon Separated by Dielectric Materials

Expected completion date: JUN 2012

Estimated size (number of pages): 120

Elsevier VAT number: GB 494627212

Permissions price: 0.00 USD

VAT/Local Sales Tax: 0.0 USD / 0.0 GBP

Total: 0.00 USD 